\title{
Fluorium-Initiated Dealkylative Cyanation of Thioethers to Thiocyanates
}

\author{
Yang Chen, ${ }^{\dagger}$ Hongyi Qi,$\stackrel{\star}{ }$ Ning Chen,${ }^{\dagger}$ Demin Ren,${ }^{\perp}$ Jiaxi Xu,${ }^{* \dagger}$ and Zhanhui Yang* $* \dagger$ \\ ${ }^{\dagger}$ State Key Laboratory of Chemical Resource Engineering, Department of Organic Chemistry, Faculty \\ of Science, ${ }^{\star}$ College of Materials Science and Engineering, Beijing University of Chemical \\ Technology, Beijing 100029, P. R. China \\ ${ }^{\perp}$ Hunan Provincial Key Laboratory of Controllable Preparation and Functional Application of Fine \\ Polymers, Hunan University of Science and Technology, Xiangtan 411201, China
}

\author{
Corresponding Authors \\ * zhyang@mail.buct.edu.cn (Z.Y.) \\ *jxxu@mail.buct.edu.cn (J.X.)
}




\section{Contents}

1. MS Spectra of Some Crude Reaction Mixtures ................................. S3

1.1 HRMS of the Crude Reaction Mixture of 2-methylthiopyridine (1u) .

1.2 GC-MS of the Crude Reaction Mixture of $\mathbf{3 g}, \mathbf{3 h}$, and $\mathbf{3 i} \ldots \ldots \ldots . . . .54$

2. MS and ${ }^{1} \mathrm{H}$ NMR Spectra in the Mechanistic Studies .......................S10

3. ${ }^{1} \mathrm{H},{ }^{13} \mathrm{C}$ NMR Spectra and MS Spectra of Products.......................... S20

4. ${ }^{1} \mathrm{H}$ NMR Spectra of Crude Reaction Mixtures in Table 3...................S71 


\section{MS Spectra of Some Crude Reaction Mixtures}

\subsection{HRMS of the Crude Reaction Mixture of 2-methylthiopyridine}

(1u)

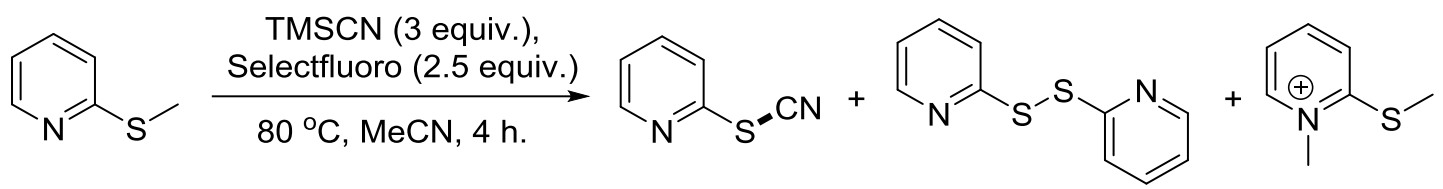<smiles>c1ccc(SSc2ccccn2)nc1</smiles>

Chemical Formula: $\mathrm{C}_{10} \mathrm{H}_{9} \mathrm{~N}_{2} \mathrm{~S}_{2}{ }^{+}$

Exact Mass: 221.0202

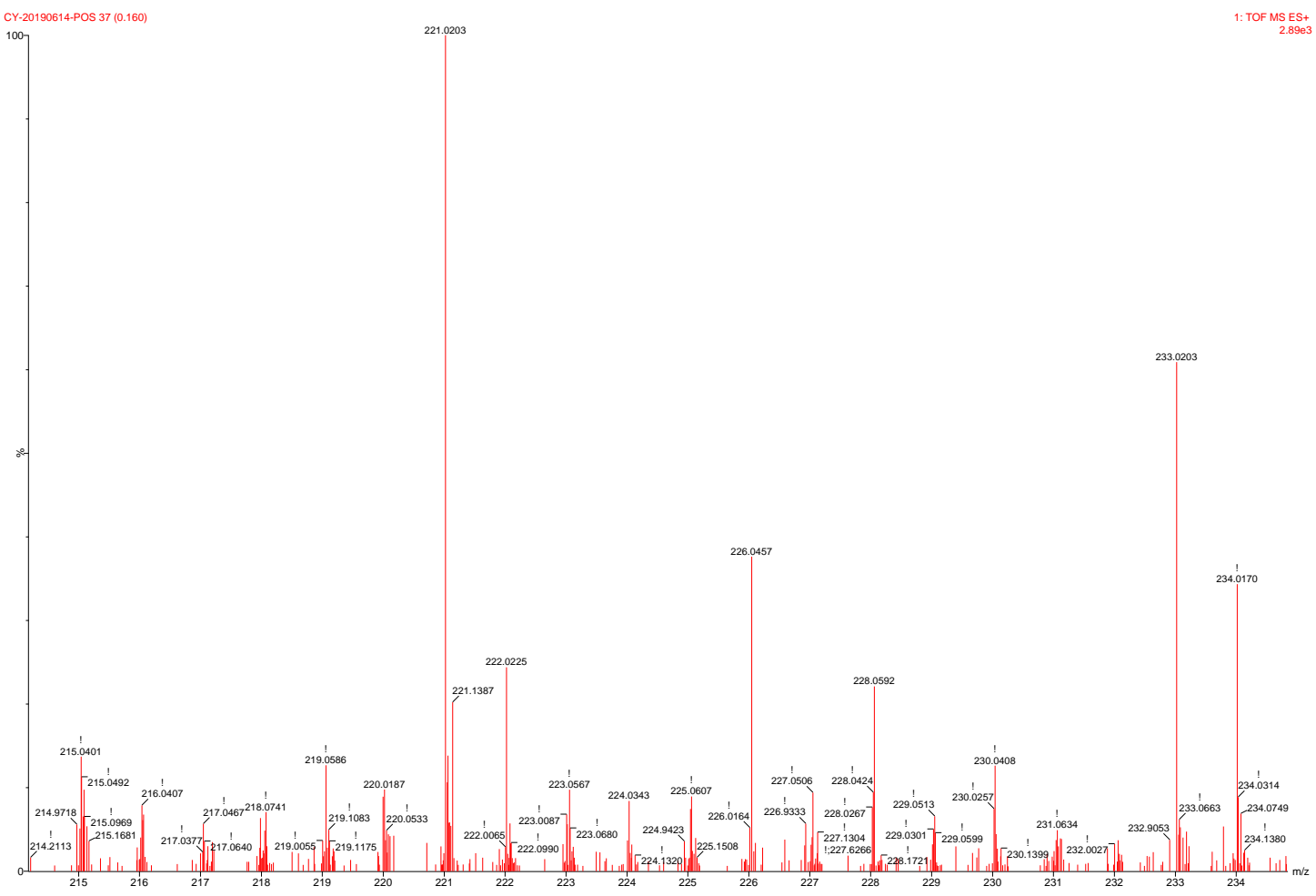

Figure S1. HRMS Spectra of Di(pyridin-2-yl) Disulfide. 


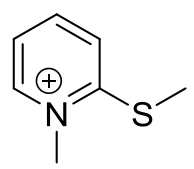

Chemical Formula: $\mathrm{C}_{7} \mathrm{H}_{10} \mathrm{NS}^{+}$

Exact Mass: 140.0528

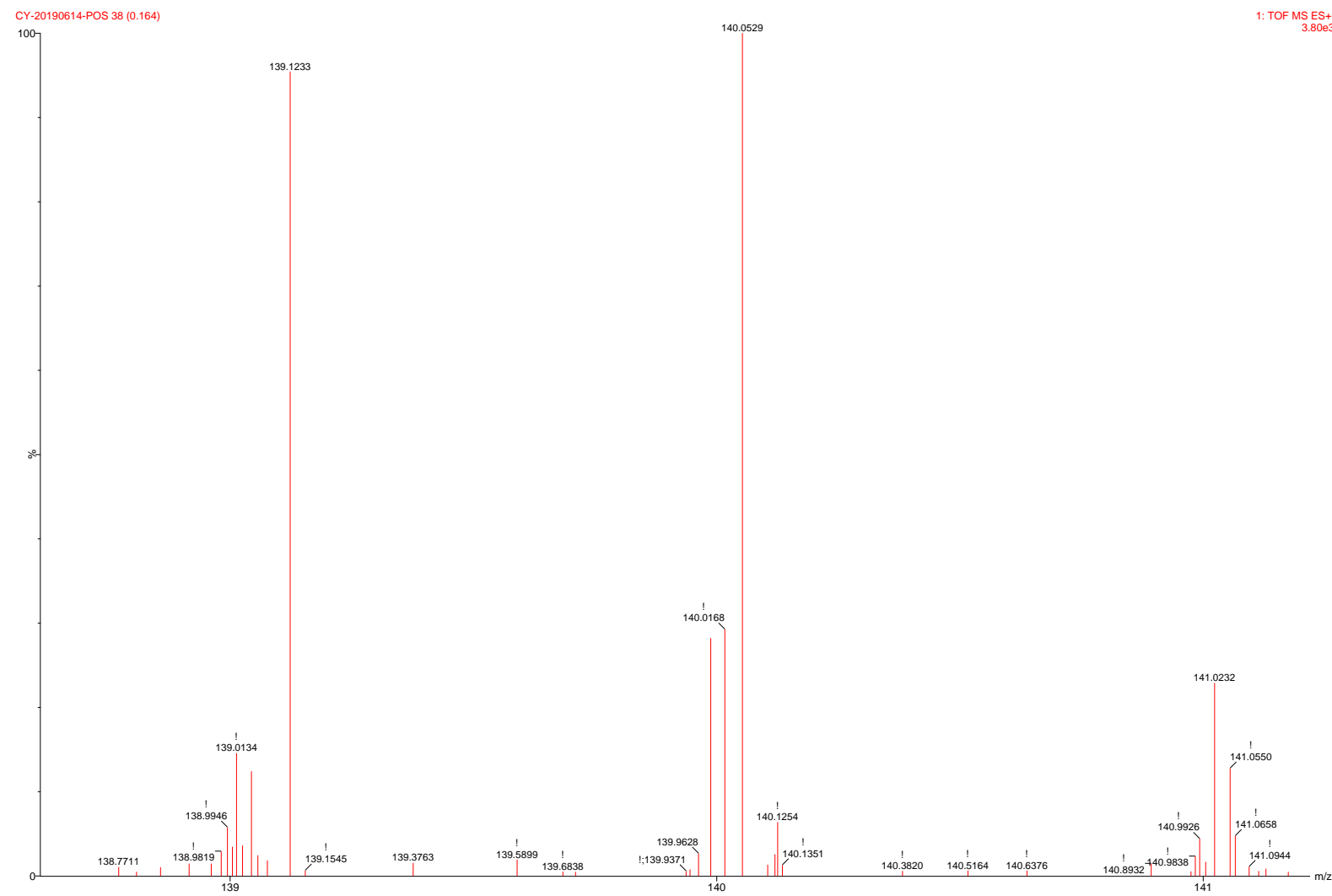

Figure S2. HRMS Spectra of N-Methyl 2-Methylthiopyridium.

\subsection{GC-MS of the Crude Reaction Mixture of $3 g, 3 h$, and $3 i$}

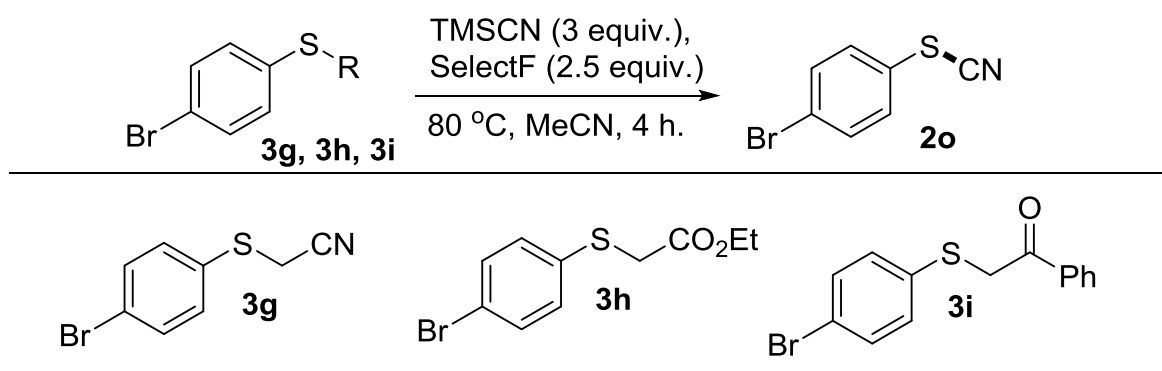




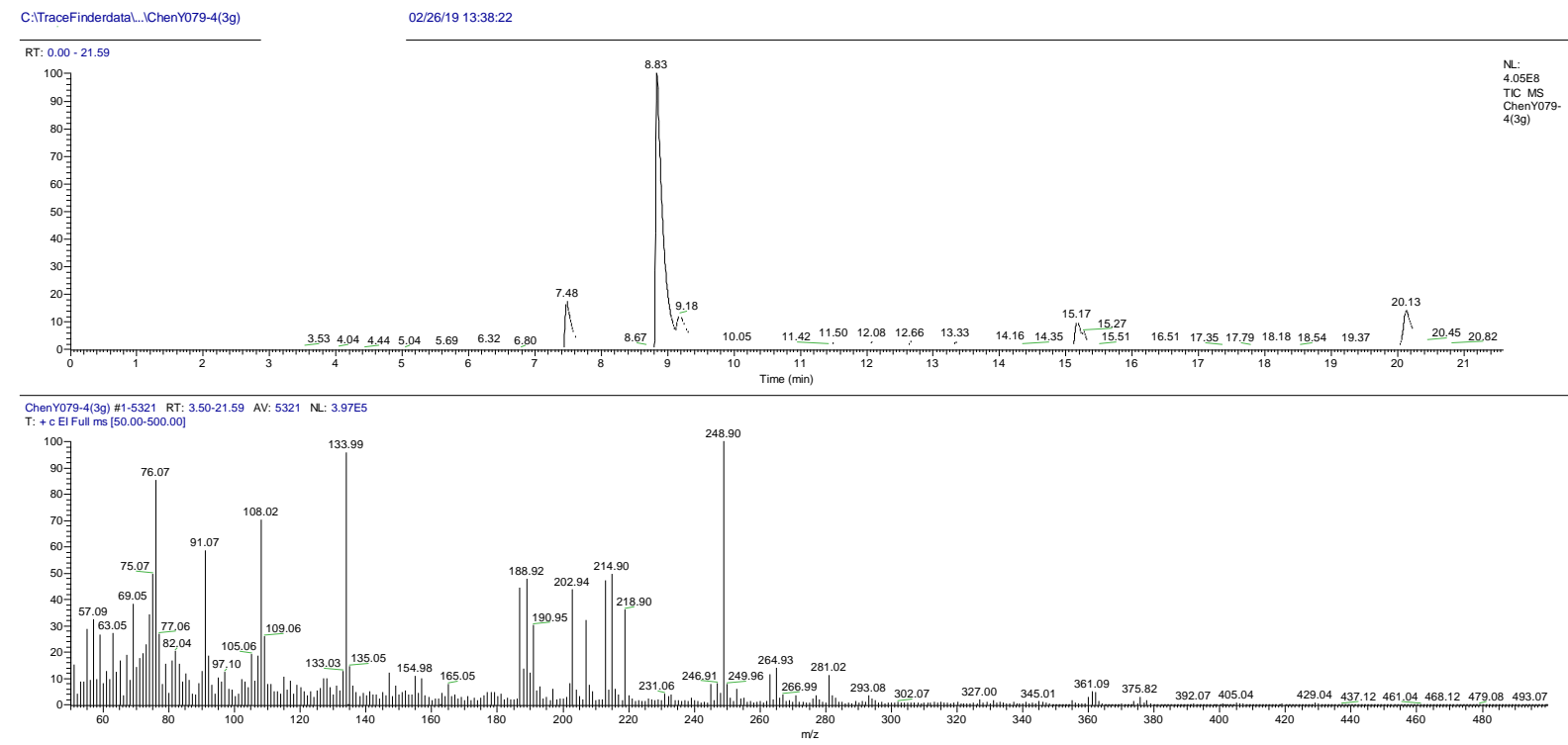

Figure S3. The GC-MS (EI) Spectrum of the Crude Reaction Mixture 3g<smiles>N#CC(F)(F)Sc1ccc(Br)cc1</smiles>

\section{Exact Mass: 262.92}

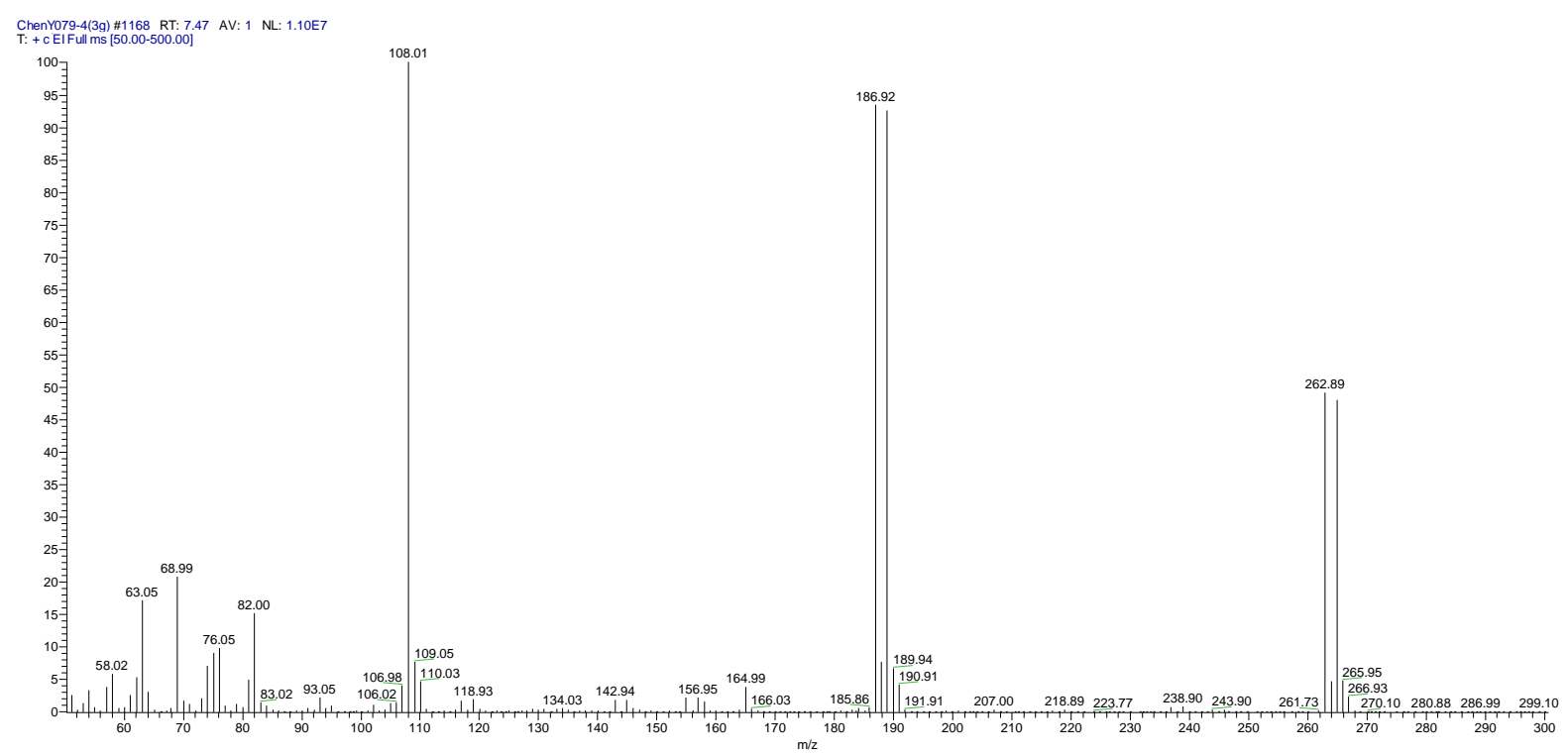

Figure S4. Detection of difluorination product in the reaction of $\mathbf{3 g}$ 


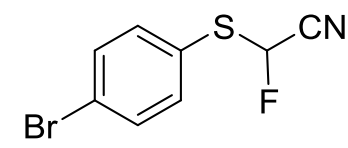

\section{Exact Mass: 244.93}

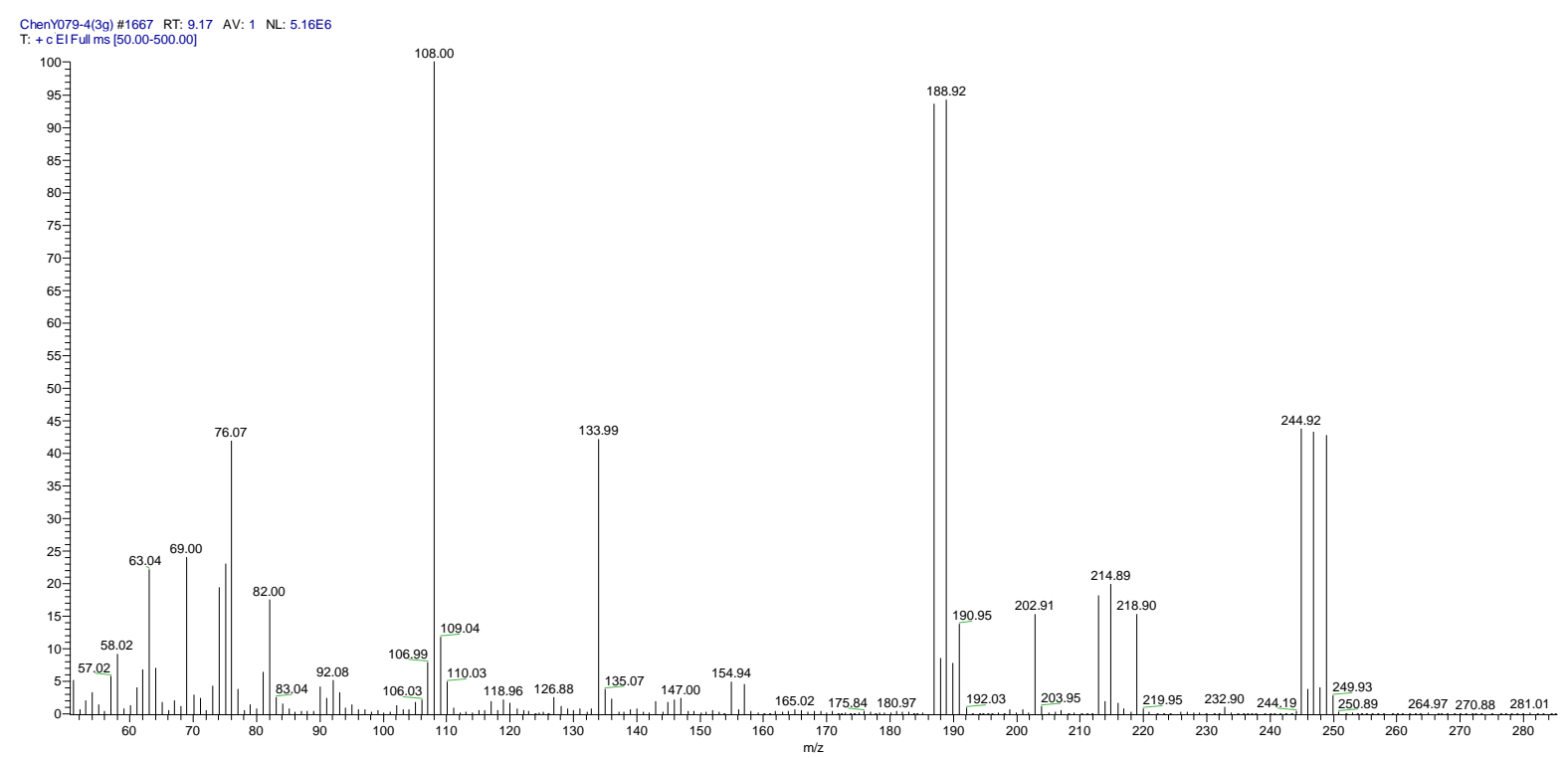

Figure S5. Detection of monofluorination product in the reaction of $\mathbf{3 g}$<smiles>Brc1ccc(SSc2ccc(Br)cc2)cc1</smiles>

Exact Mass: 373.84

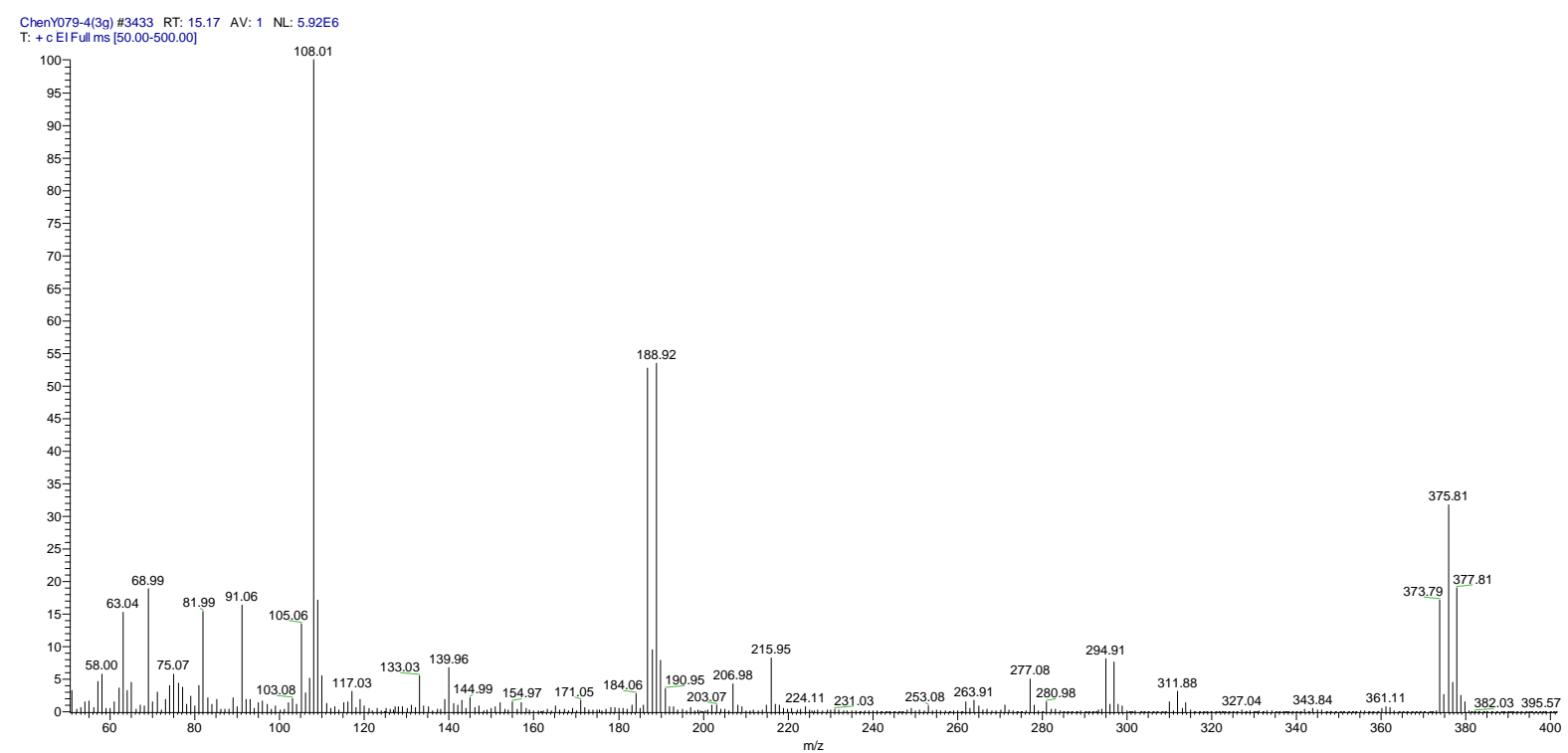

Figure S6. Detection of disulfide product in the reaction of $\mathbf{3 g}$ 

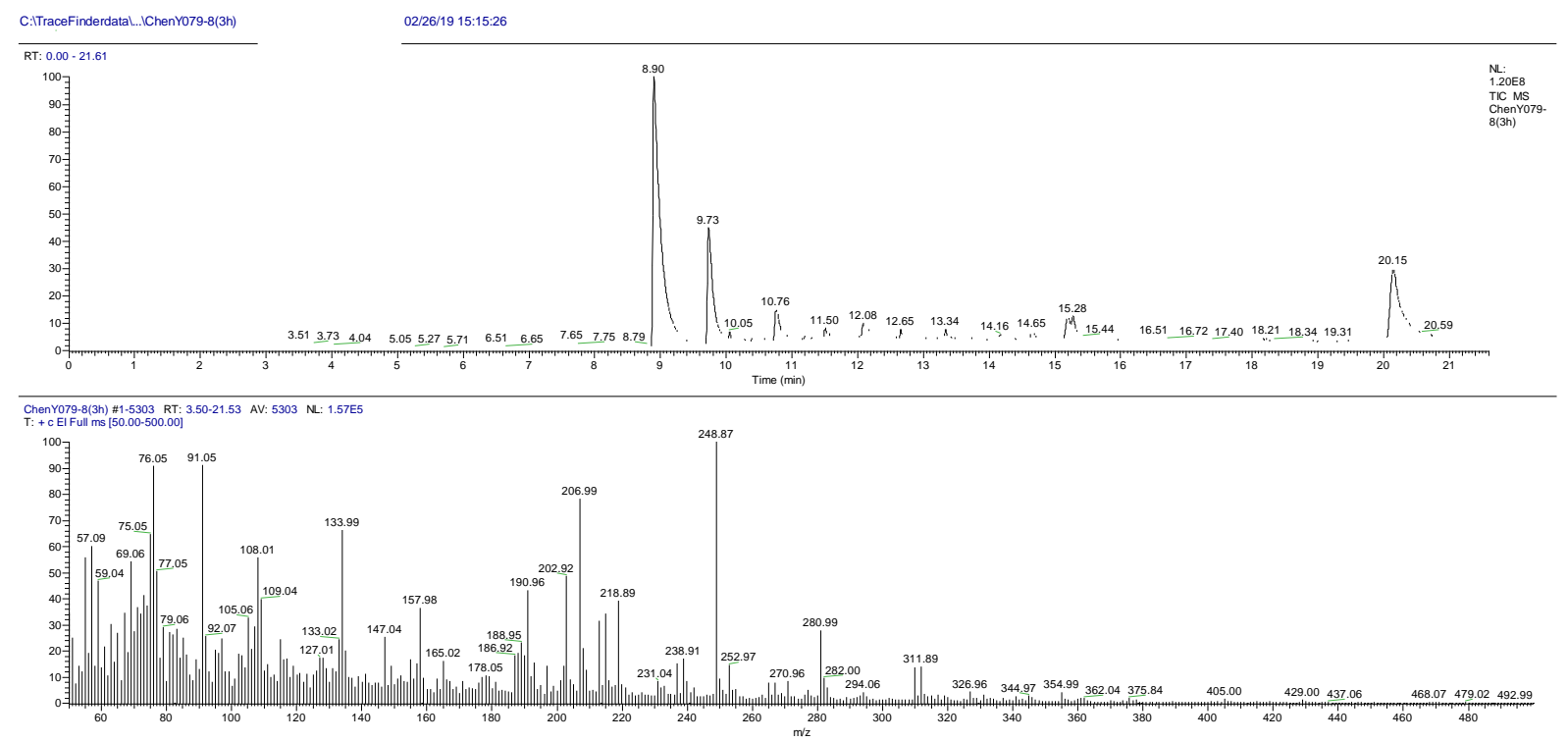

Figure S7. The GCMS (EI) Spectrum of the Crude Reaction Mixture of $\mathbf{3 h}$.<smiles>CCOC(=O)C(F)(F)Sc1ccc(Br)cc1</smiles>

Exact Mass: 309.95

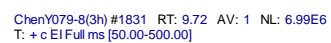
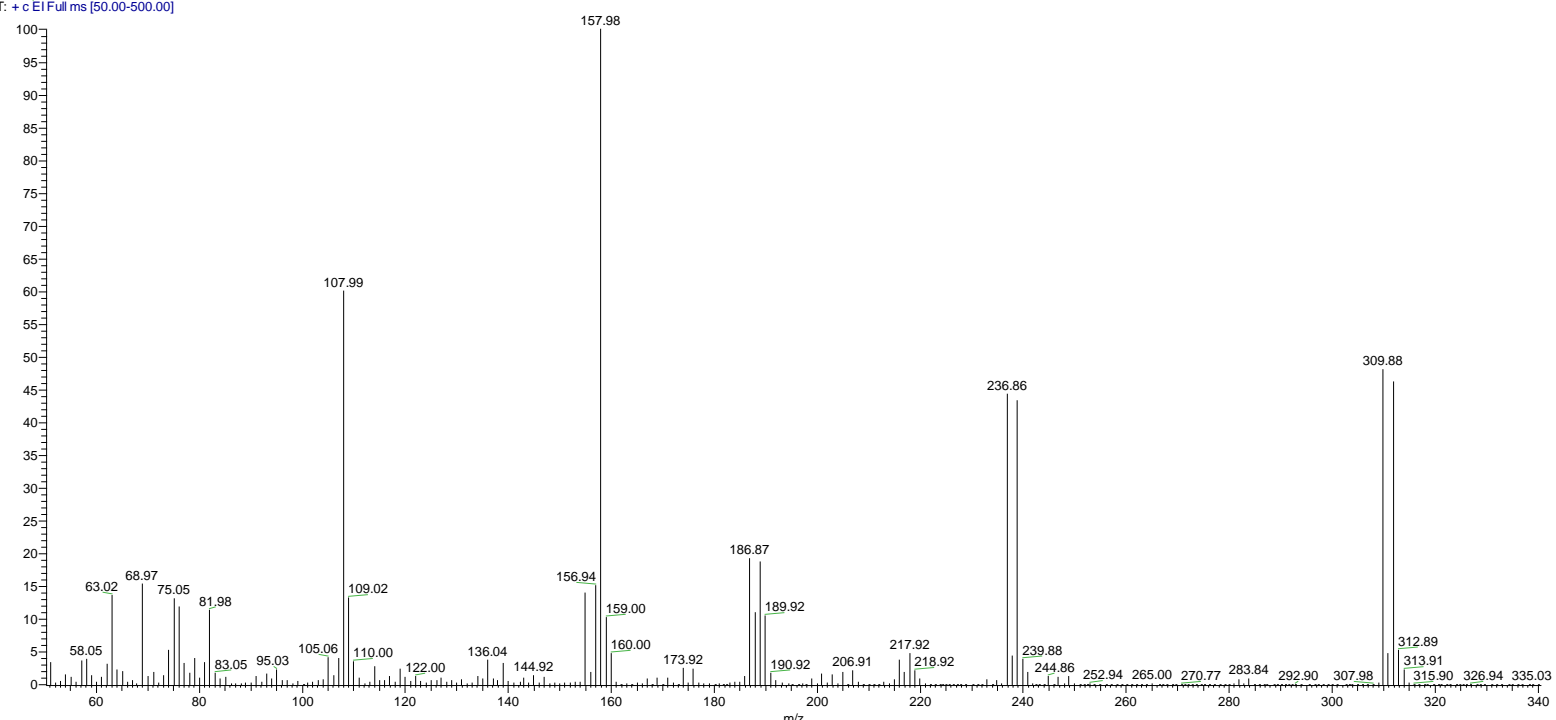

Figure S8. Detection of difluorination product in the reaction of $\mathbf{3 h}$<smiles>Brc1ccc(SSc2ccc(Br)cc2)cc1</smiles>

Exact Mass: 373.84 


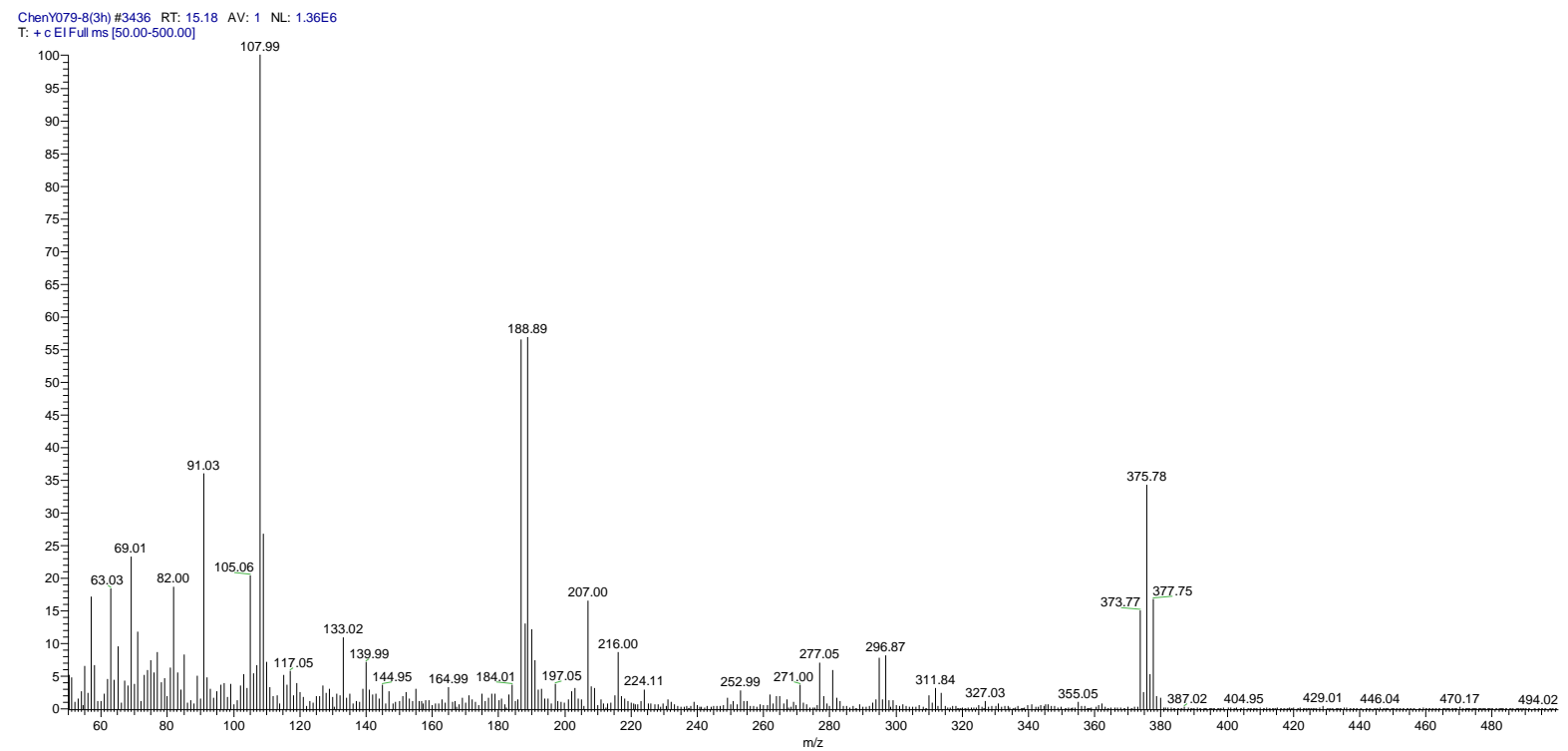

Figure S9. Detection of disulfide product in the reaction of $\mathbf{3 h}$

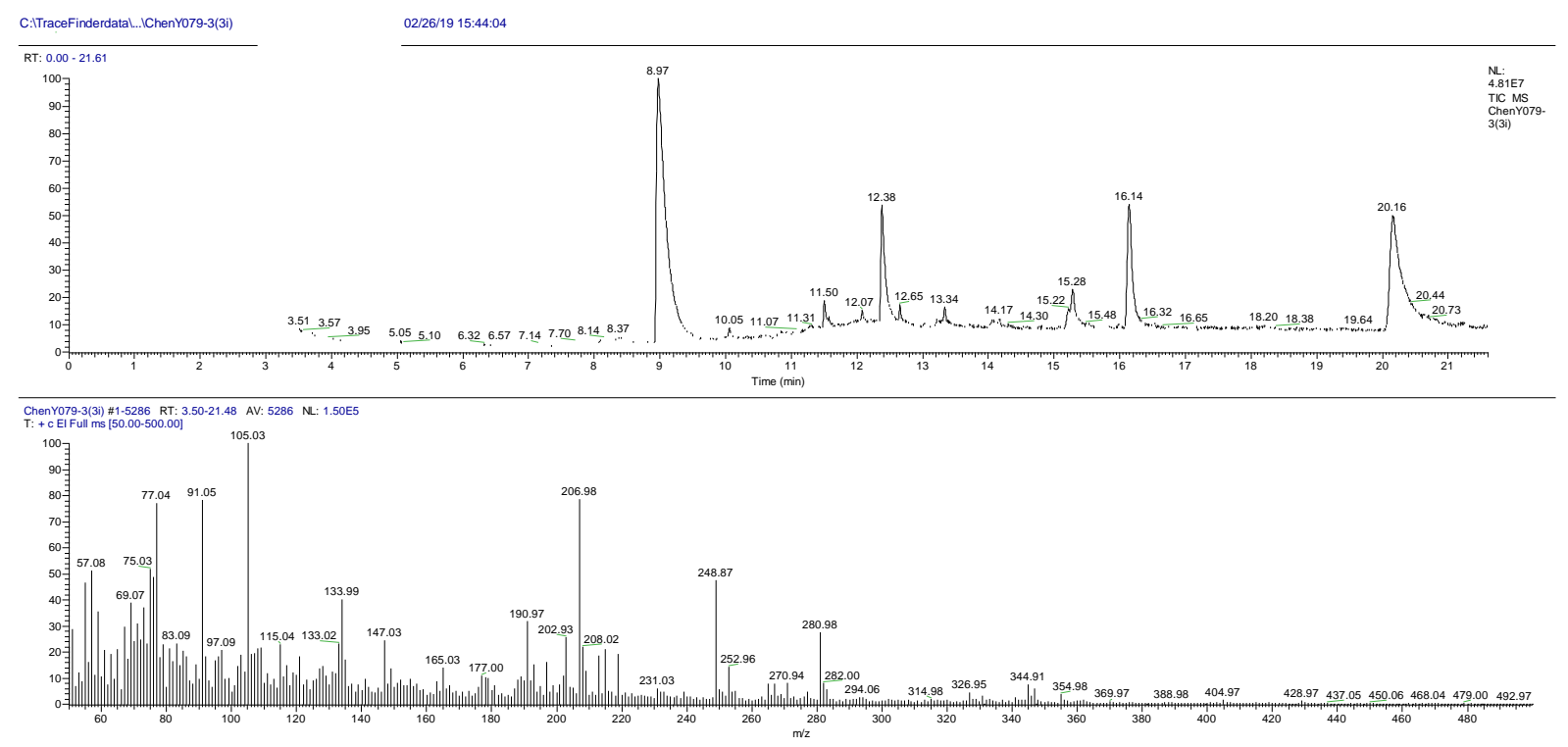

Figure S10. The GC-MS (EI) Spectrum of the Crude Reaction Mixture of 3i<smiles>CC(C)(C)OC(=O)c1ccccc1C(=O)C(F)(F)Sc1ccc(Br)cc1</smiles> 


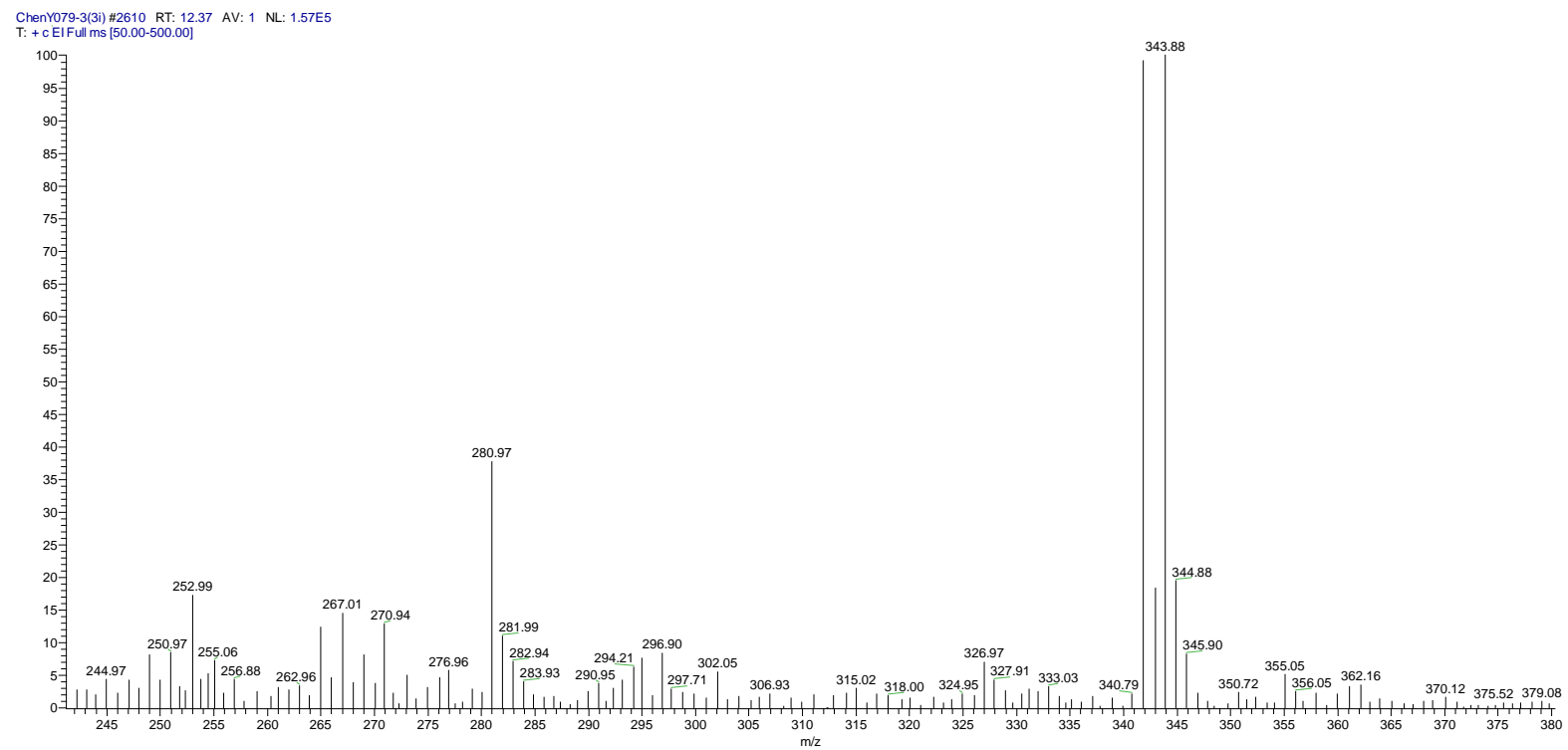

Figure S11. Detection of difluorination product in the reaction of $\mathbf{3 i}$<smiles>Brc1ccc(SSc2ccc(Br)cc2)cc1</smiles>

Exact Mass: 373.84

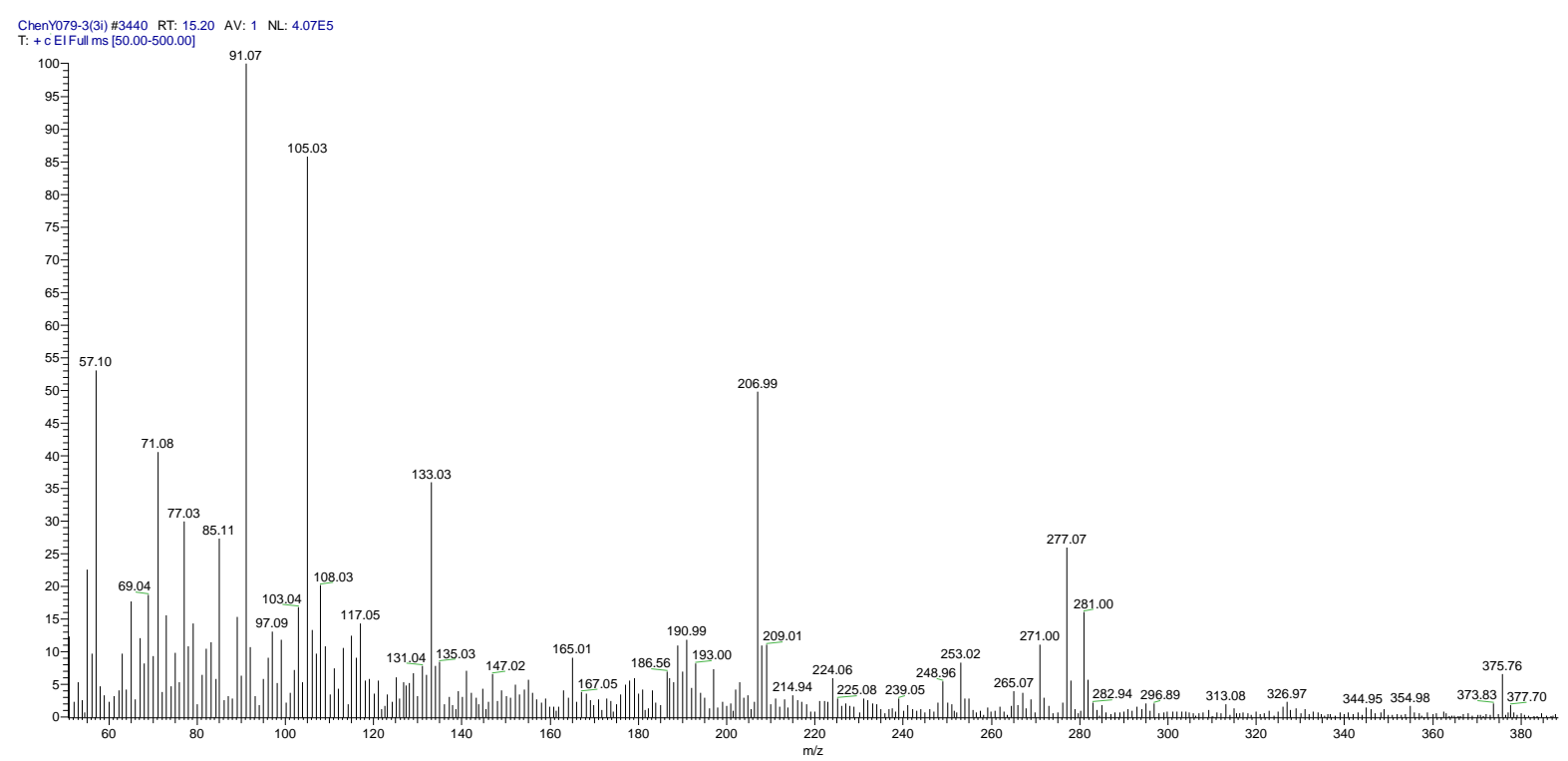

Figure S12. Detection of disulfide product in the reaction of $\mathbf{3 i}$ 


\section{MS and ${ }^{1} \mathrm{H}$ NMR Spectra in the Mechanistic Studies}

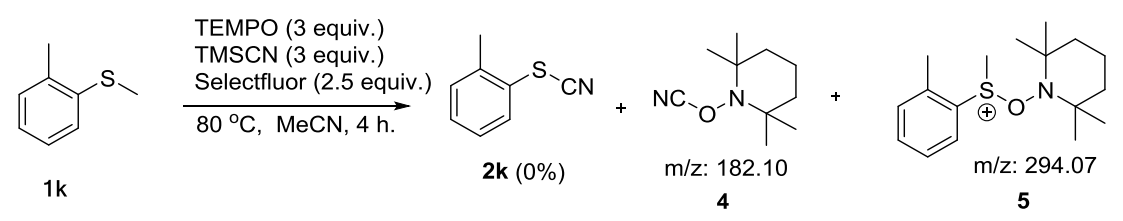

Scheme S1. Radical probing experiment

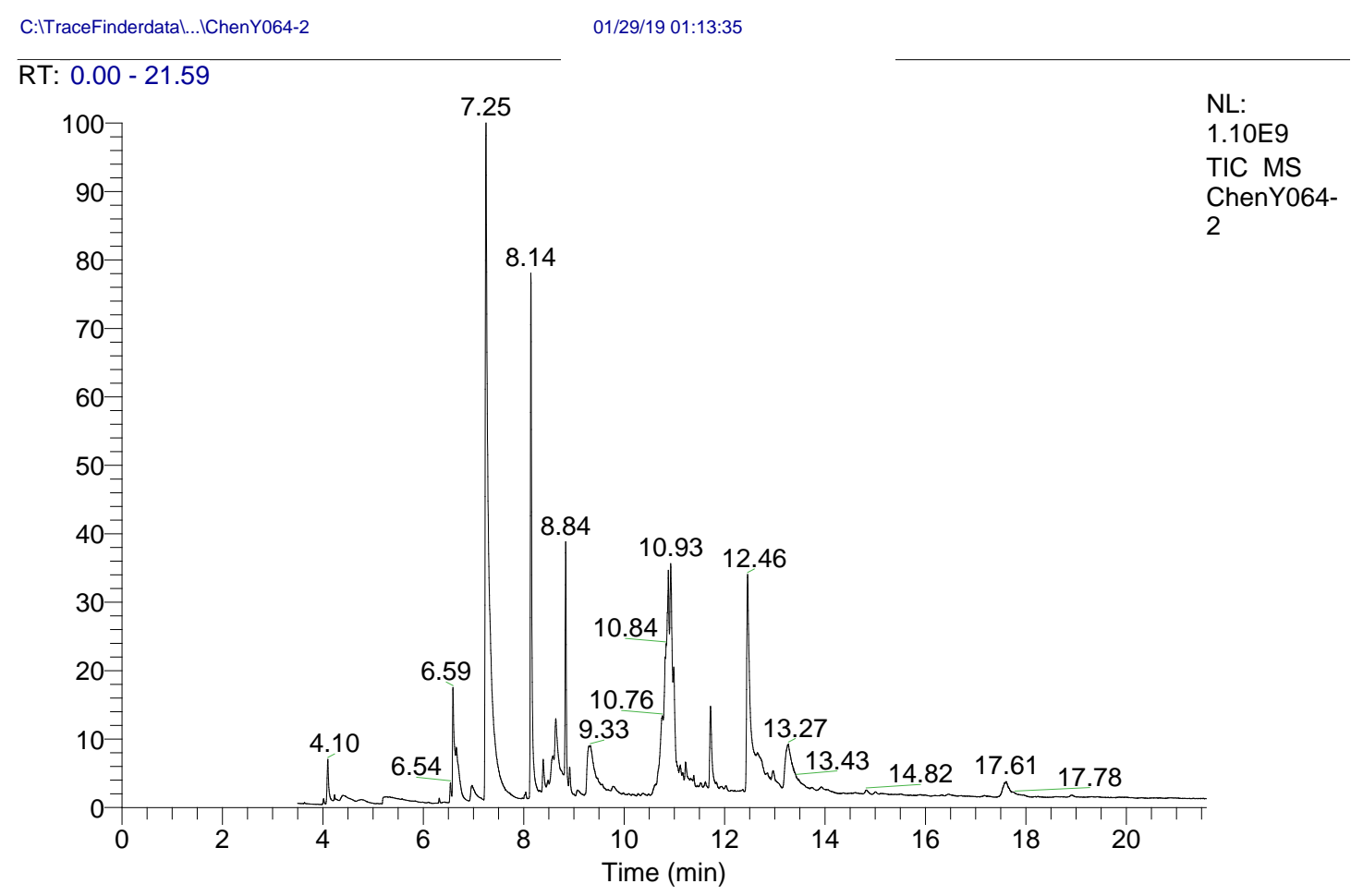

Figure S13. GC spectrum of the crude reaction mixture 


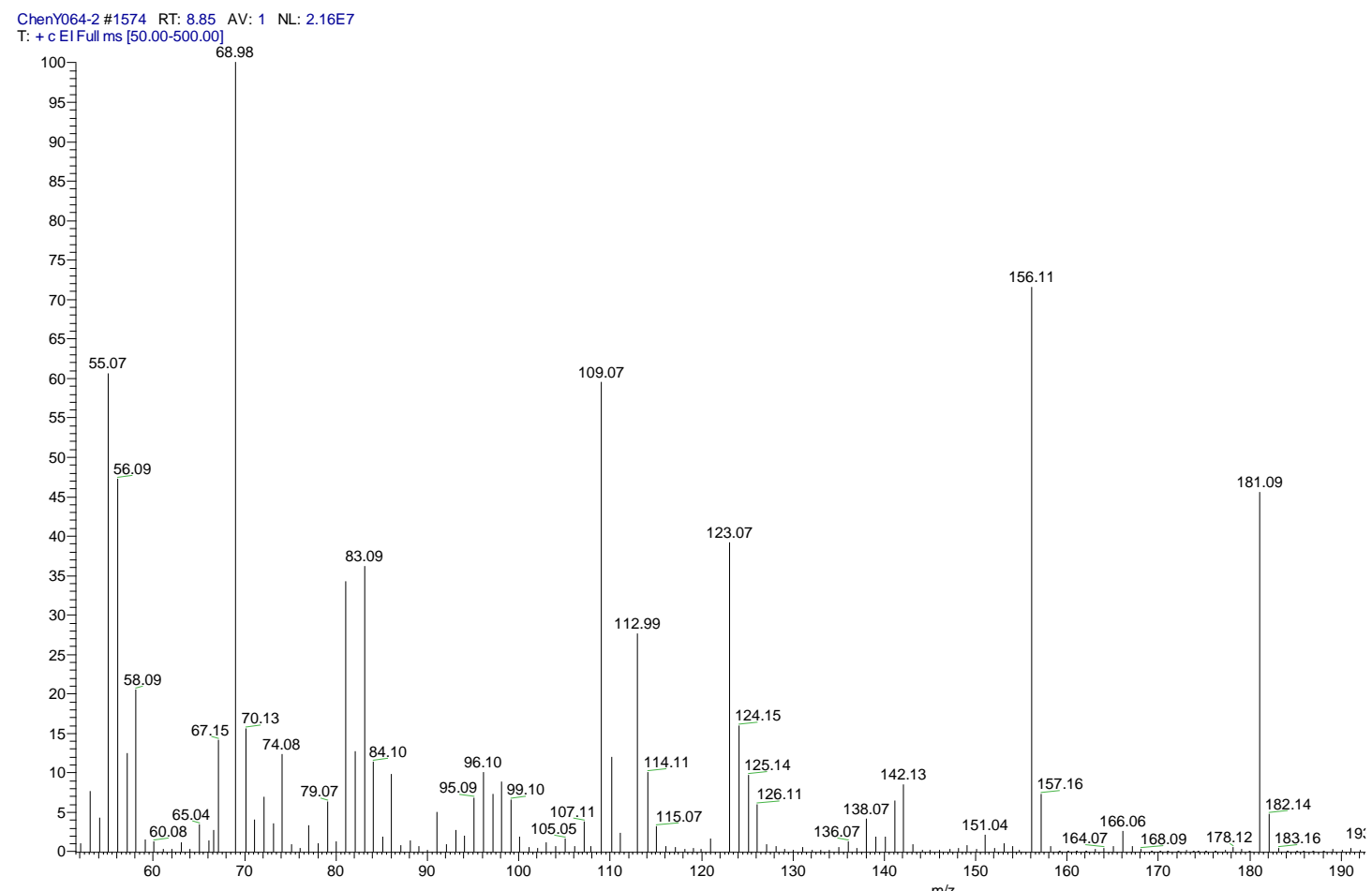

Figure S14. The MS spectrum of 4.

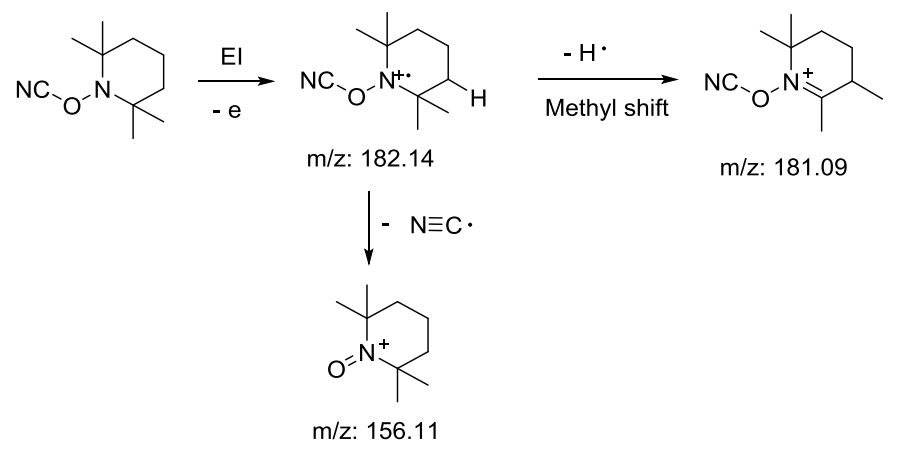

Scheme S2. Plausible mechanistic explanation for some main fragment ion peaks of 4. 


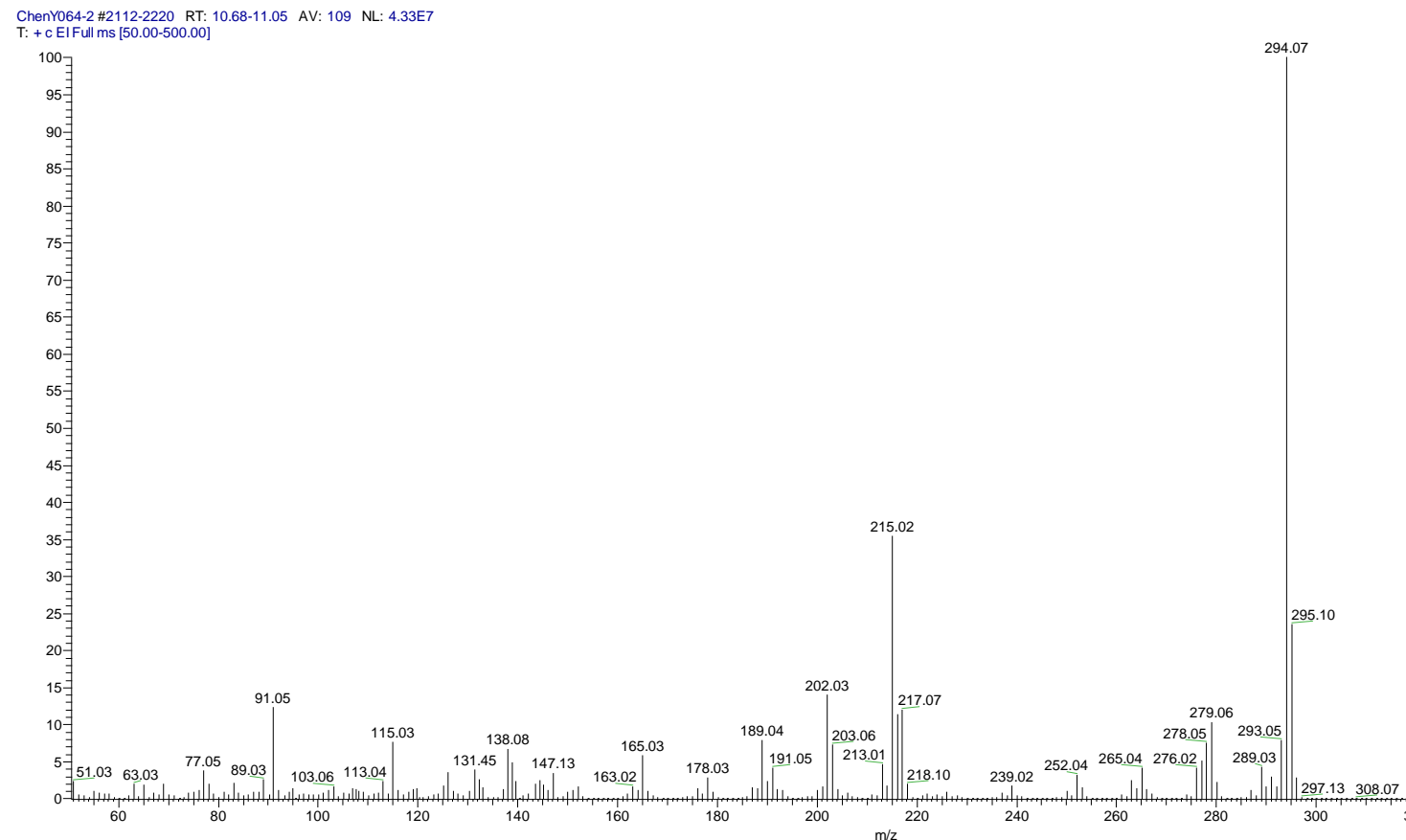

Figure S15. The MS spectrum of 5.

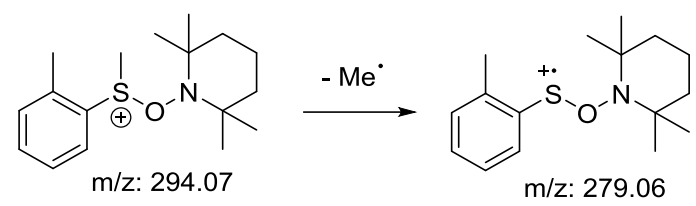

Scheme S3. Plausible mechanistic explanation for some main fragment ion peaks of 5. 
b. Determination of key byproducts by HRMS

$\mathrm{R}=\mathrm{Me}, \mathbf{6 o}$
$\mathrm{R}=\mathrm{Et}, \mathbf{6 a}$
$\mathrm{R}=\mathrm{Bu}, \mathbf{6 b}$
$\mathrm{R}=\mathrm{Bn}, \mathbf{6 c}$
$\mathrm{R}=\mathrm{CH}_{2} \mathrm{Bn}, \mathbf{6 d}$
$\mathrm{R}=i-\mathrm{Pr}, 6 \mathrm{e}$
$\mathrm{R}=t-\mathrm{Bu}, \mathbf{6 f}$
$\mathrm{R}=\mathrm{H}, \mathbf{7 H}$

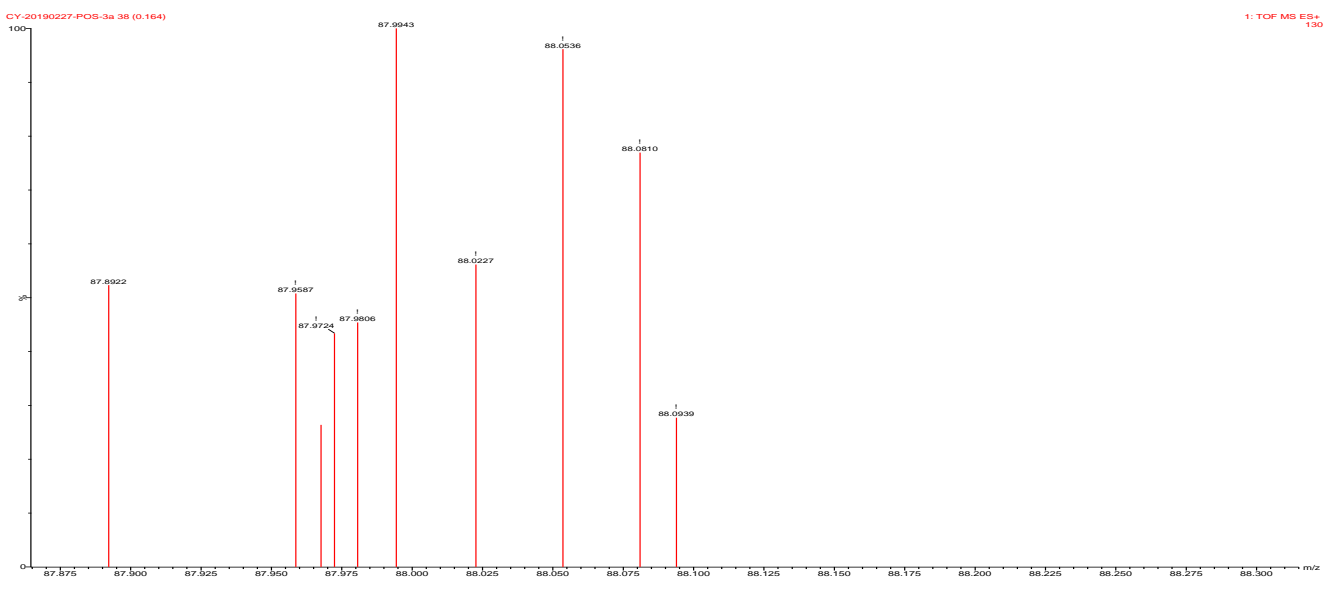

Figure S16. The HRMS spectrum of 6o. HRMS (ESI): m/z M $\mathrm{M}^{2+}$ calcd for $\mathrm{C}_{8} \mathrm{H}_{17} \mathrm{CIN}_{2}$ : 88.0535; found: 88.0536 .

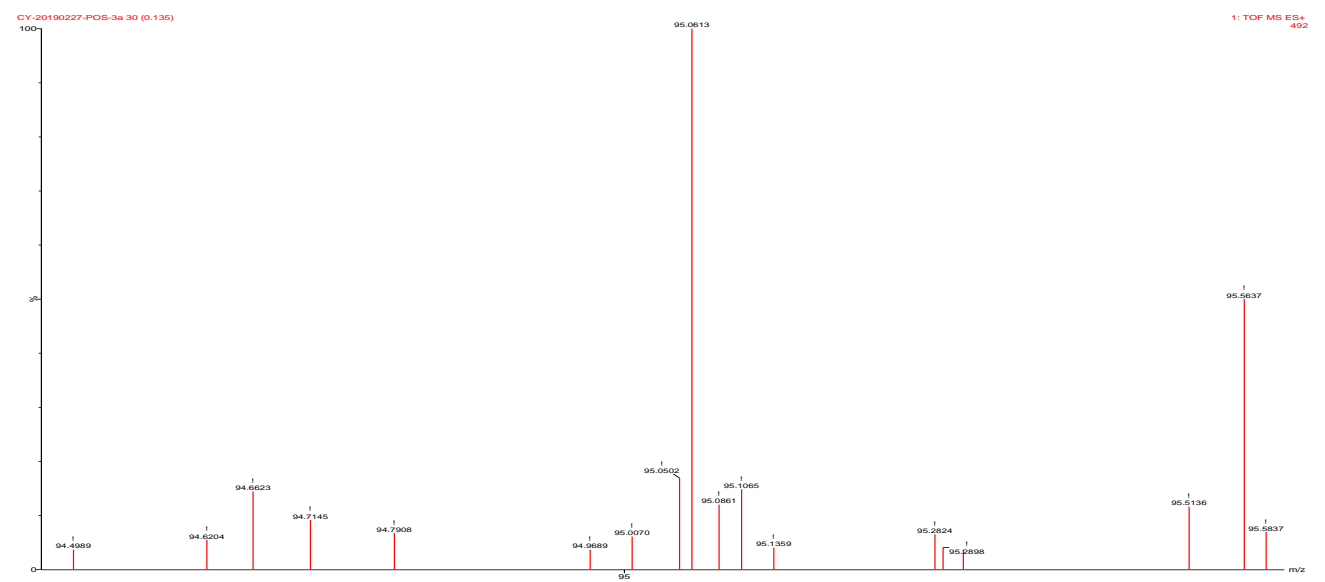

Figure S17. The HRMS spectrum of 6a. HRMS (ESI): m/z M $\mathrm{M}^{2+}$ calcd for $\mathrm{C}_{9} \mathrm{H}_{19} \mathrm{CIN}_{2}$ : 95.0613; found: 95.0613. 


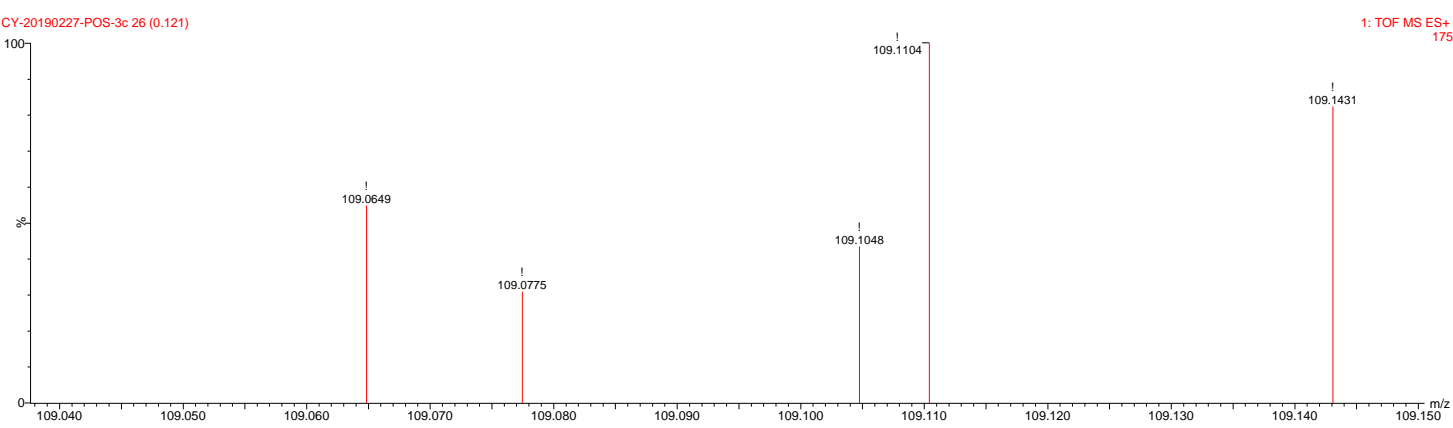

Figure S18. The HRMS spectrum of 6 b. HRMS (ESI): $\mathrm{m} / \mathrm{z} \mathrm{M} \mathrm{M}^{2+}$ calcd for $\mathrm{C}_{11} \mathrm{H}_{23} \mathrm{ClN}_{2}{ }^{2+}$ : 109.0769; found: 109.0770 .

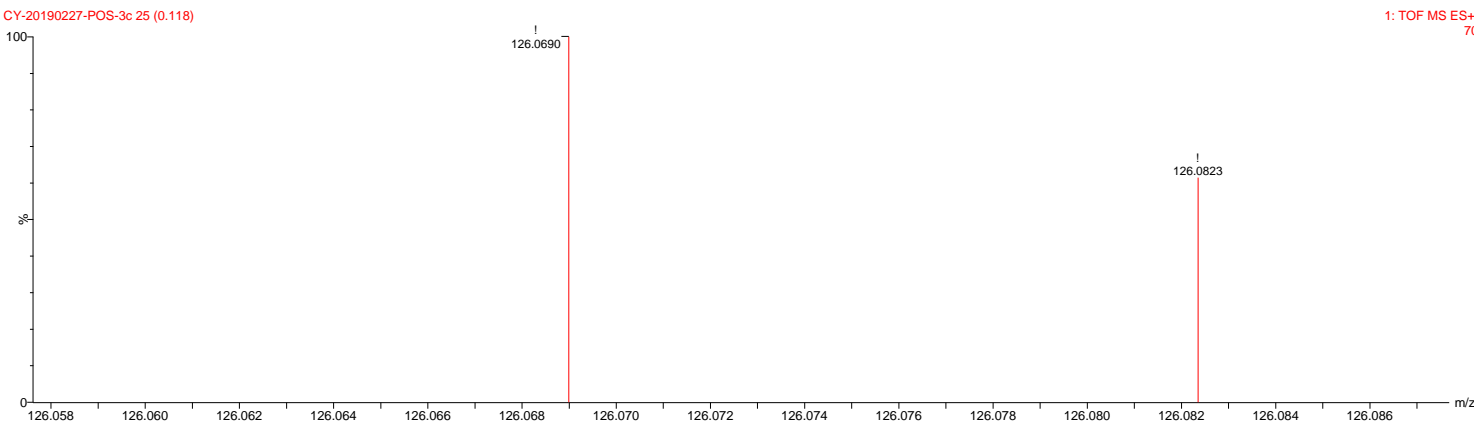

Figure S19. The HRMS spectrum of 6c. HRMS (ESI): $\mathrm{m} / \mathrm{z} \mathrm{M}^{2+}$ calcd for $\mathrm{C}_{14} \mathrm{H} 21 \mathrm{CIN}_{2}: 126.0691$; found: 126.0690 .

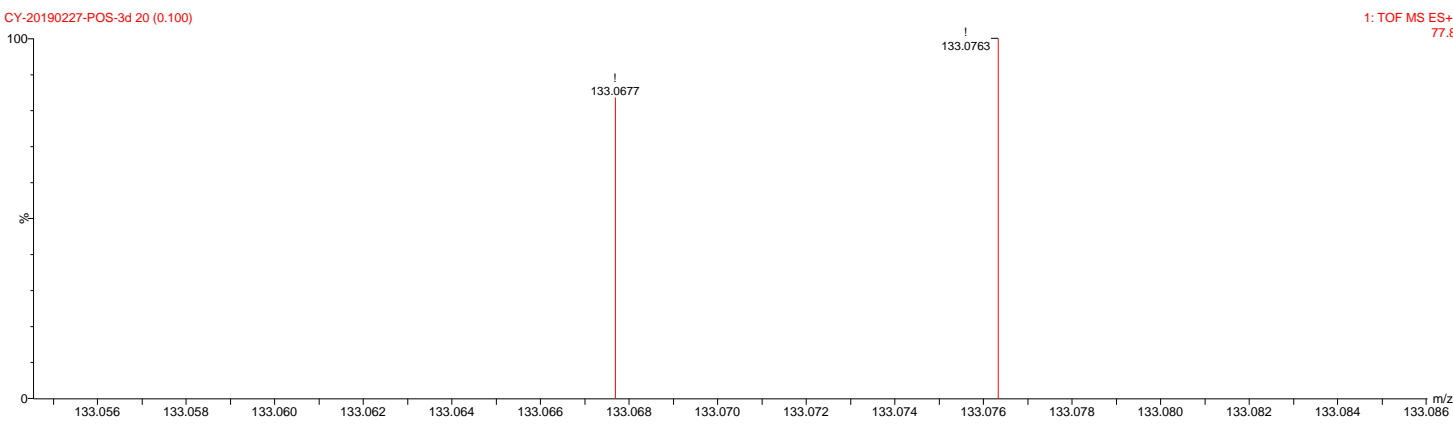

Figure S20. The HRMS spectrum of $6 \mathrm{~d}$. HRMS (ESI): $\mathrm{m} / \mathrm{z} \mathrm{M}{ }^{2+}$ calcd for $\mathrm{C}_{15} \mathrm{H}_{23} \mathrm{ClN}_{2}: 133.0769$; found: 133.0763 


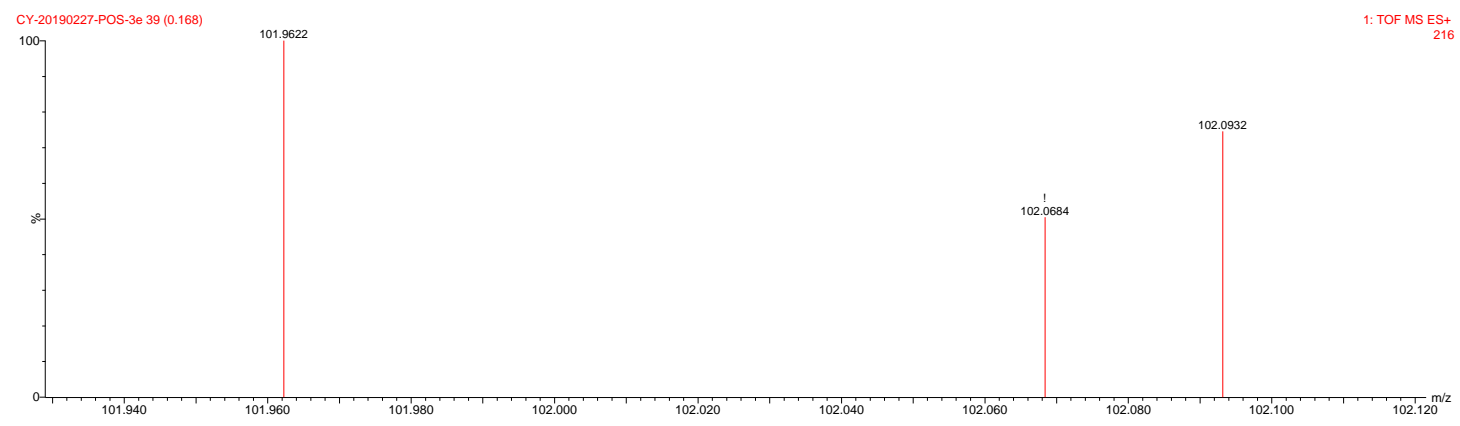

Figure S21. The HRMS spectrum of 6 e. HRMS (ESI): $\mathrm{m} / 2 \mathrm{M}^{2+}$ calcd for $\mathrm{C}_{10} \mathrm{H}_{21} \mathrm{CIN}_{2}$ : 102.0691; found: 102.0684

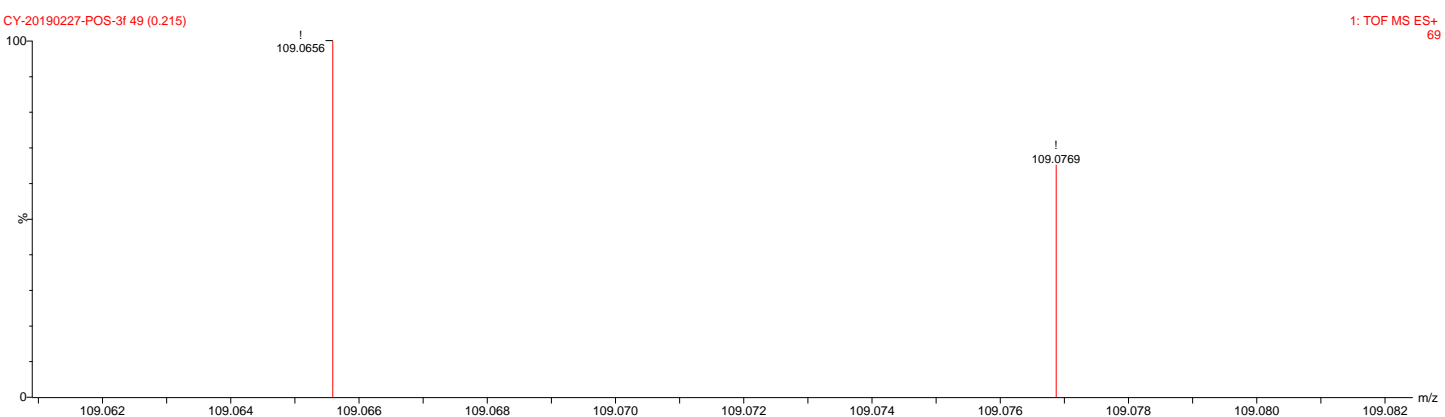

Figure S22. The HRMS spectrum of 6f. HRMS (ESI): $\mathrm{m} / 2 \mathrm{M}^{2+}$ calcd for $\mathrm{C}_{11} \mathrm{H}_{23} \mathrm{CIN}_{2}$ : 109.0769; found: 109.0769.

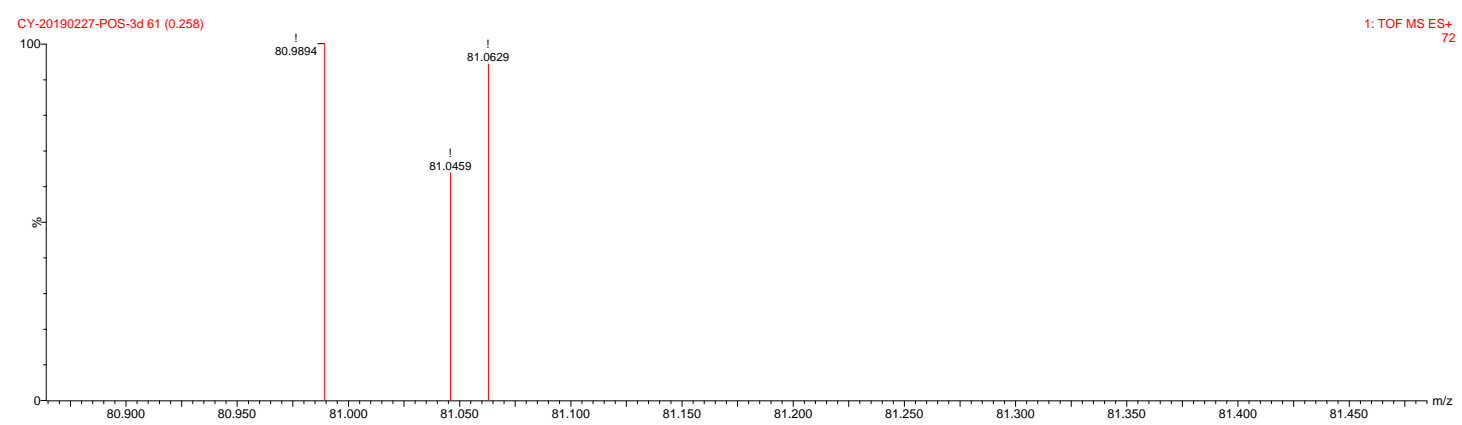

Figure S23. The HRMS spectrum of 7H. HRMS (ESI): $\mathrm{m} / \mathrm{z} \mathrm{M}^{2+}$ calcd for $\mathrm{C}_{11} \mathrm{H}_{23} \mathrm{CIN}_{2}$ : 81.0456; found: 81.0459 . 


\section{c. Byproduct determination}

For a similar spectrum in different reaction system, see: Yang, K.; Zhang, H.; Niu, B.; Tang, T.; Ge, H. Benzisothiazol-3-ones Through a Metal-Free Intramolecular N-S Bond Formation. Eur. J. Org. Chem. 2018, 5520-5523.

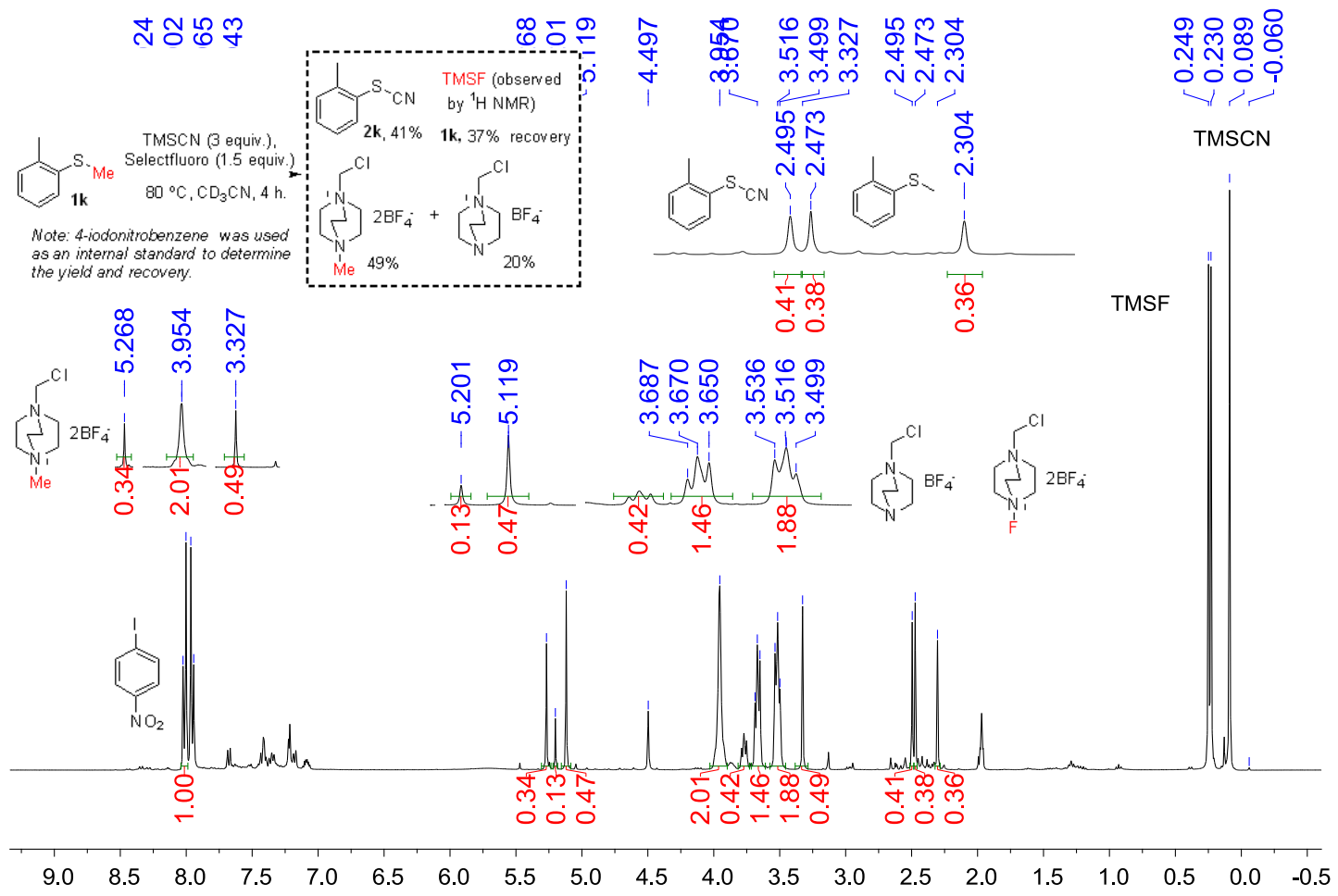

Figure S24. The ${ }^{1} \mathrm{H}$ NMR spectrum of the crude reaction mixture, with 4-nitroiodobenzene as an internal standard $\left(400 \mathrm{M}, \mathrm{CD}_{3} \mathrm{CN}\right)$.

\section{d. ${ }^{1} \mathrm{H},{ }^{19} \mathrm{~F}$, and ${ }^{13} \mathrm{C}$ NMR Spectra of Crude Reaction Mixture of TMSCN and Selectfluor (in $\mathrm{CD}_{3} \mathrm{CN}$ )}




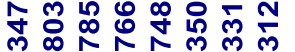

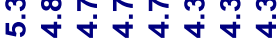

\section{$\underbrace{2}_{i=1}$}

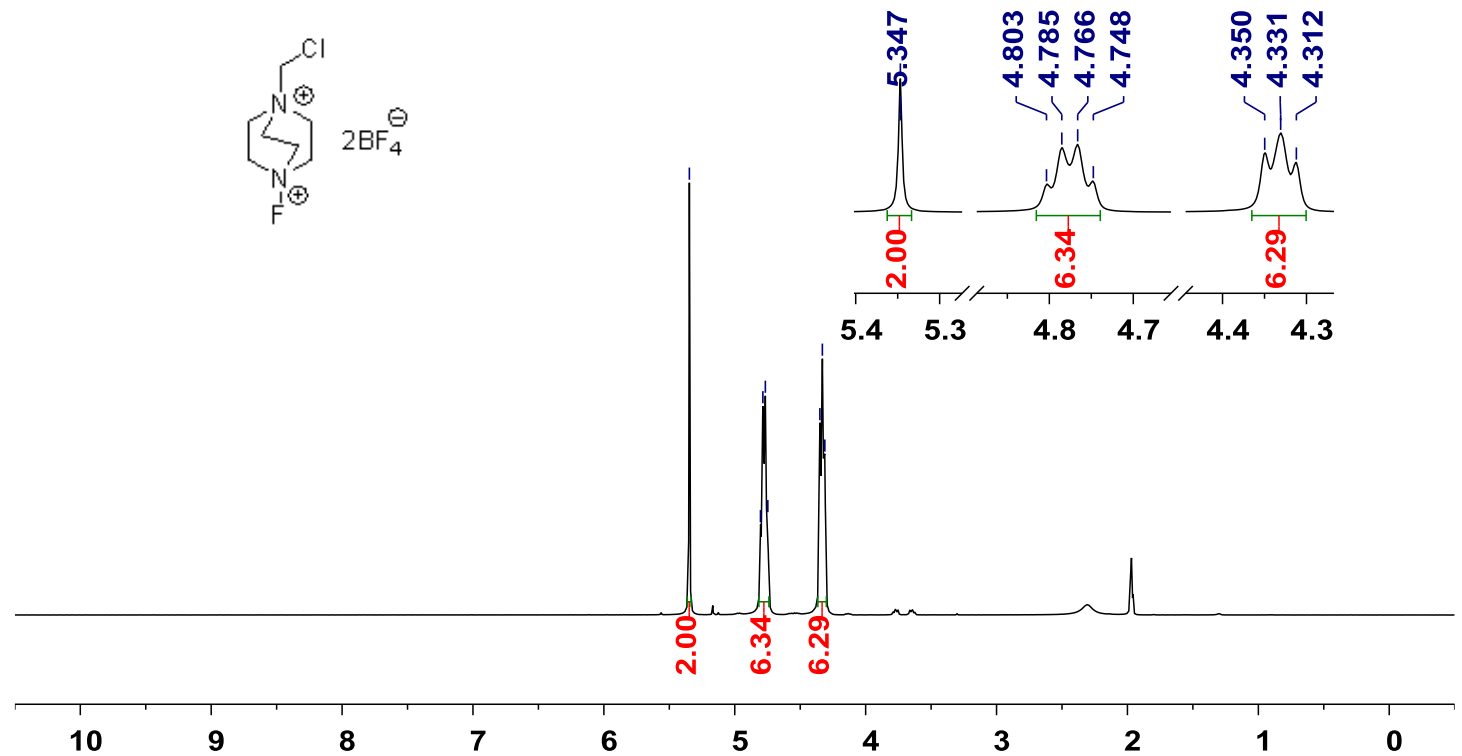

Figure S25. The ${ }^{1} \mathrm{H}$ NMR spectrum of Selectfluor in $\mathrm{CD}_{3} \mathrm{CN}$.
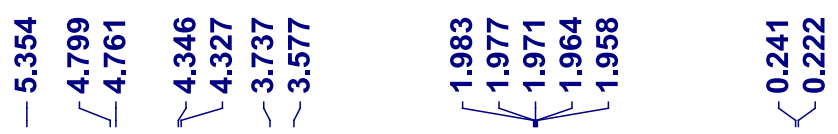

SelectF + TMSCN $\left(\mathrm{CD}_{3} \mathrm{CN}, 80^{\circ} \mathrm{C}, 2 \mathrm{~h}\right)$

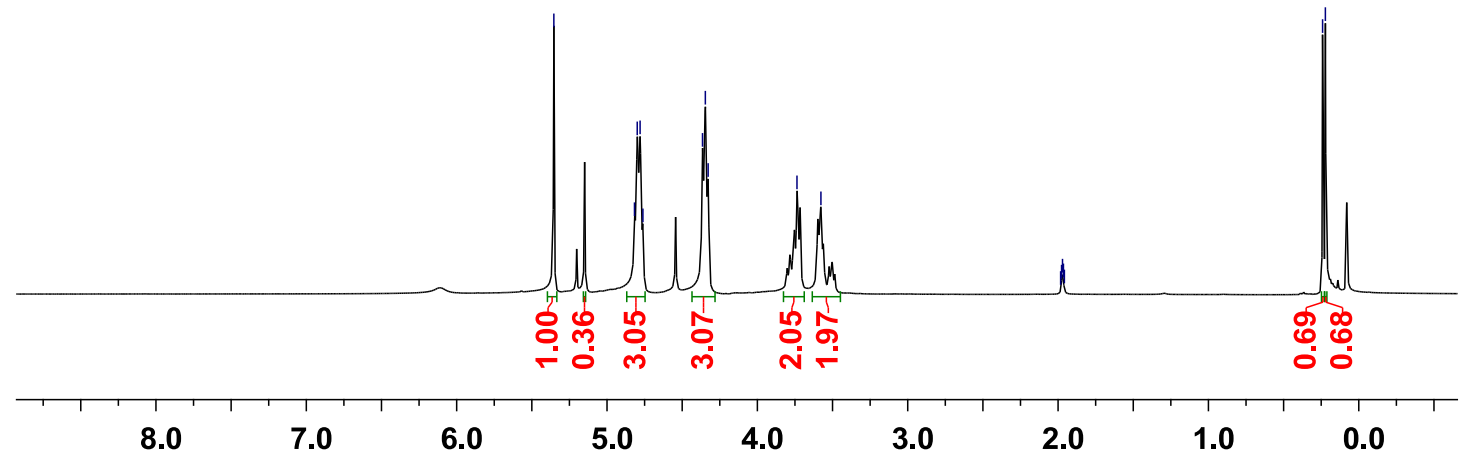

Figure S26. The ${ }^{1} \mathrm{H}$ NMR spectrum of the crude reaction mixture of Selectfluor and TMSCN in $\mathrm{CD}_{3} \mathrm{CN}$. 


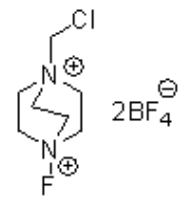

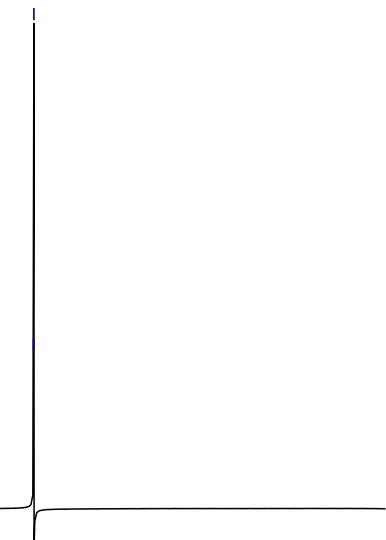

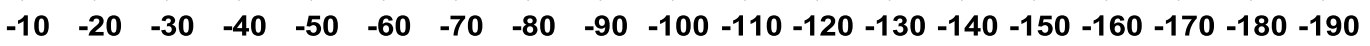

Figure S27. The ${ }^{19} \mathrm{~F}$ NMR spectrum of Selectfluor in $\mathrm{CD}_{3} \mathrm{CN}$.

Figure S28. The ${ }^{19} \mathrm{~F}$ NMR spectrum of the crude reaction mixture of Selectfluor and TMSCN in $\mathrm{CD}_{3}$ CN. (-157.4 indicates TMSF, see J. Fluor. Chem. 2009, 130, 667-670). 


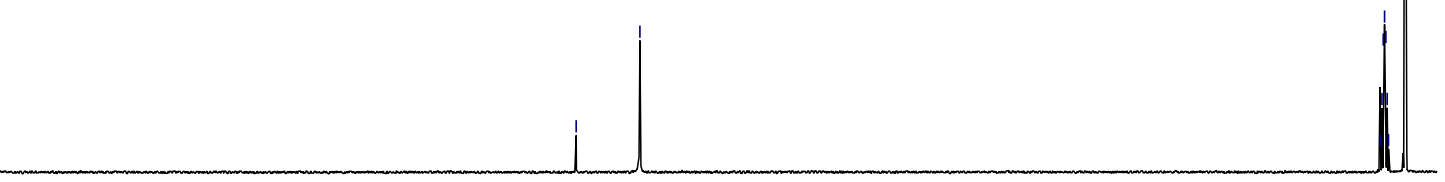

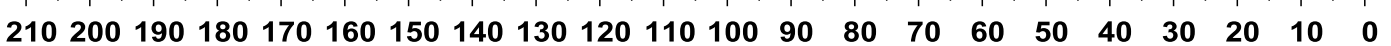

Figure S29. The ${ }^{13} \mathrm{C}$ NMR spectrum of $\mathrm{TMSCN}$ in $\mathrm{CD}_{3} \mathrm{CN}$.

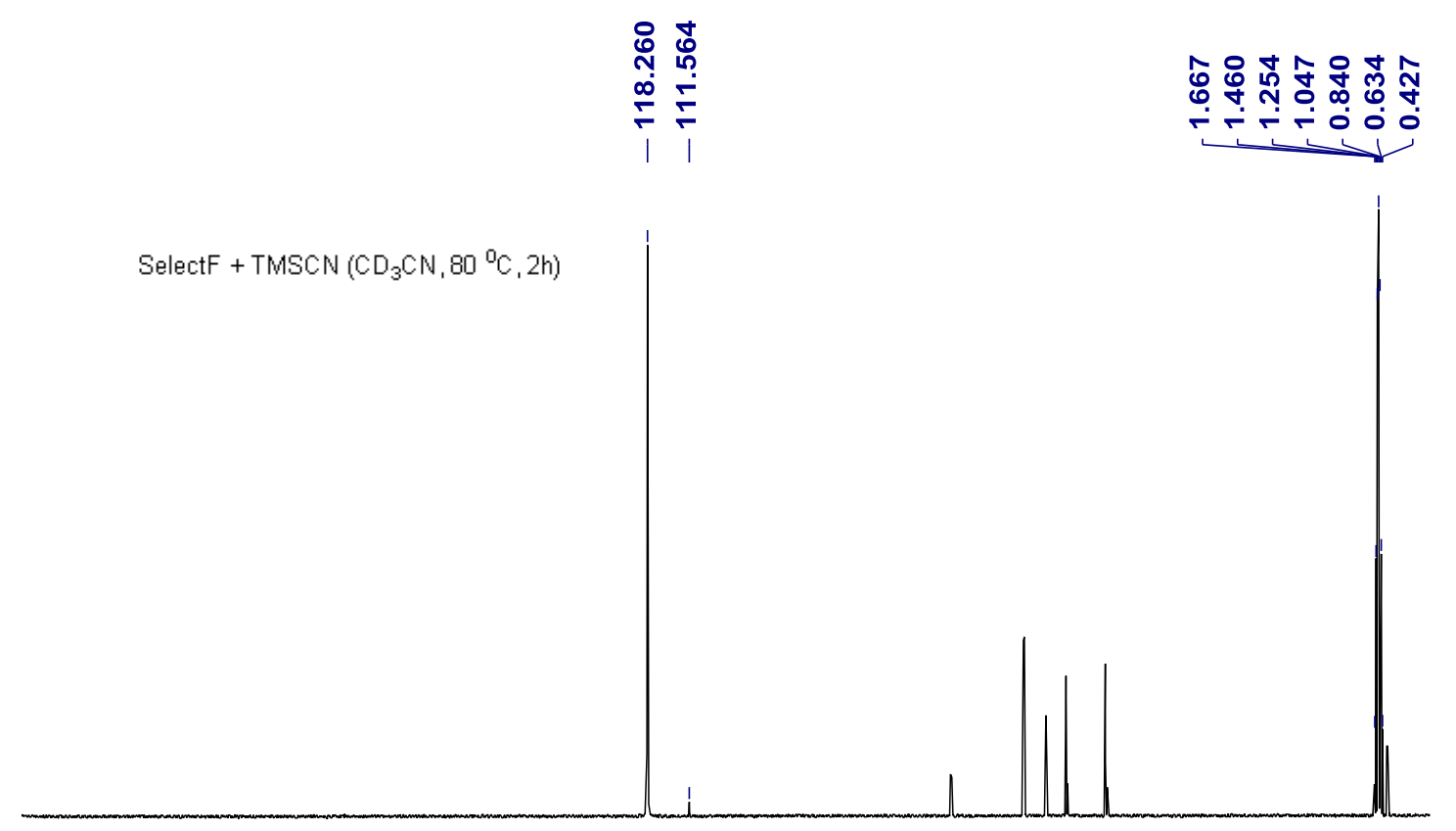

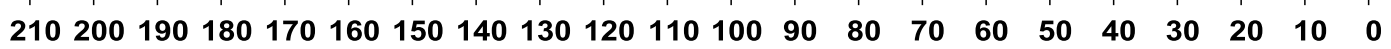

Figure S30. The ${ }^{13} \mathrm{C}$ NMR spectrum of the crude reaction mixture of Selectfluor and TMSCN in $\mathrm{CD}_{3} \mathrm{CN}$ (TMSCN decomposed). 


\section{3. ${ }^{1} \mathrm{H},{ }^{13} \mathrm{C}$ NMR Spectra and MS Spectra of Products}

${ }^{1} \mathrm{H}$ and ${ }^{13} \mathrm{C}$ Spectra of Thiocyanatobenzene (2a) in $\mathrm{CDCl}_{3}(400 \mathrm{M})$

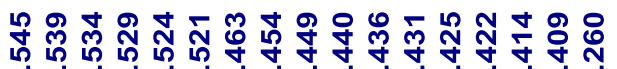

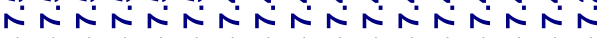

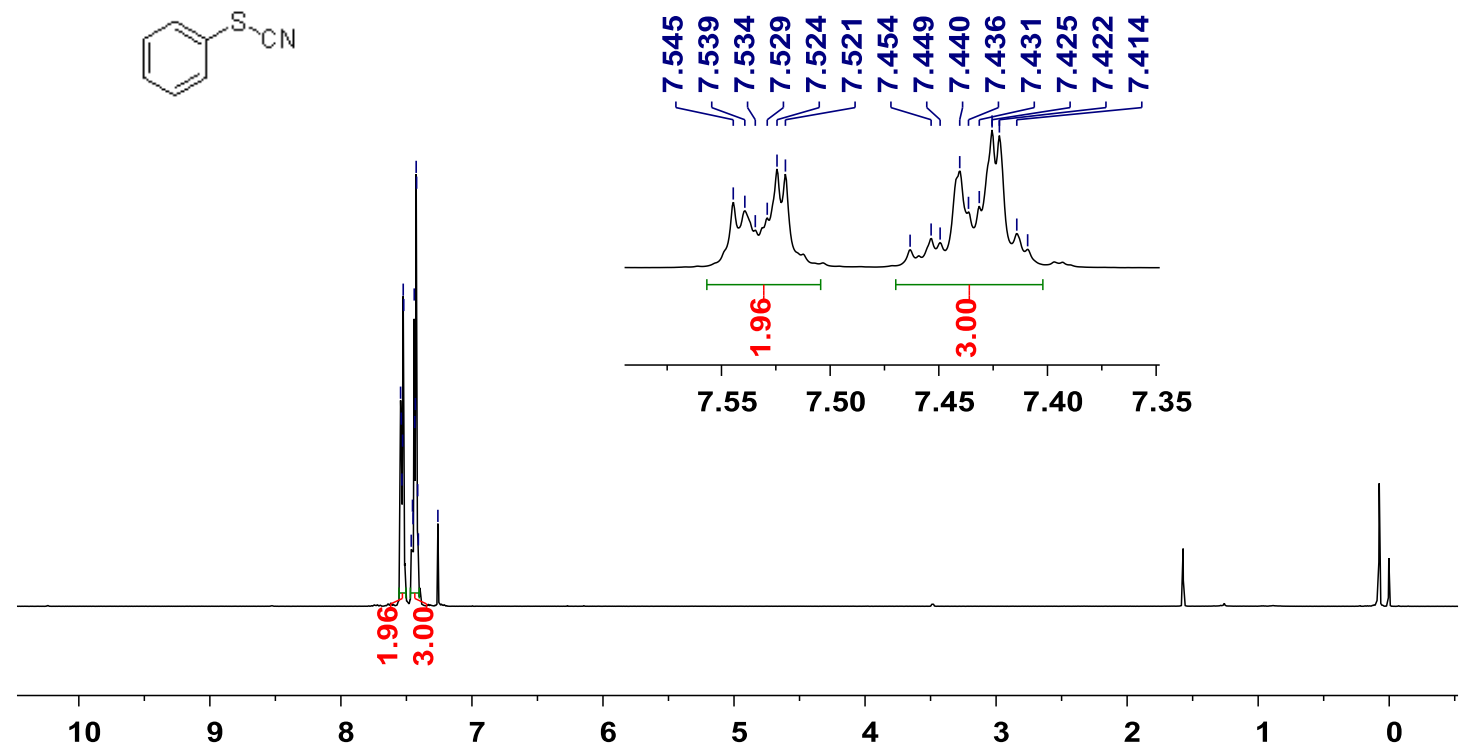

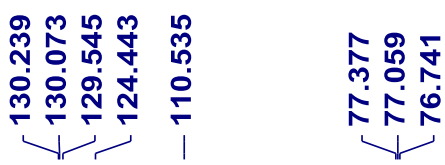

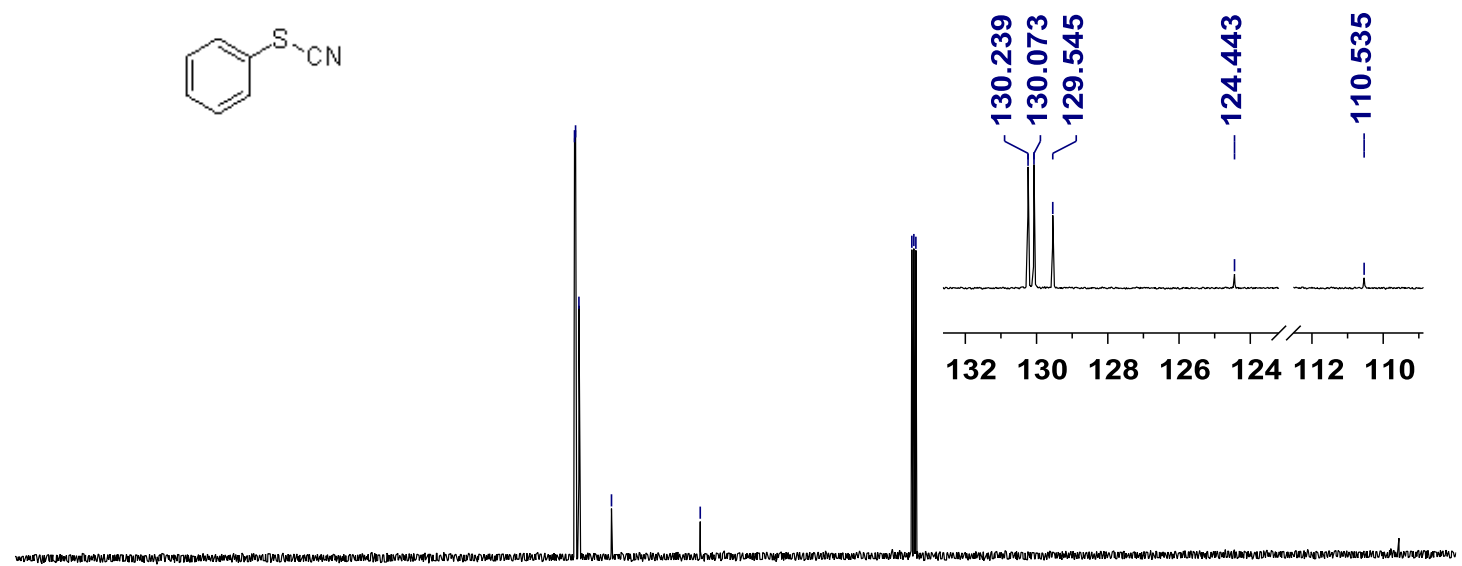

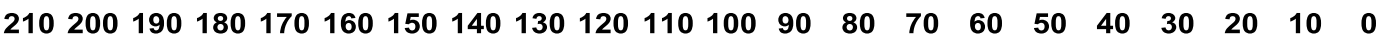


MS (EI) Spectrum of Thiocyanatobenzene (2a)

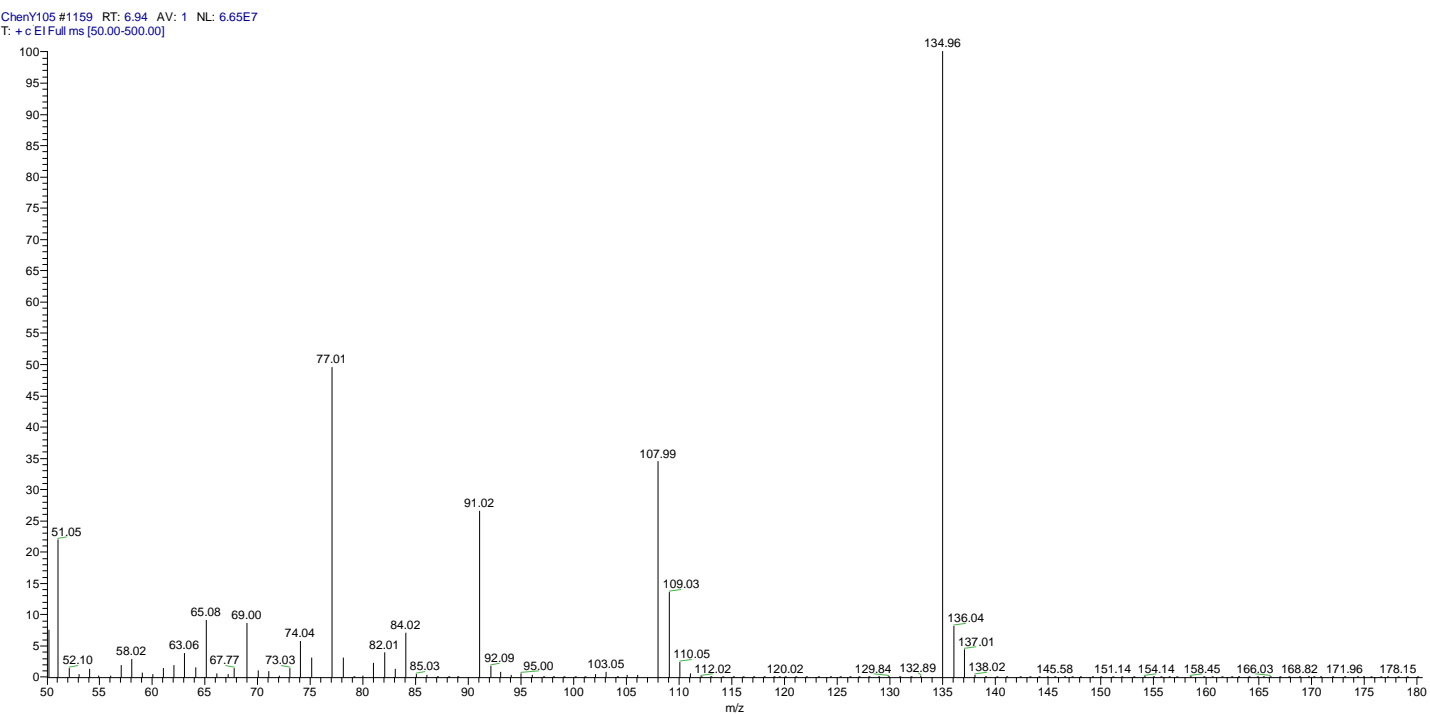


${ }^{1} \mathrm{H}$ and ${ }^{13} \mathrm{C}$ Spectra of 1-methoxy-4-thiocyanatobenzene (2b) in $\mathrm{CDCl}_{3}$ (400M)

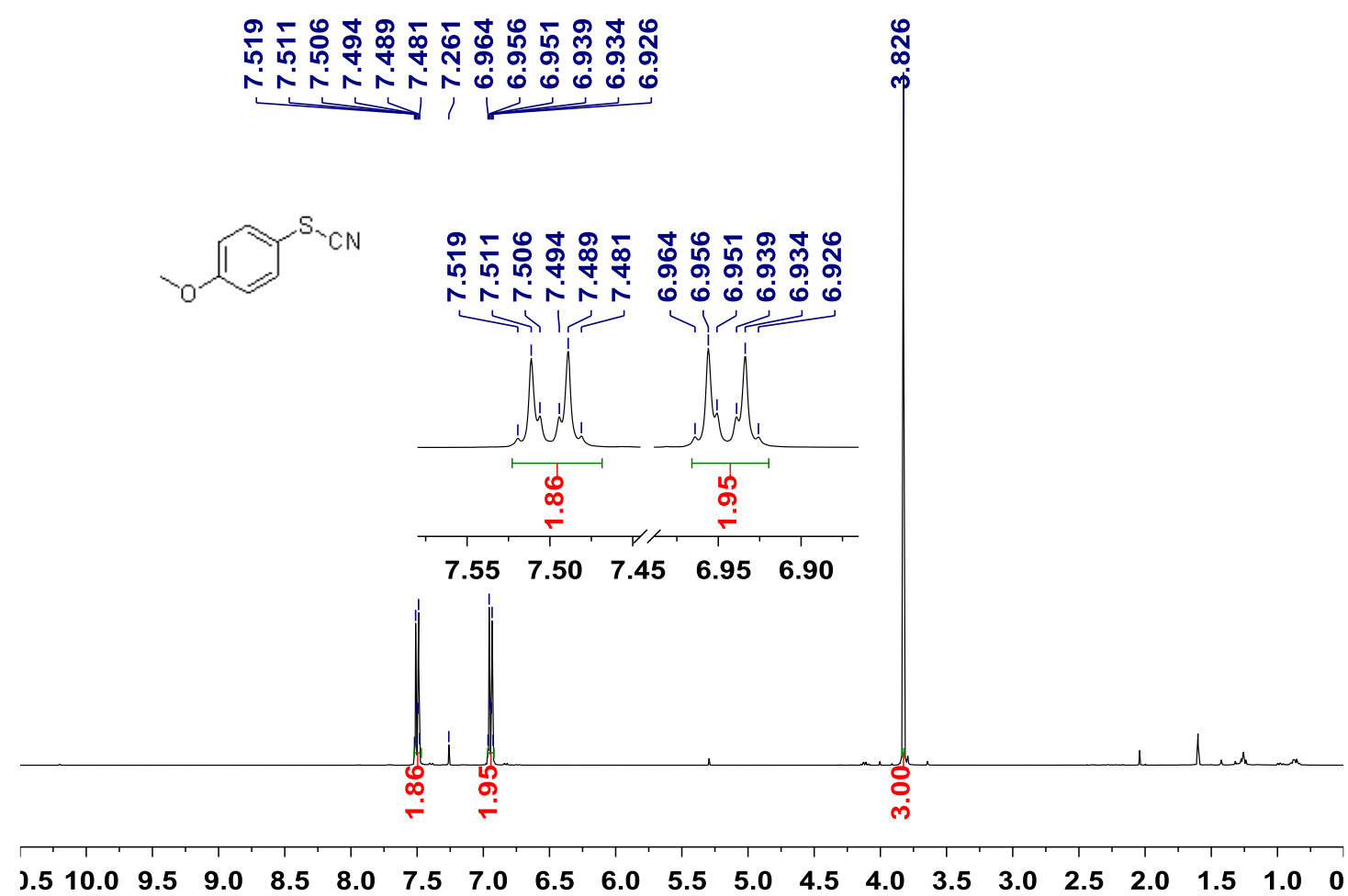

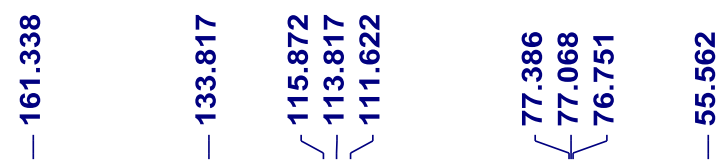

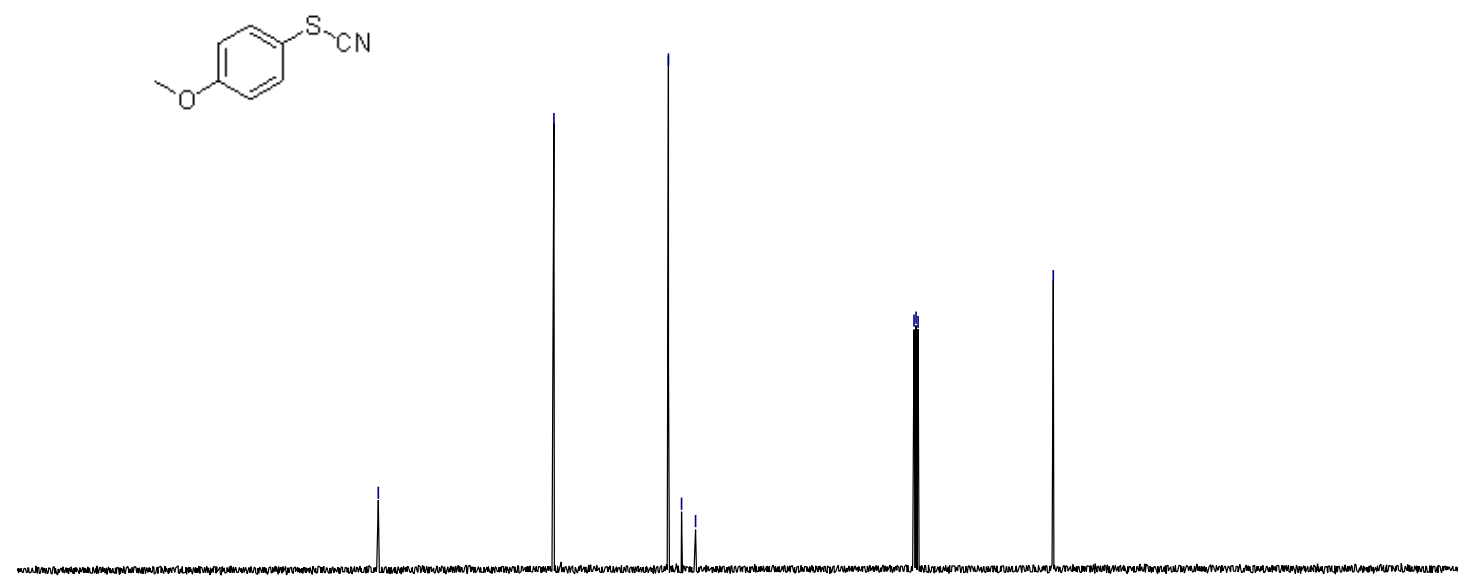

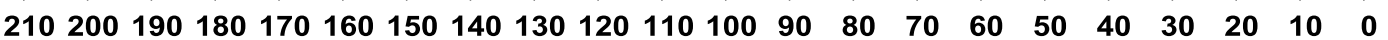


MS (EI) Spectrum of 1-methoxy-4-thiocyanatobenzene (2b)

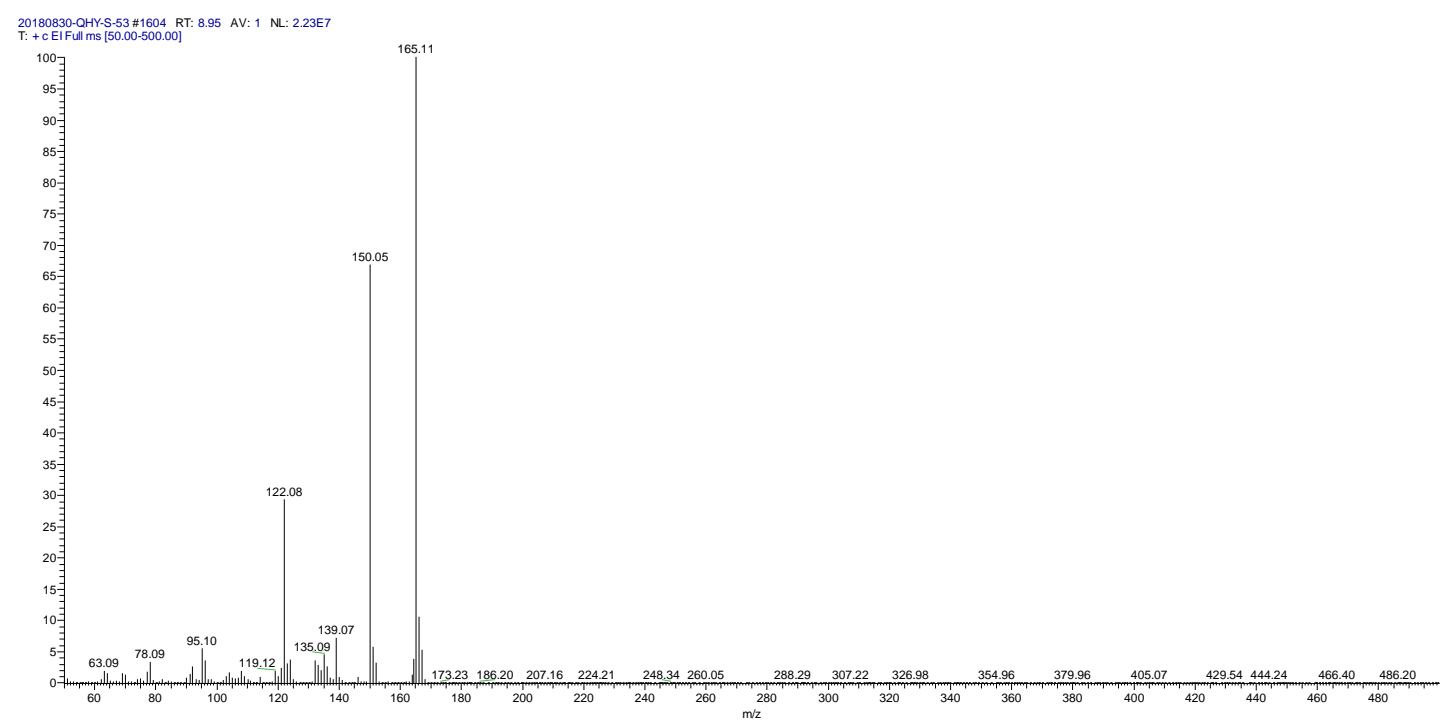


${ }^{1} \mathrm{H}$ and ${ }^{13} \mathrm{C}$ Spectra of 1-ethoxy-4-thiocyanatobenzene (2c) in $\mathrm{CDCl}_{3}(400 \mathrm{M})$
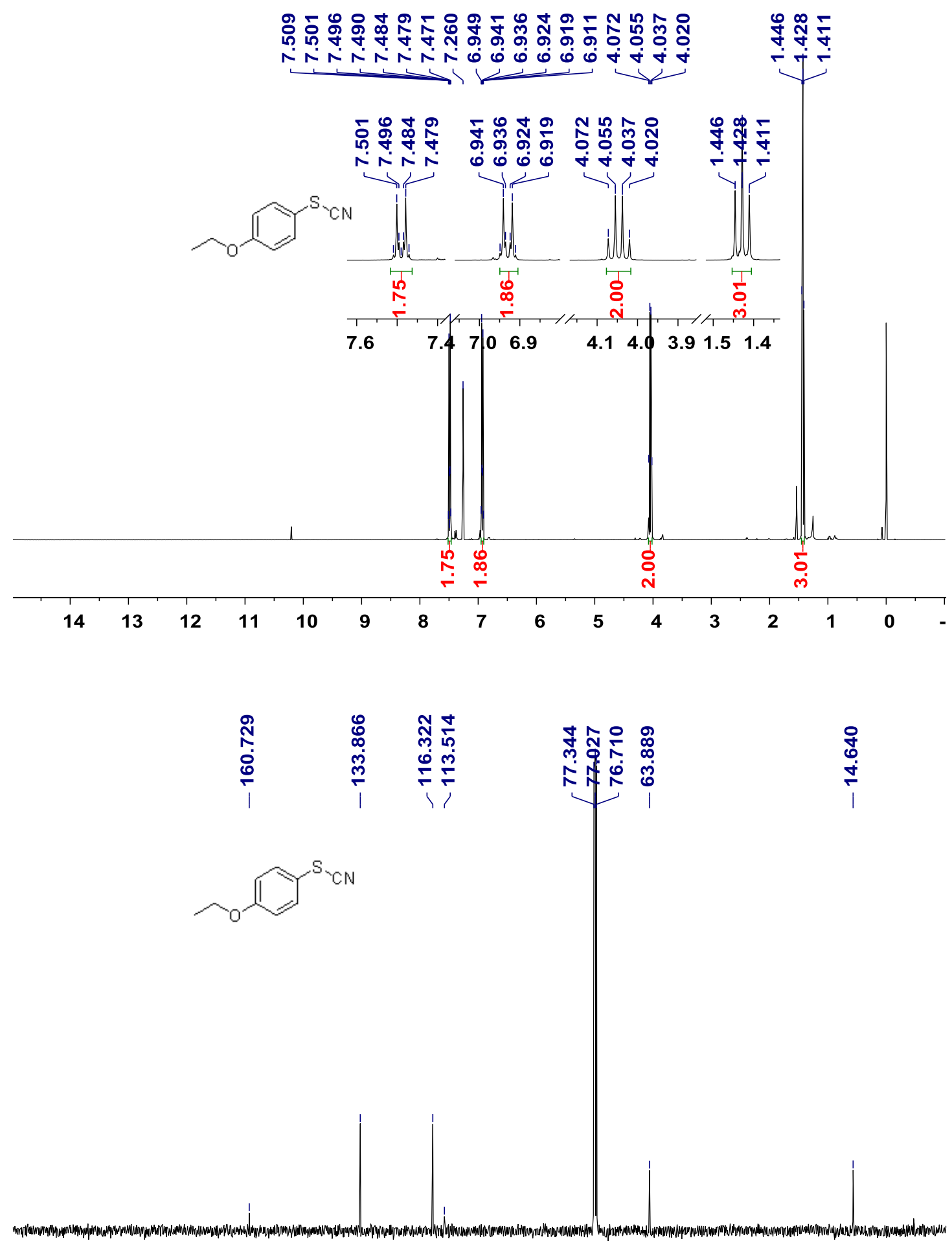

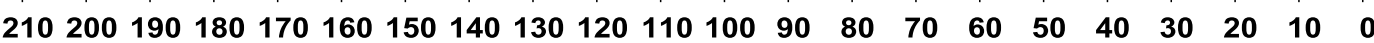


MS (EI) Spectrum of 1-ethoxy-4-thiocyanatobenzene (2c)

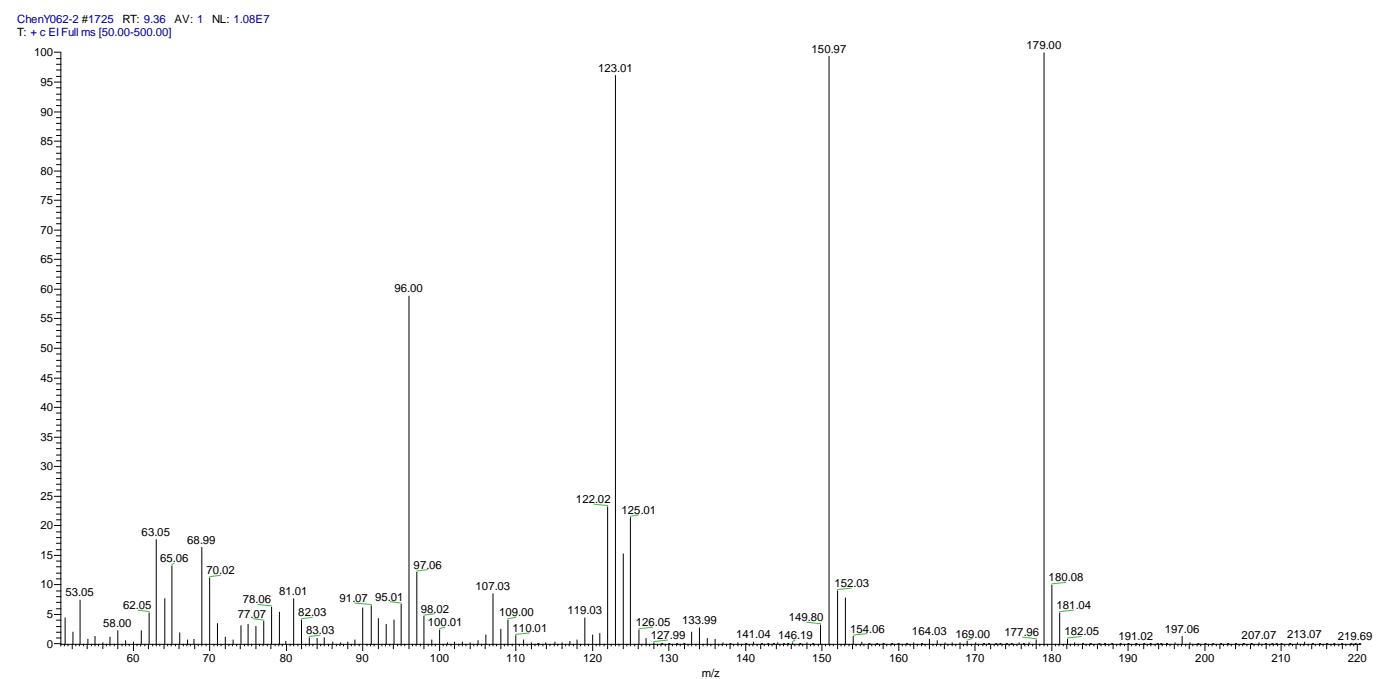


${ }^{1} \mathrm{H}$ and ${ }^{13} \mathrm{C}$ Spectra of 1-butoxy-4-thiocyanatobenzene (2d) in $\mathrm{CDCl}_{3}(400 \mathrm{M})$

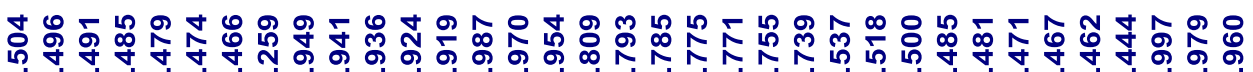

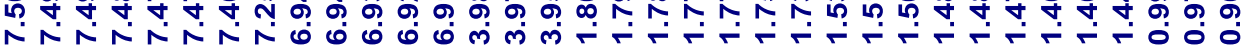

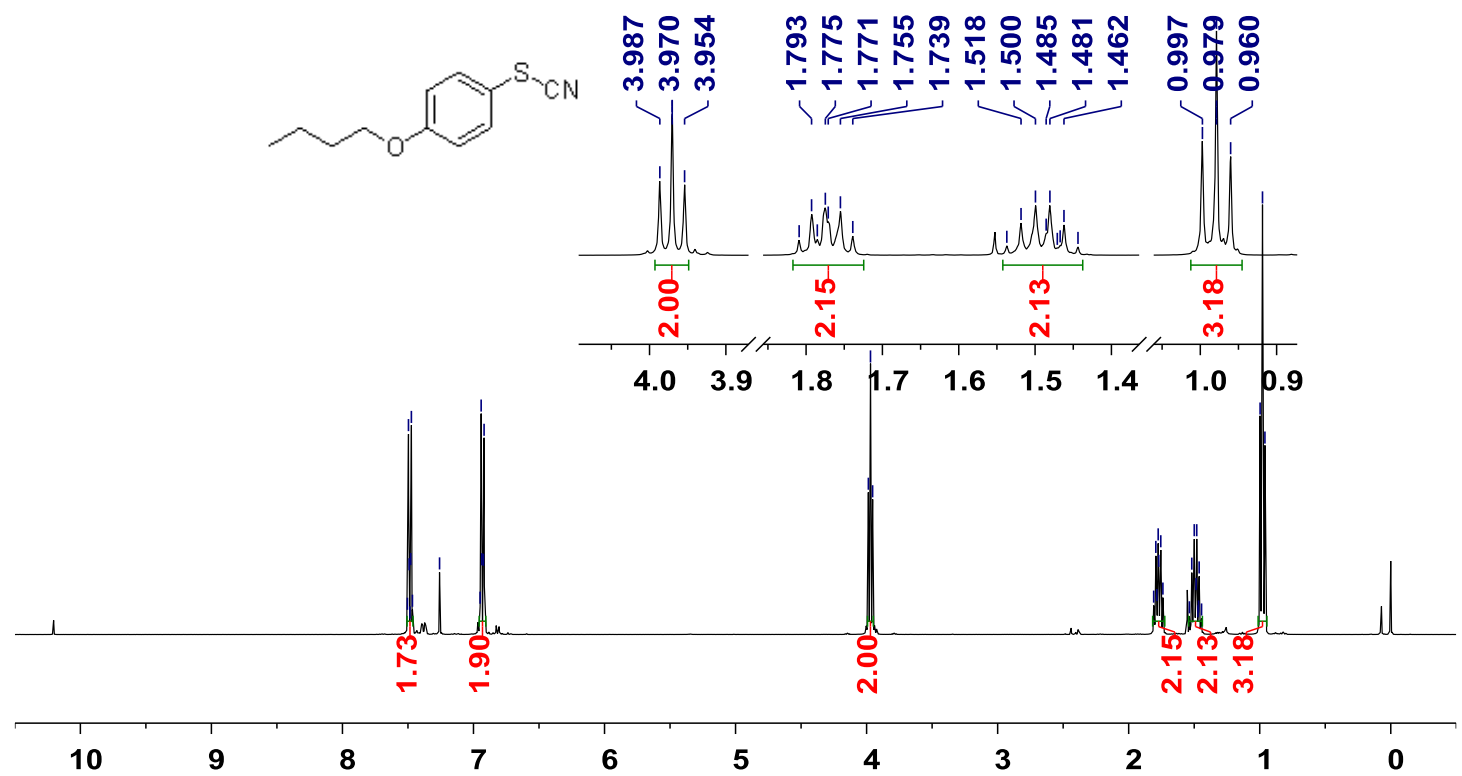

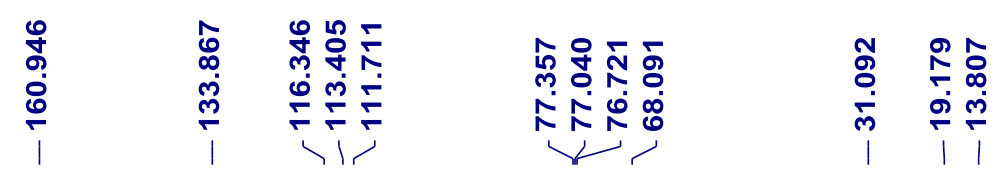

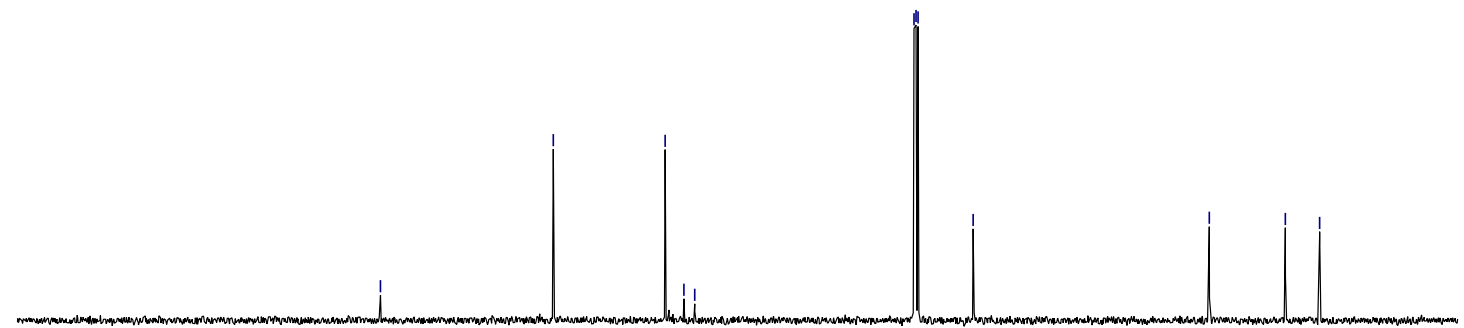

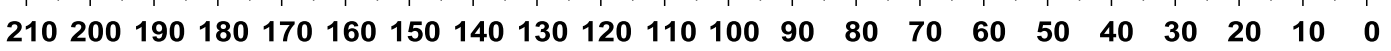


MS (EI) Spectrum of 1-butoxy-4-thiocyanatobenzene (2d)

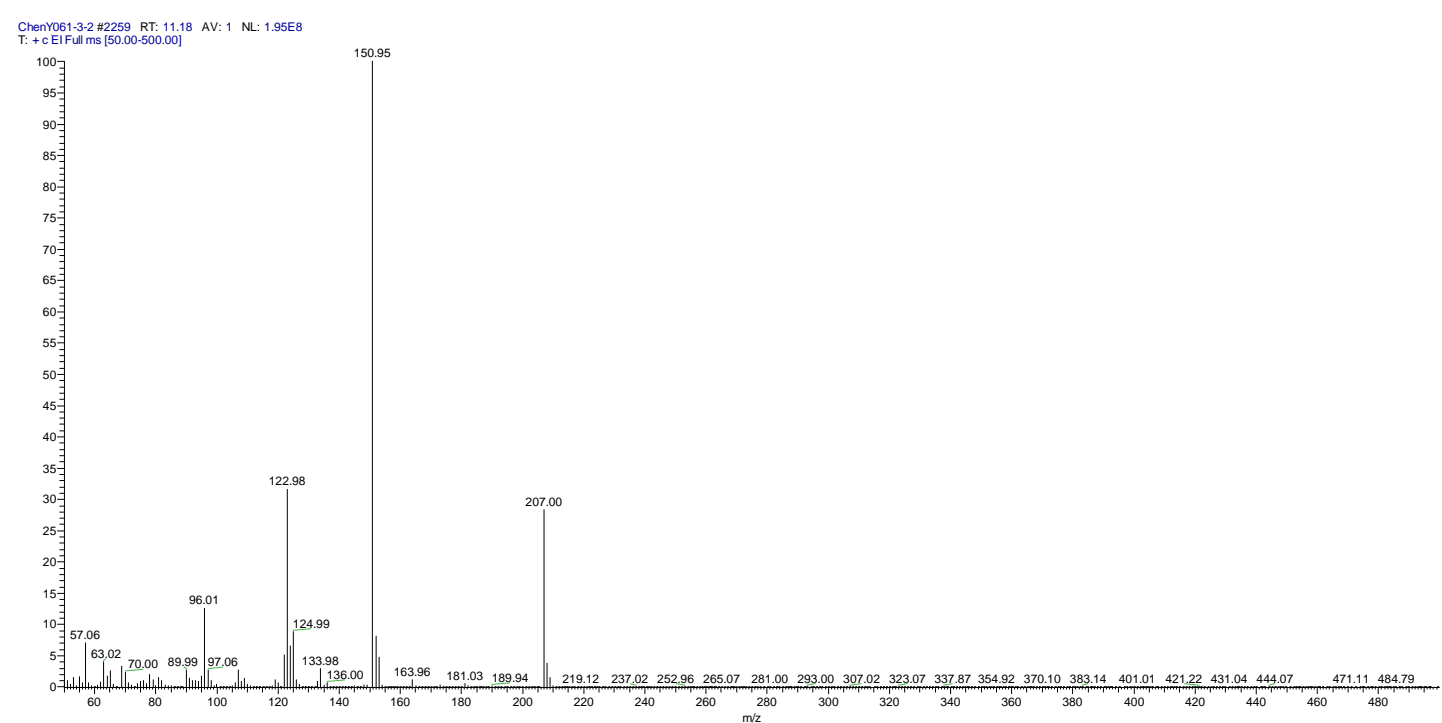


${ }^{1} \mathrm{H}$ and ${ }^{13} \mathrm{C}$ Spectra of 1-(allyloxy)-4-thiocyanatobenzene (2e) in $\mathrm{CDCl}_{3}(400 \mathrm{M})$

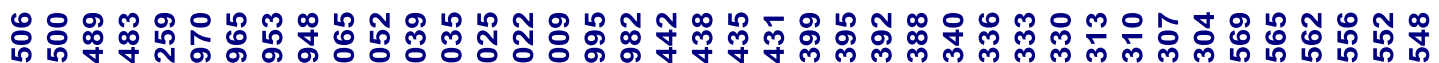

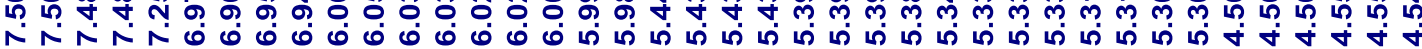
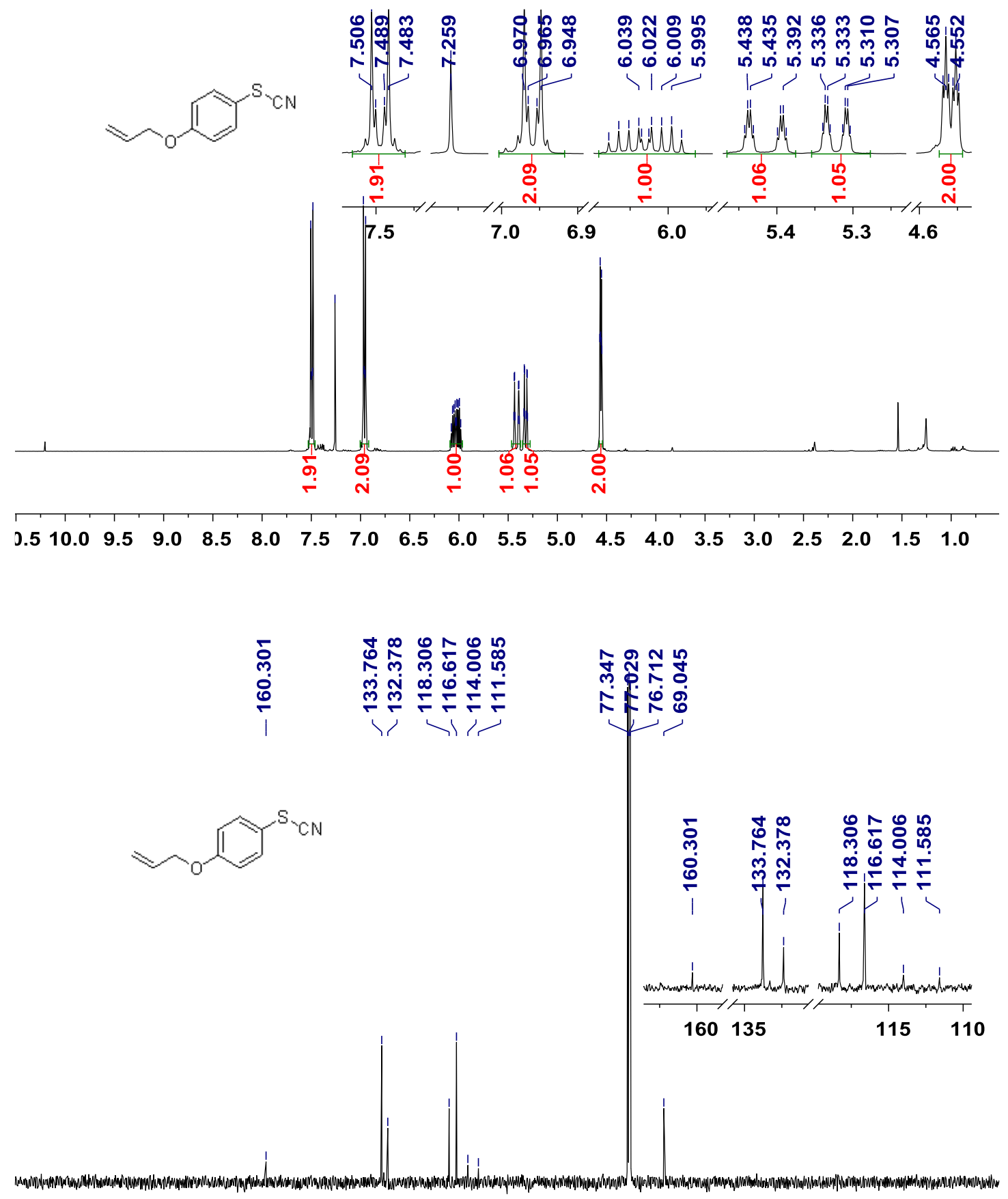

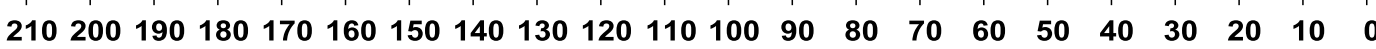


HRMS (ESI) Spectrum of 1-(allyloxy)-4-thiocyanatobenzene (2e)

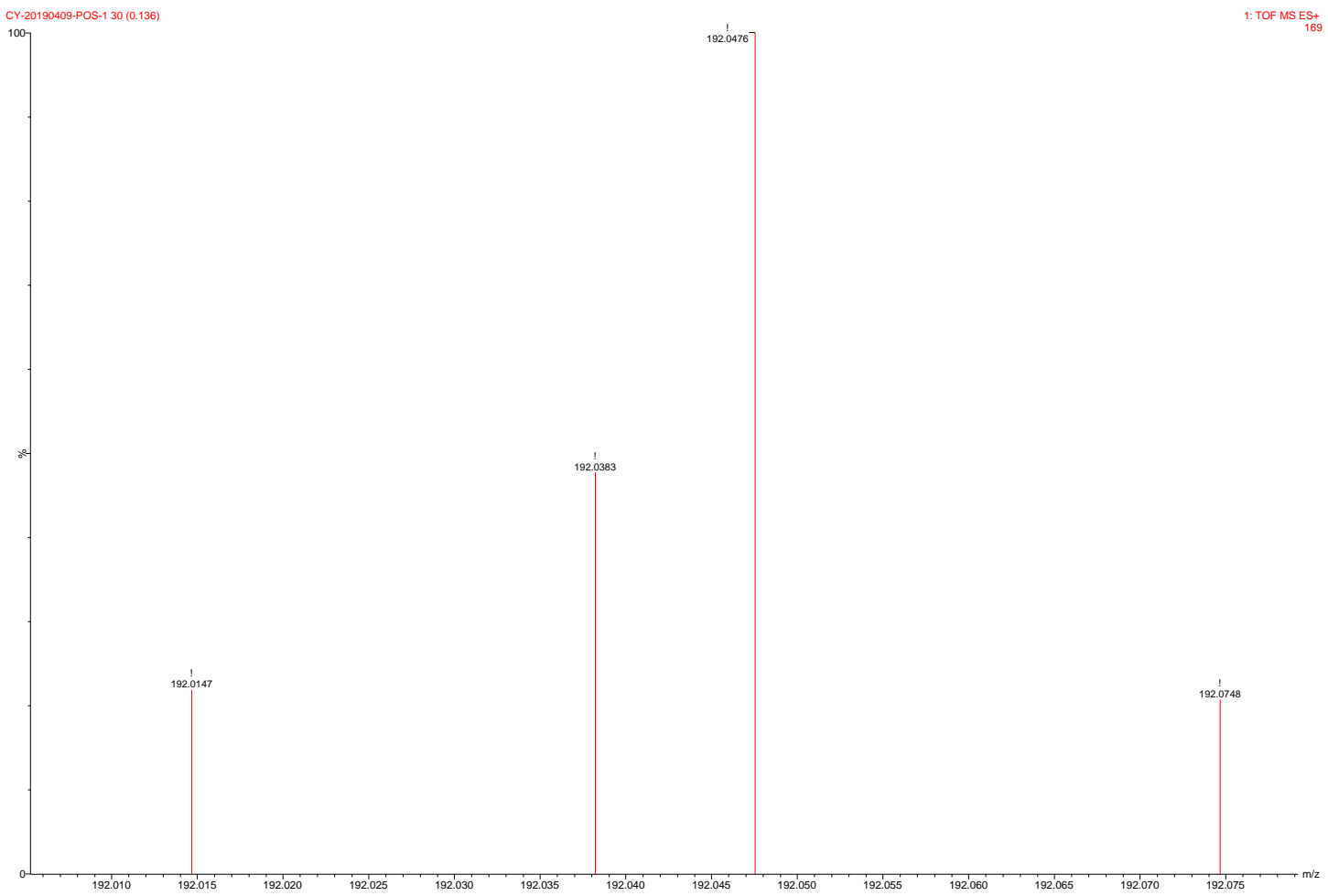


${ }^{1} \mathrm{H}$ and ${ }^{13} \mathrm{C}$ Spectra of 1-(benzyloxy)-4-thiocyanatobenzene (2f) in $\mathrm{CDCl}_{3}(400 \mathrm{M})$

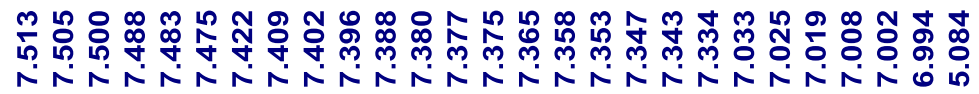
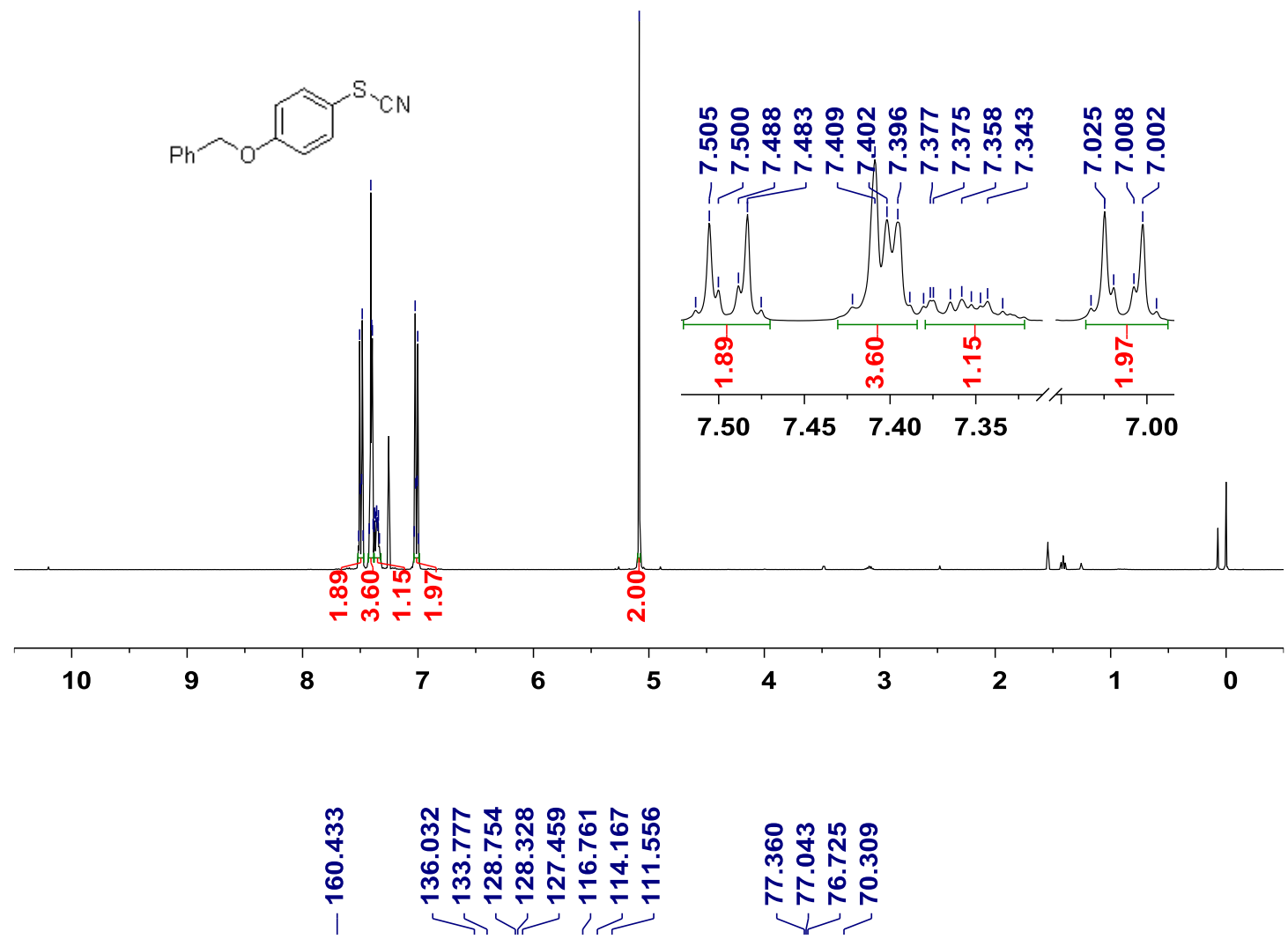

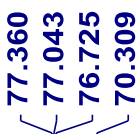

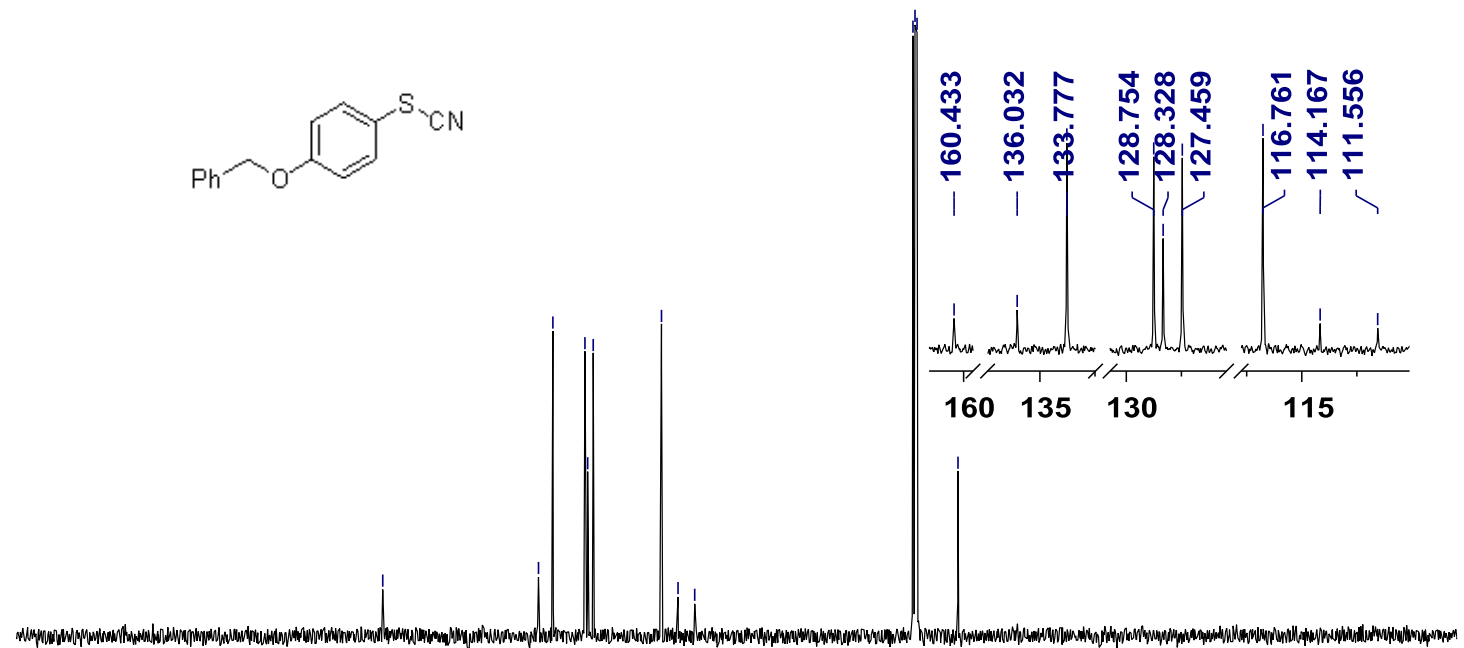

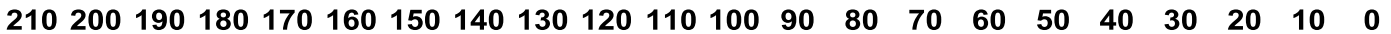


HRMS (ESI) Spectrum of 1-(benzyloxy)-4-thiocyanatobenzene (2f)

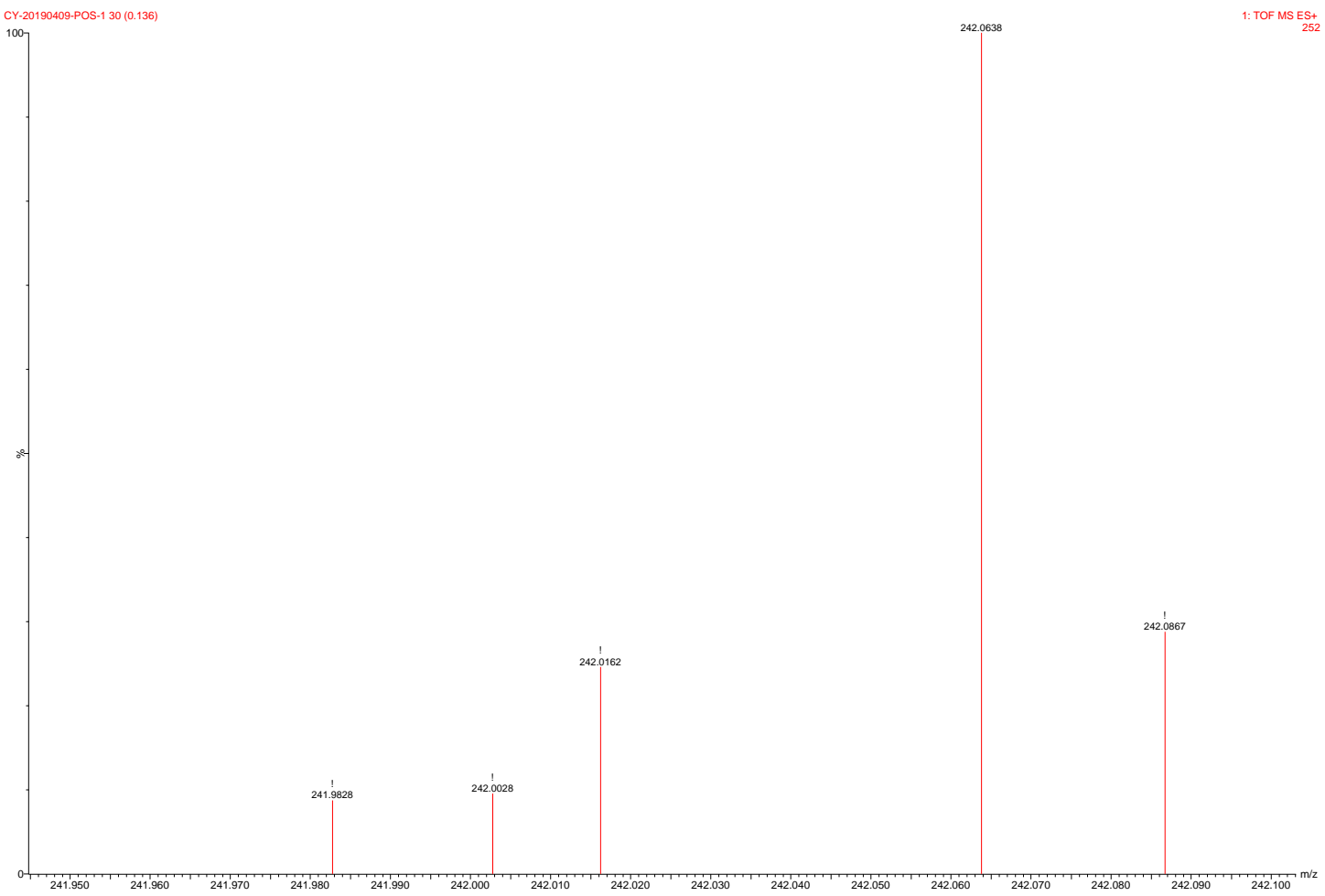


${ }^{1} \mathrm{H}$ and ${ }^{13} \mathrm{C}$ Spectra of 4-thiocyanatophenyl methanesulfonate $(2 \mathrm{~g})$ in $\mathrm{CDCl}_{3}(400 \mathrm{M})$

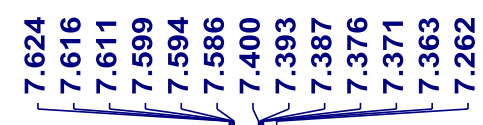

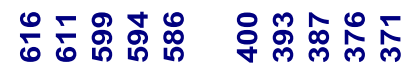

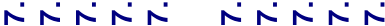
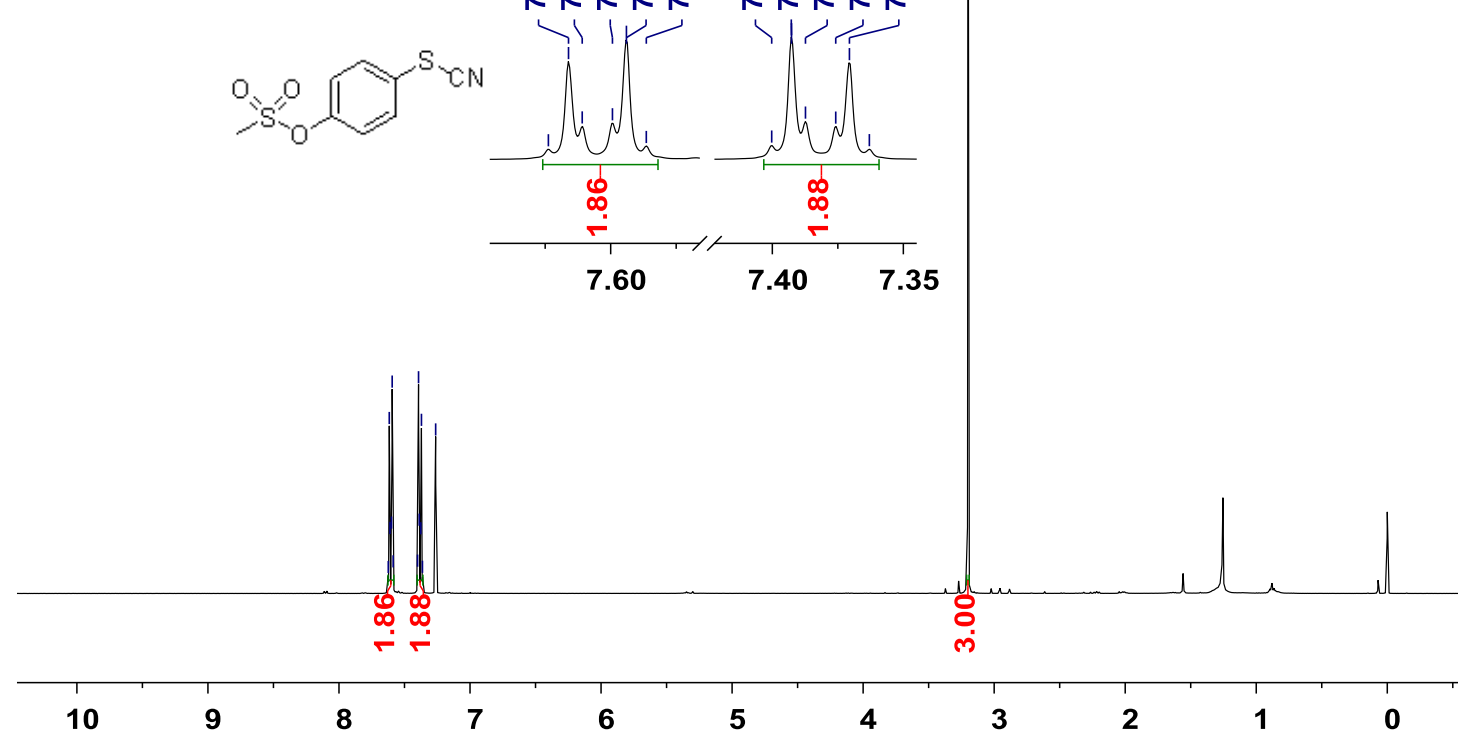

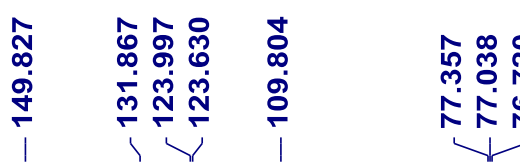

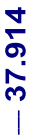
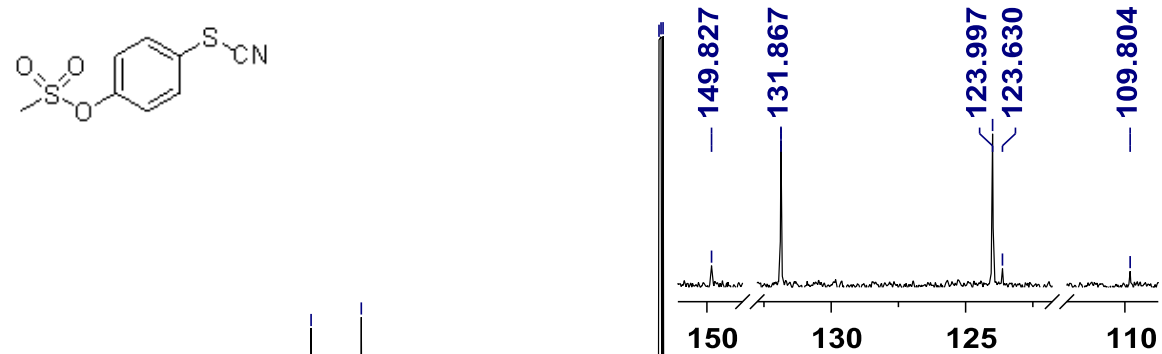

$210200190180170160150140130120110100 \quad 90 \quad 80 \quad 70 \quad 60 \quad 50 \quad 40 \quad 30 \quad 20 \quad 10 \quad 0$ 
HRMS (ESI) Spectrum of 4-thiocyanatophenyl methanesulfonate (2g)

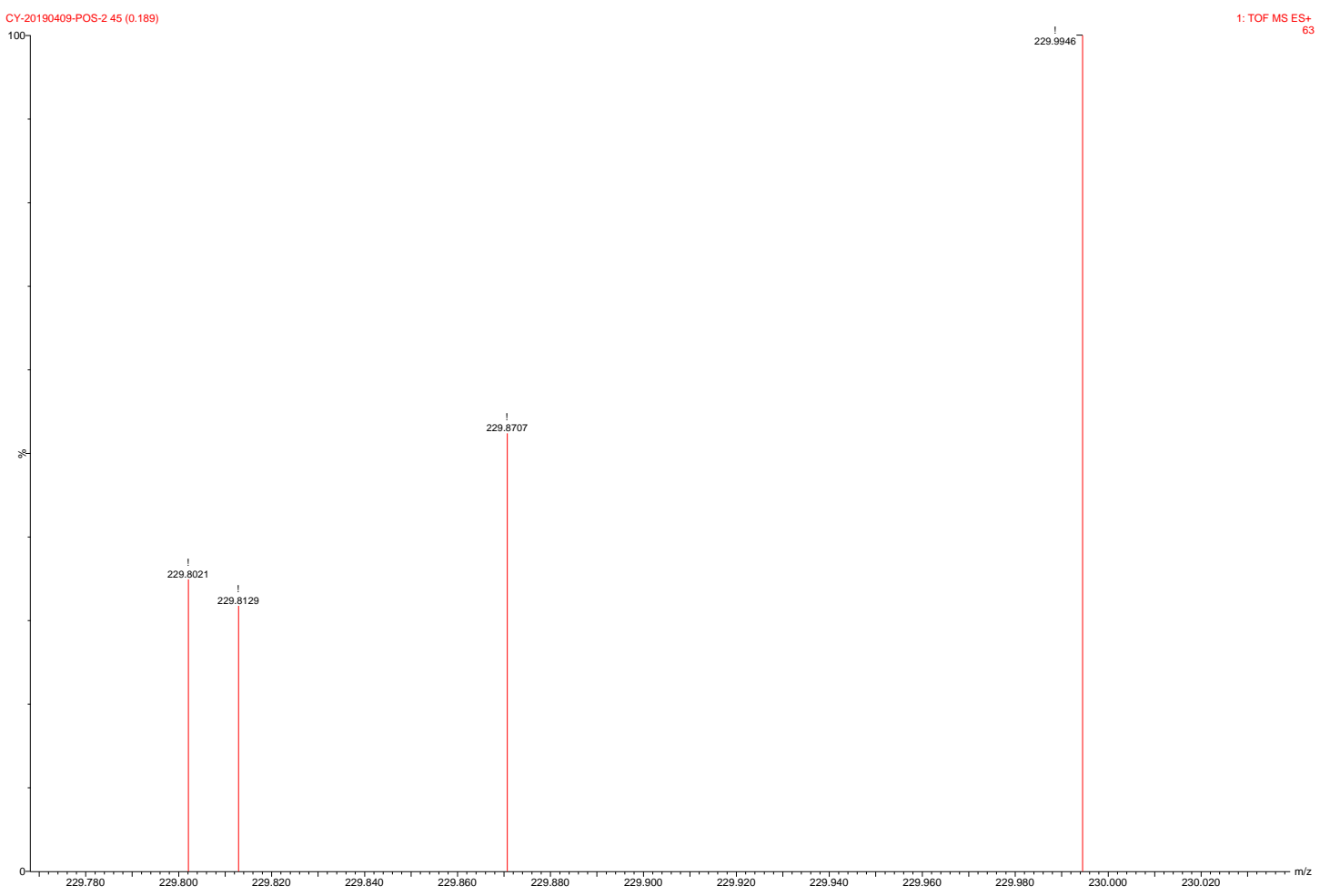


${ }^{1} \mathrm{H}$ and ${ }^{13} \mathrm{C}$ Spectra of 4-thiocyanatophenyl benzoate (2h) in $\mathrm{CDCl}_{3}(400 \mathrm{M})$

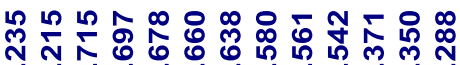

$0^{\infty} N N N N N N N$

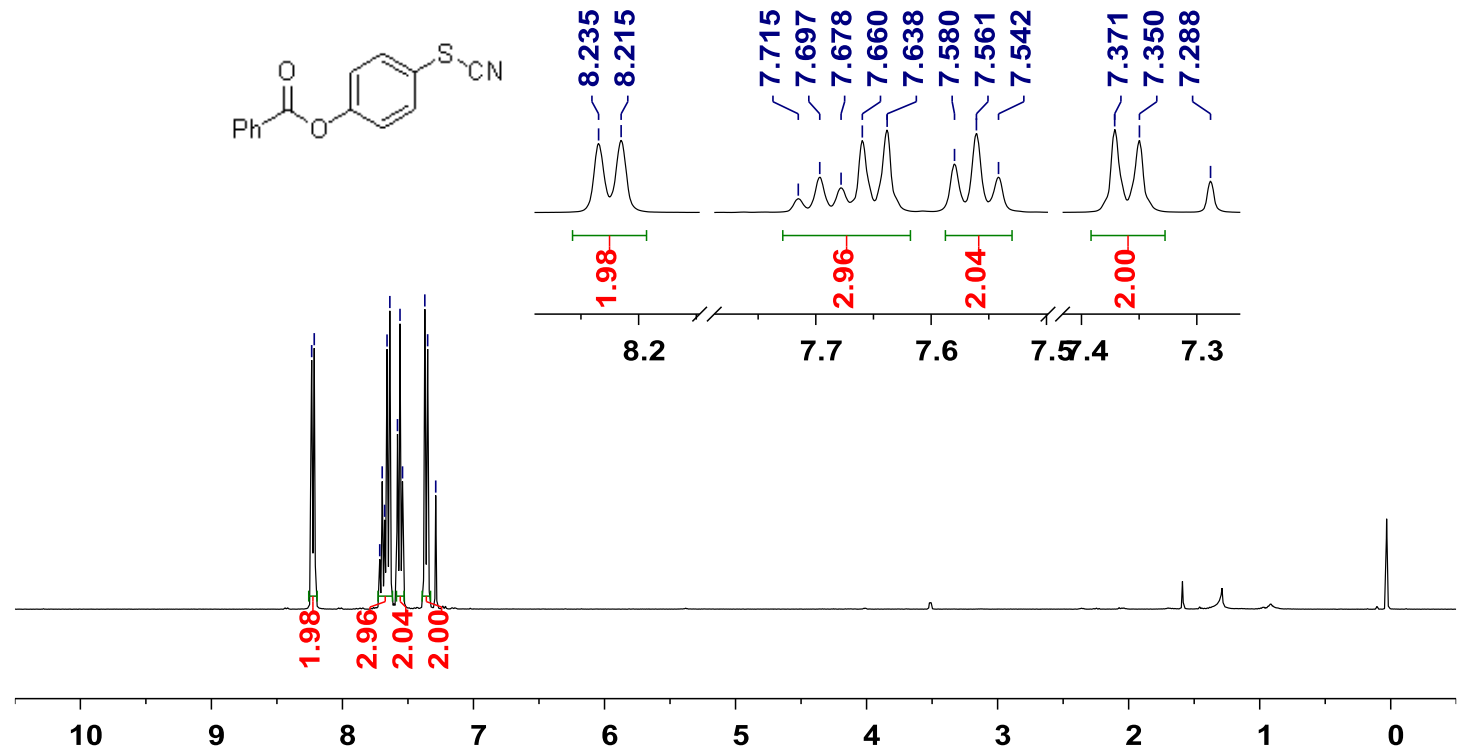

|

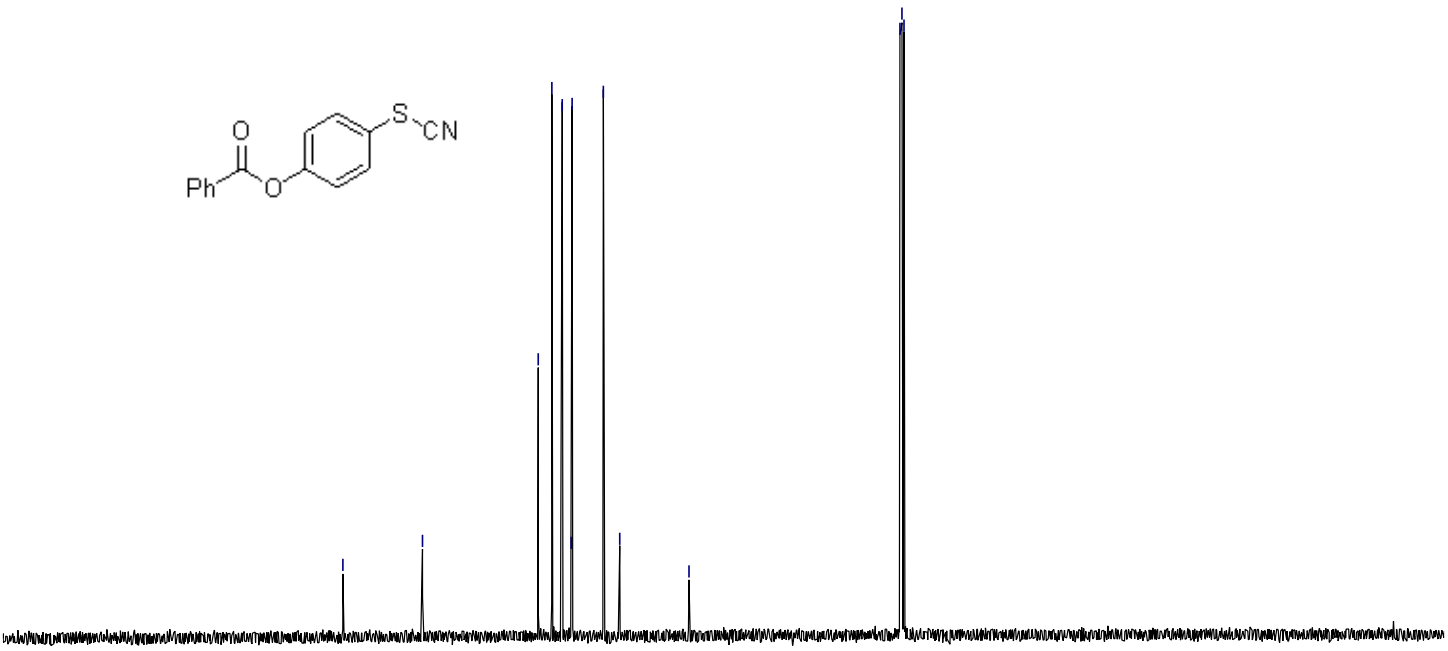

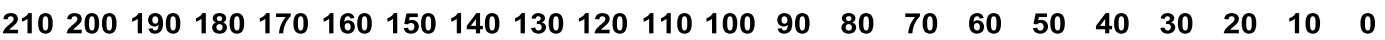


MS (EI) Spectrum of 4-thiocyanatophenyl benzoate (2h)

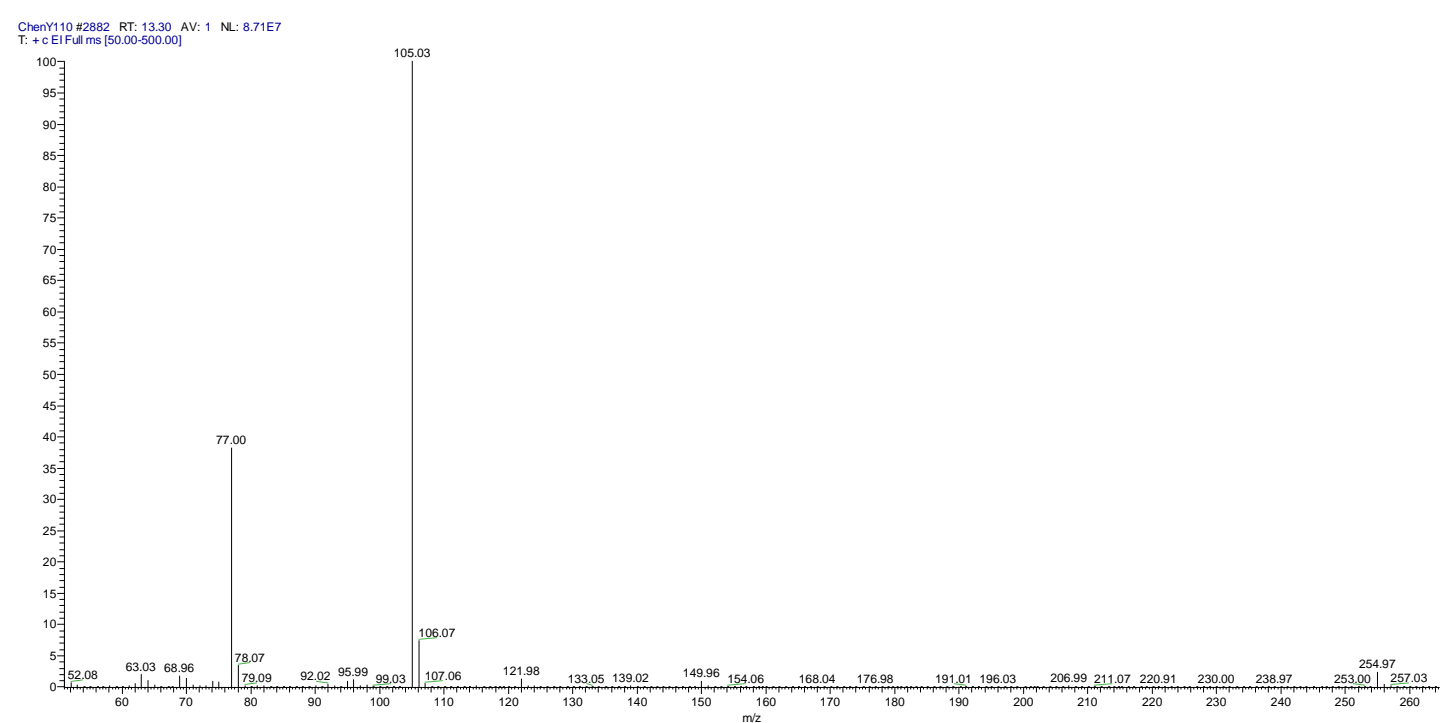


${ }^{1} \mathrm{H}$ and ${ }^{13} \mathrm{C}$ Spectra of 1-nitro-4-(4-thiocyanatophenoxy)benzene (2i) in $\mathrm{CDCl}_{3}(400 \mathrm{M})$

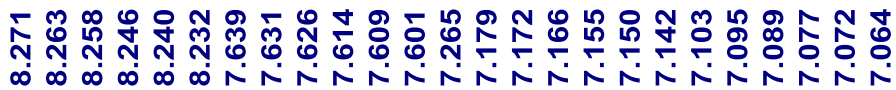
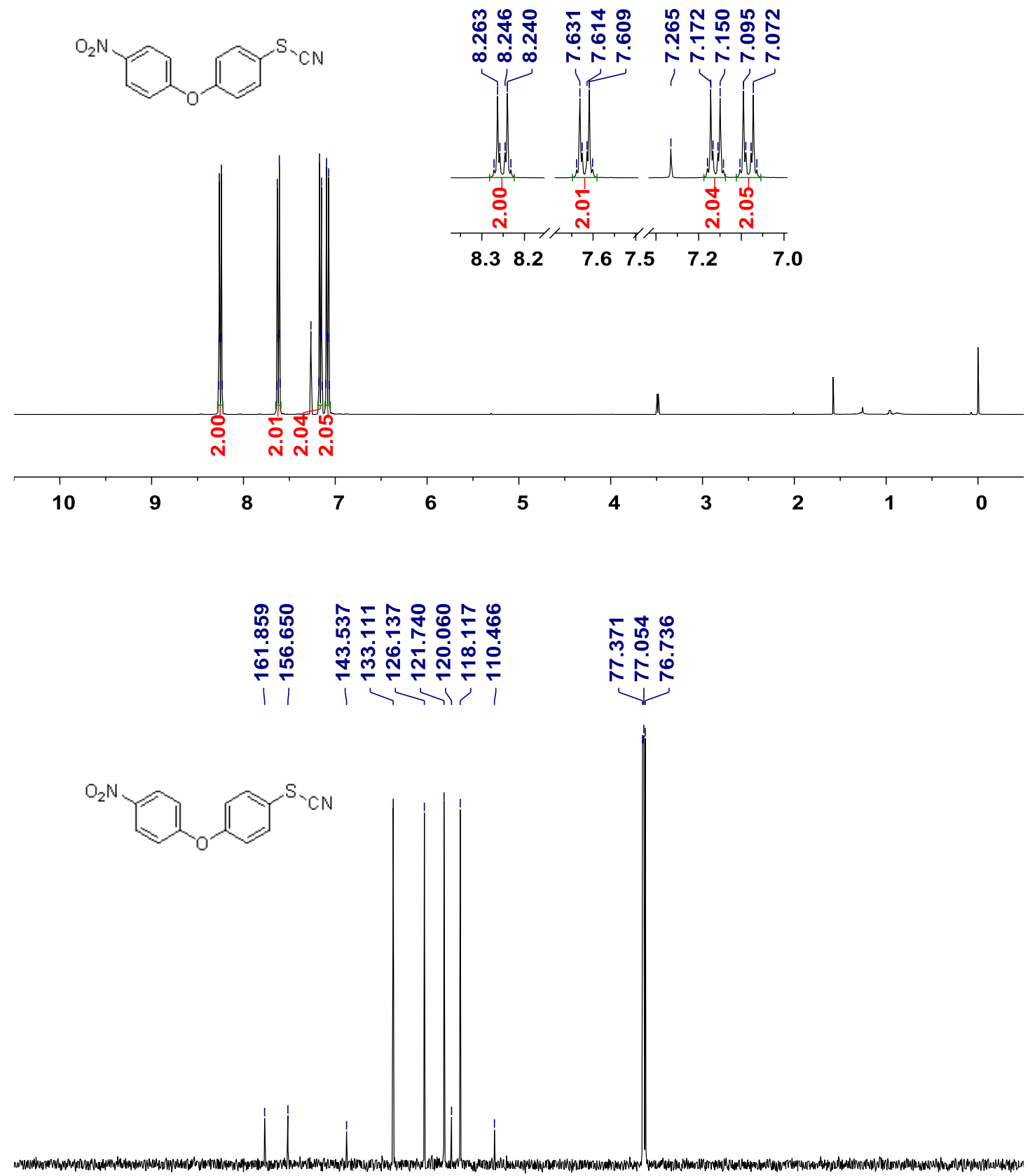

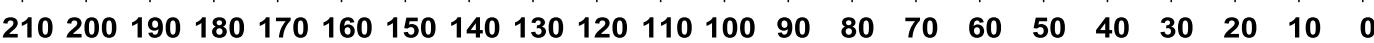


HRMS (ESI) Spectrum of 1-nitro-4-(4-thiocyanatophenoxy)benzene (2i).

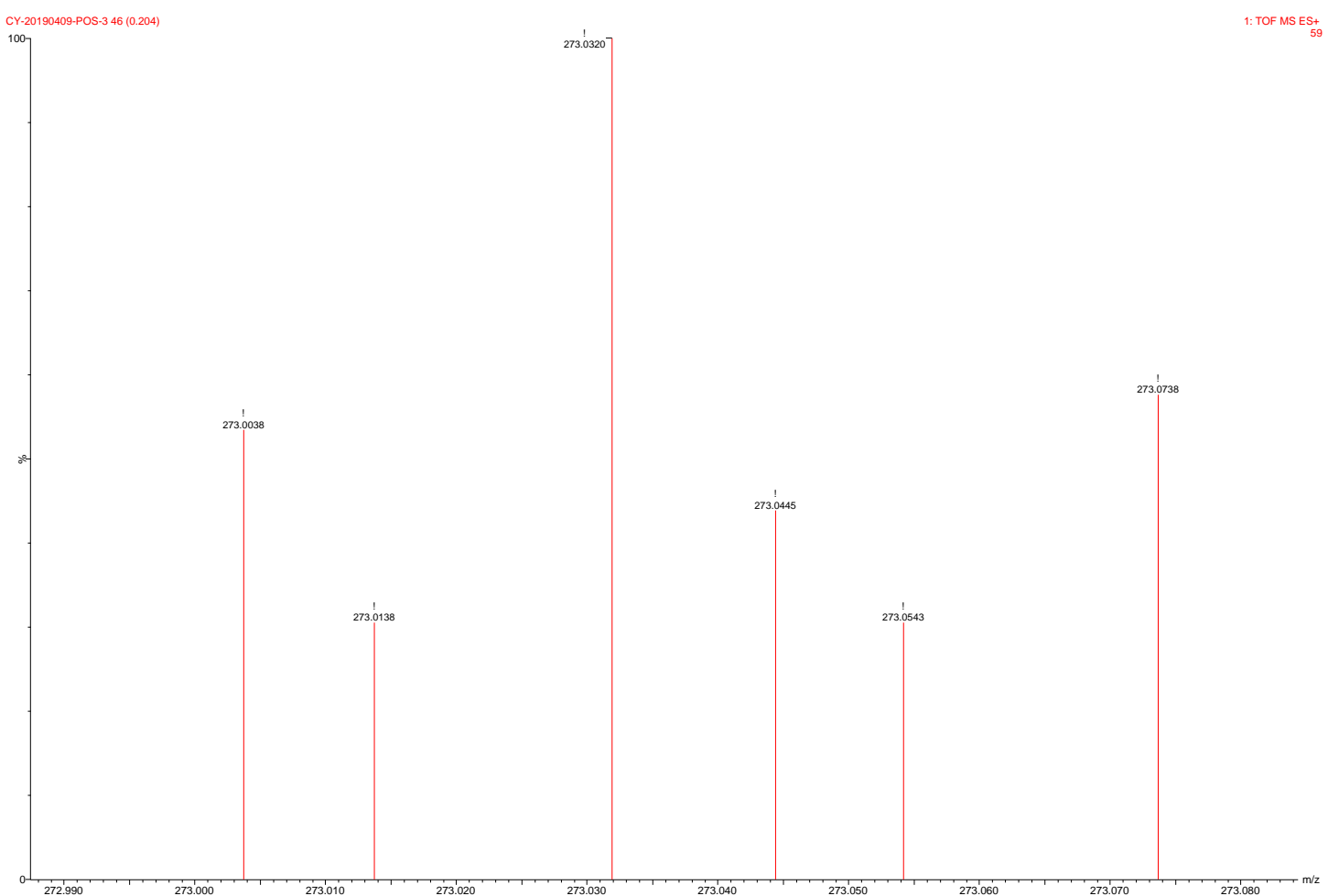


${ }^{1} \mathrm{H}$ and ${ }^{13} \mathrm{C}$ Spectra of 1-methyl-4-thiocyanatobenzene (2j) in $\mathrm{CDCl}_{3}(400 \mathrm{M})$
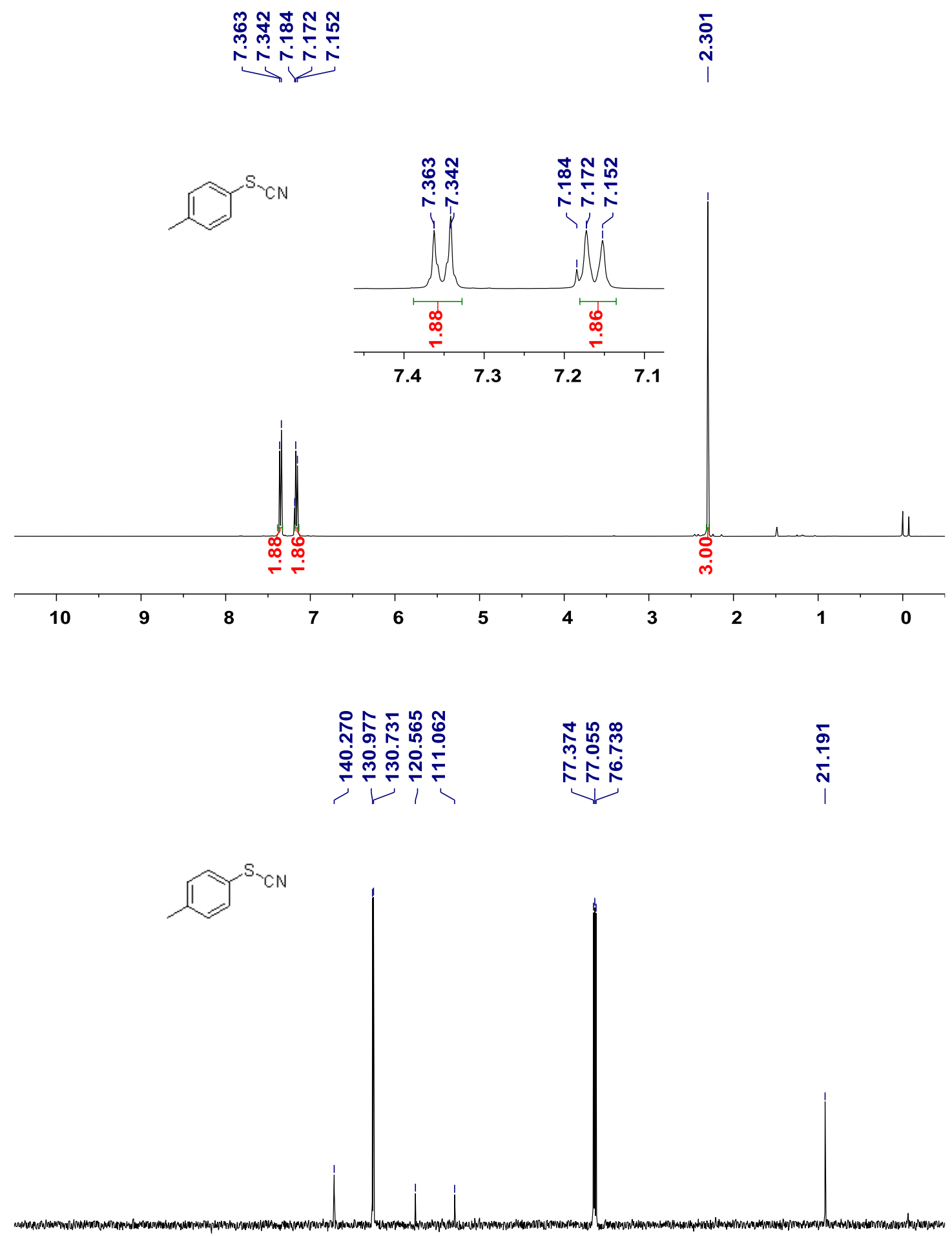

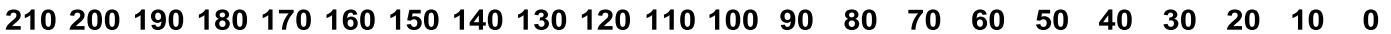


MS (EI) Spectrum of 1-methyl-4-thiocyanatobenzene (2j)

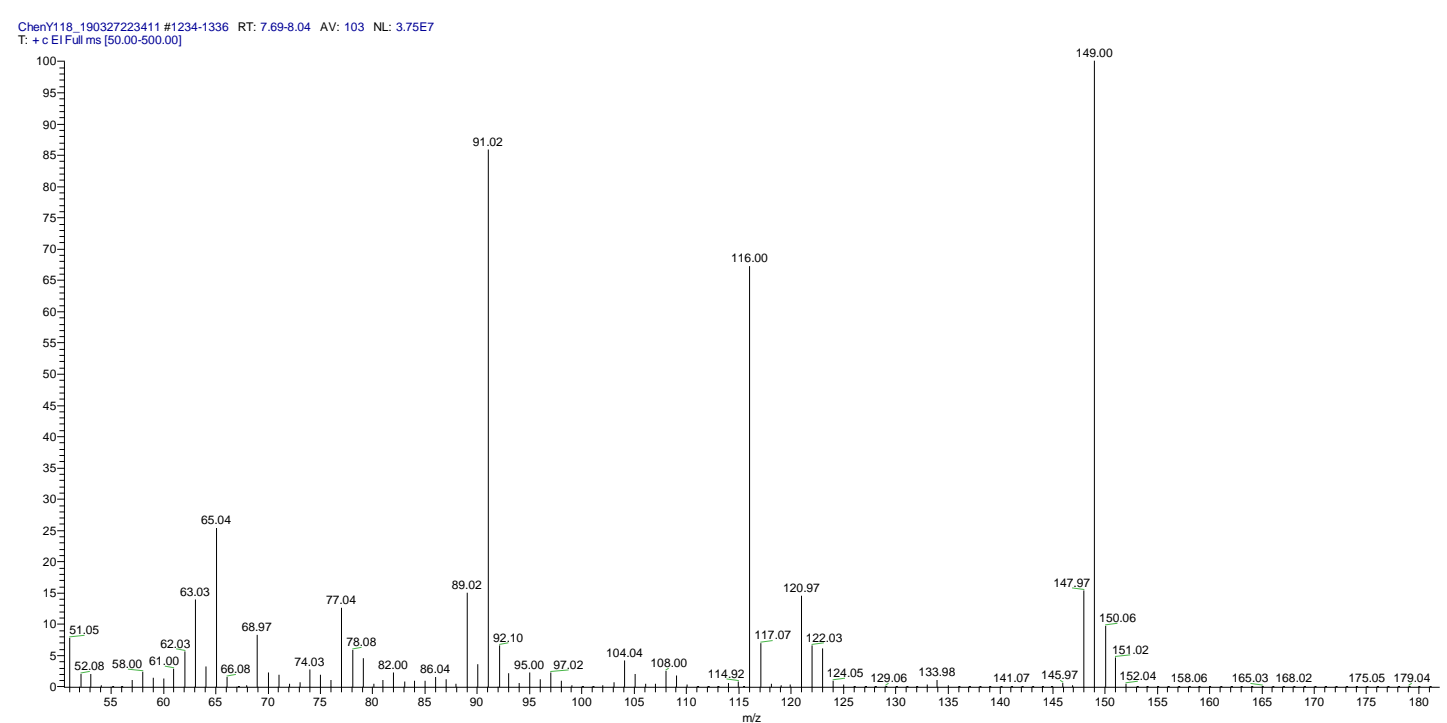


${ }^{1} \mathrm{H}$ and ${ }^{13} \mathrm{C}$ Spectra of 1-methyl-2-thiocyanatobenzene (2k) in $\mathrm{CDCl}_{3}(400 \mathrm{M})$

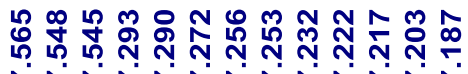

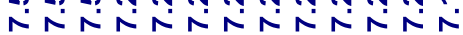

$\longrightarrow$
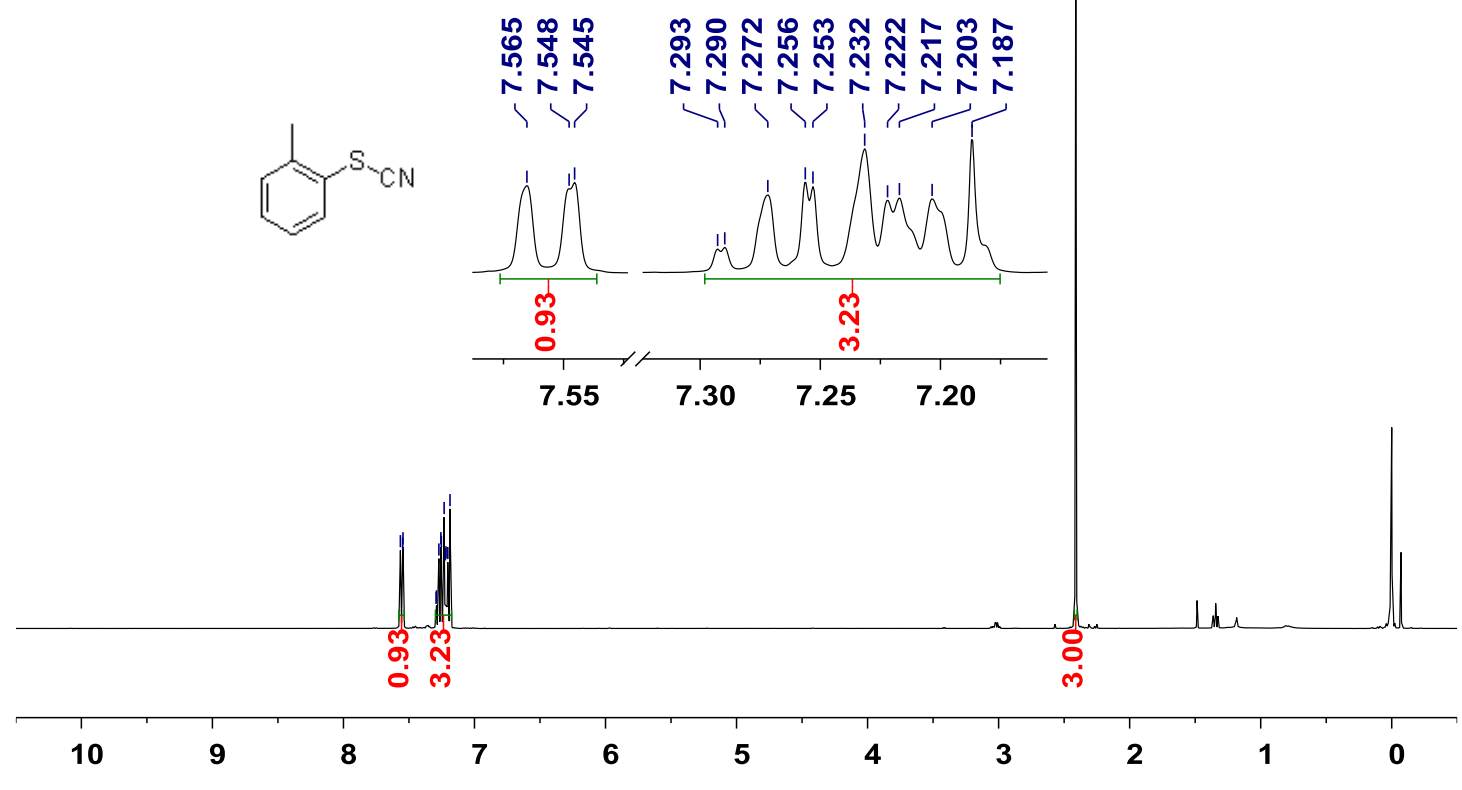

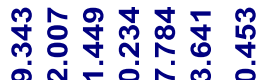

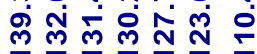

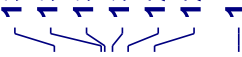

ผู

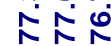

$\bar{N}$
ป̀ं
।

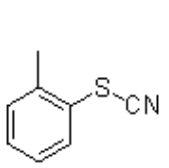

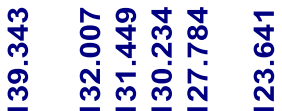

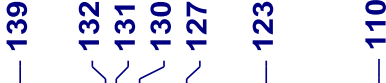
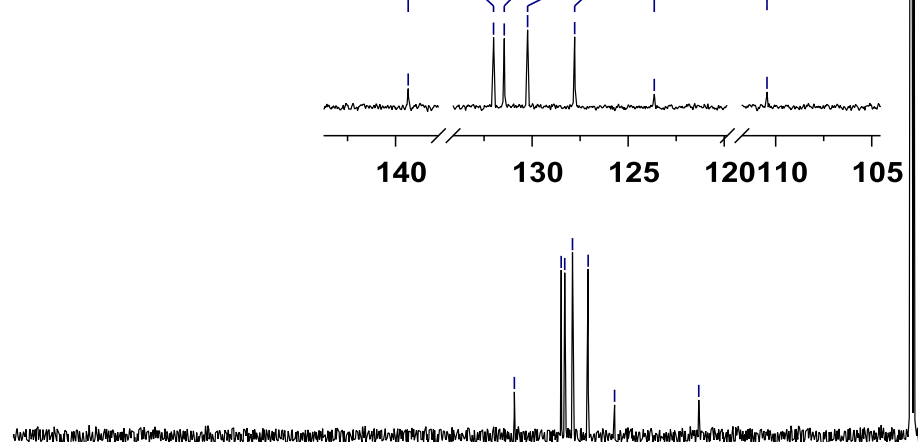

$\frac{\pi}{i}$

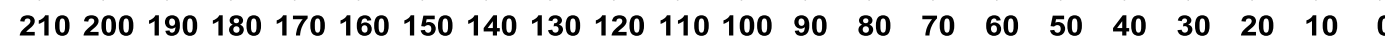


MS (EI) Spectrum of 1-methyl-2-thiocyanatobenzene (2k).

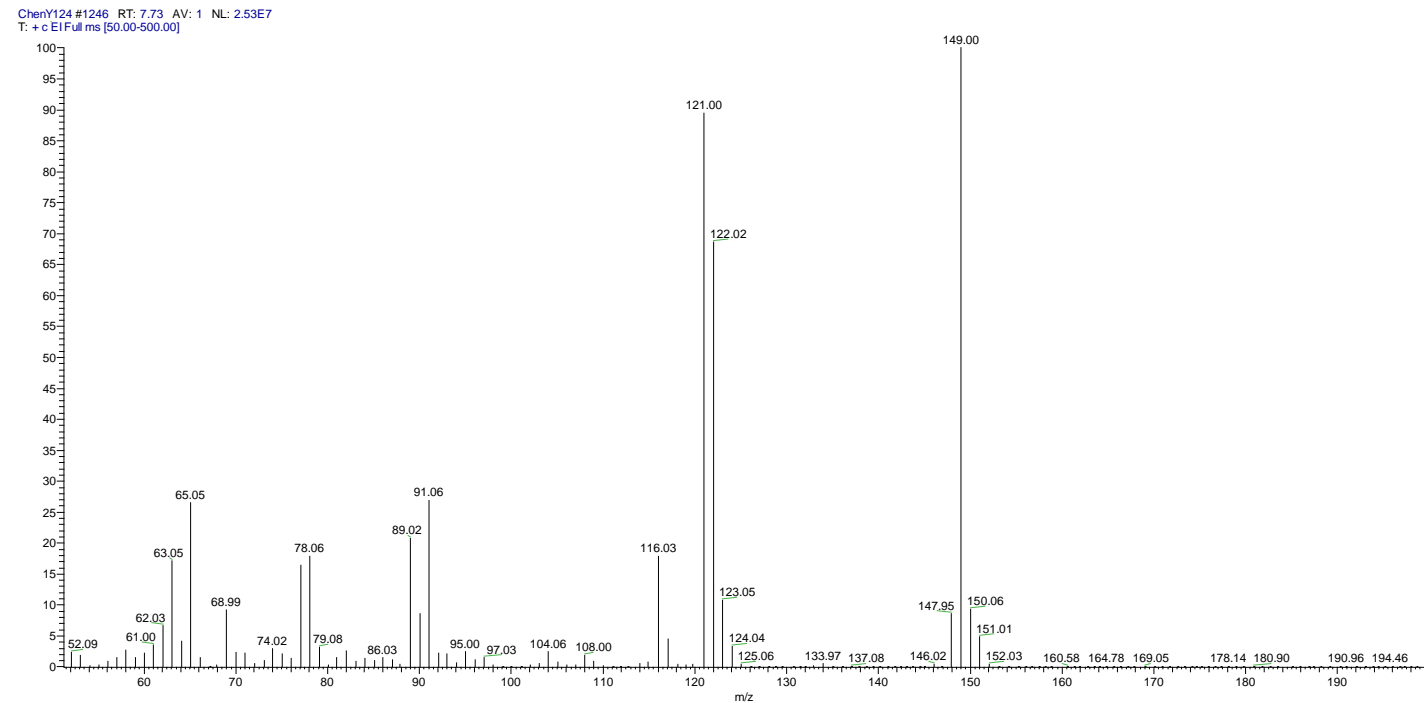


${ }^{1} \mathrm{H}$ and ${ }^{13} \mathrm{C}$ Spectra of 1-(tert-butyl)-4-thiocyanatobenzene (2I) in $\mathrm{CDCl}_{3}(400 \mathrm{M})$
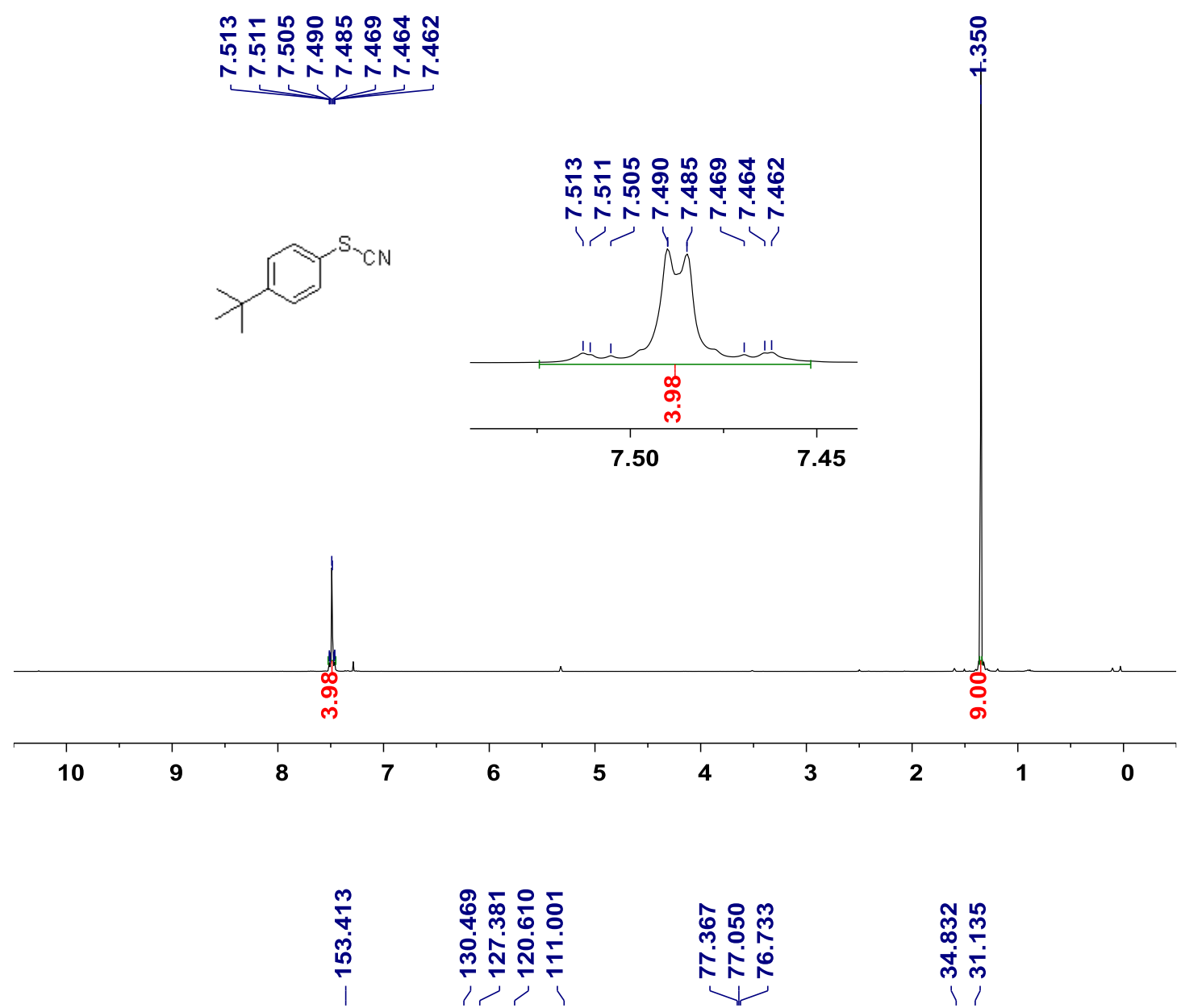

항융

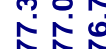

స్ల్

में

I 1
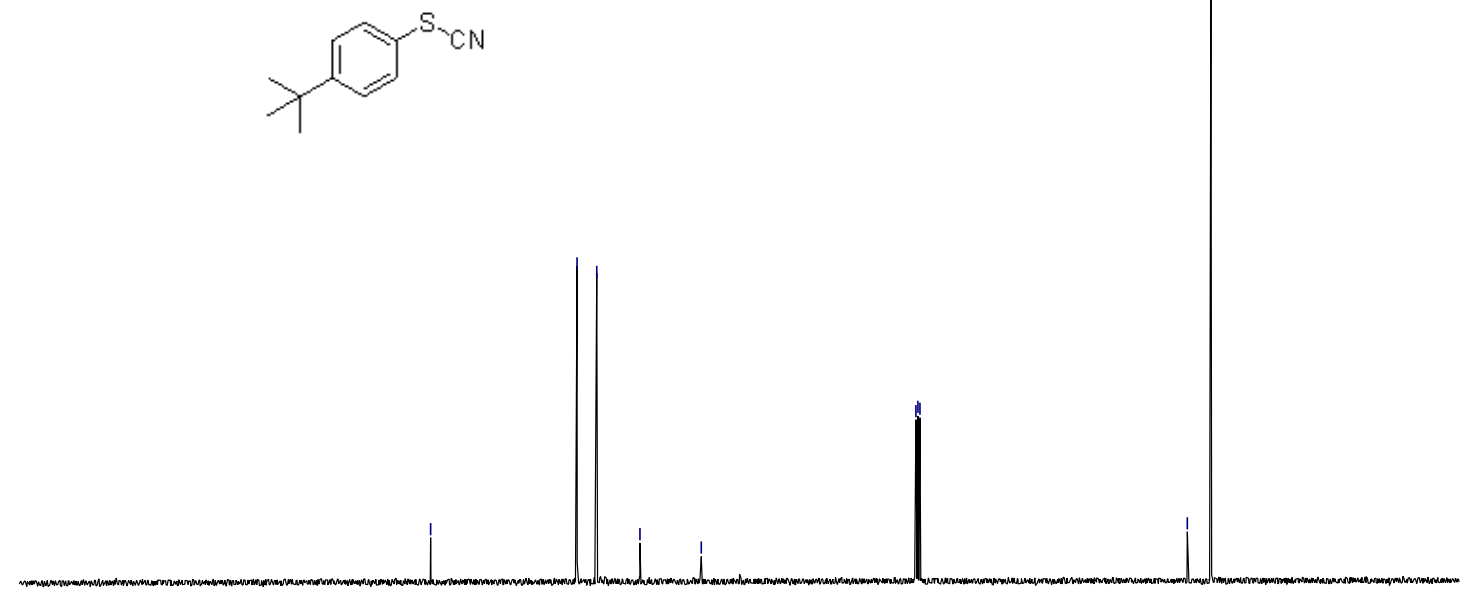

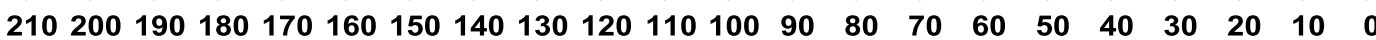


MS (EI) Spectrum of 1-(tert-butyl)-4-thiocyanatobenzene (2I)

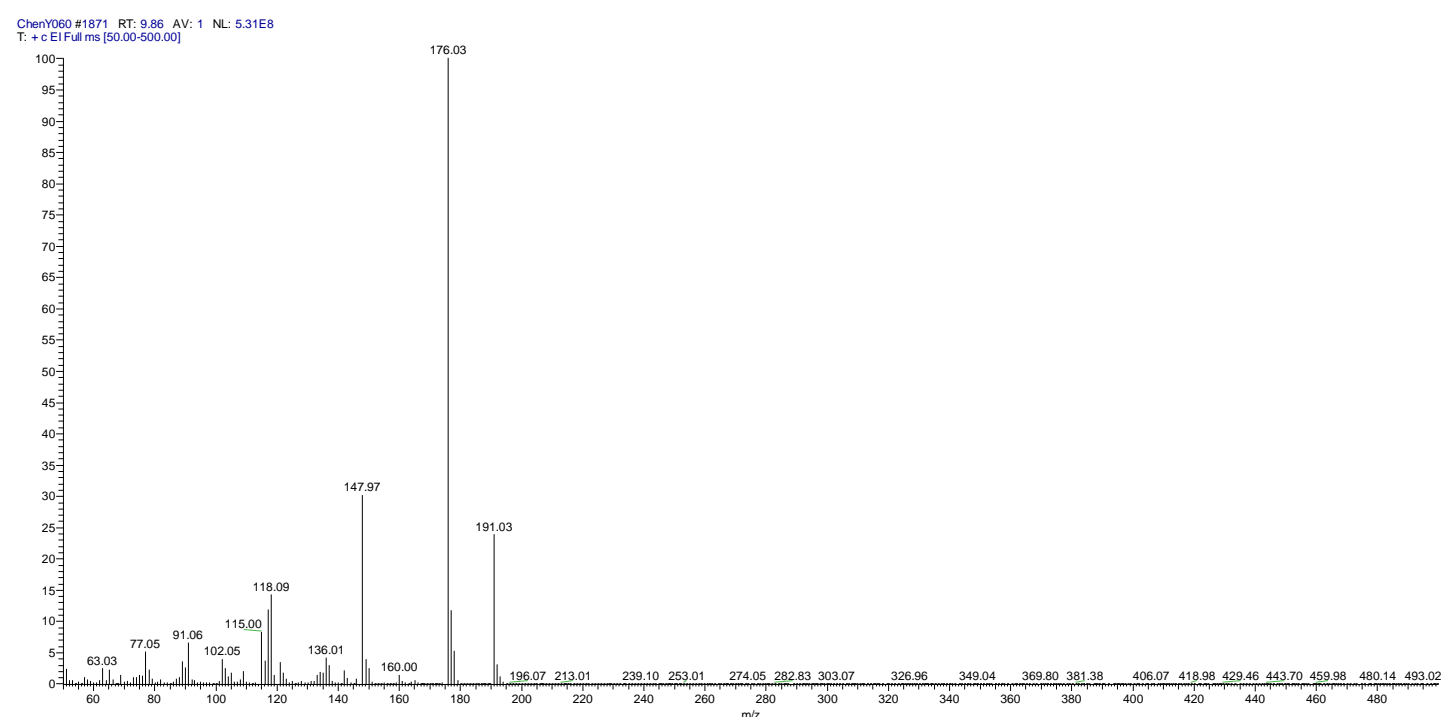


${ }^{1} \mathrm{H}$ and ${ }^{13} \mathrm{C}$ Spectra of 1-fluoro-4-thiocyanatobenzene $(2 \mathrm{~m})$ in $\mathrm{CDCl}_{3}(400 \mathrm{M})$

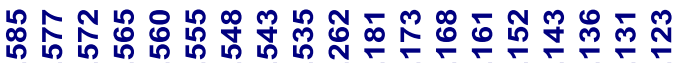

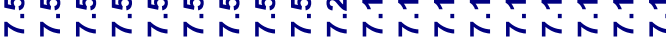
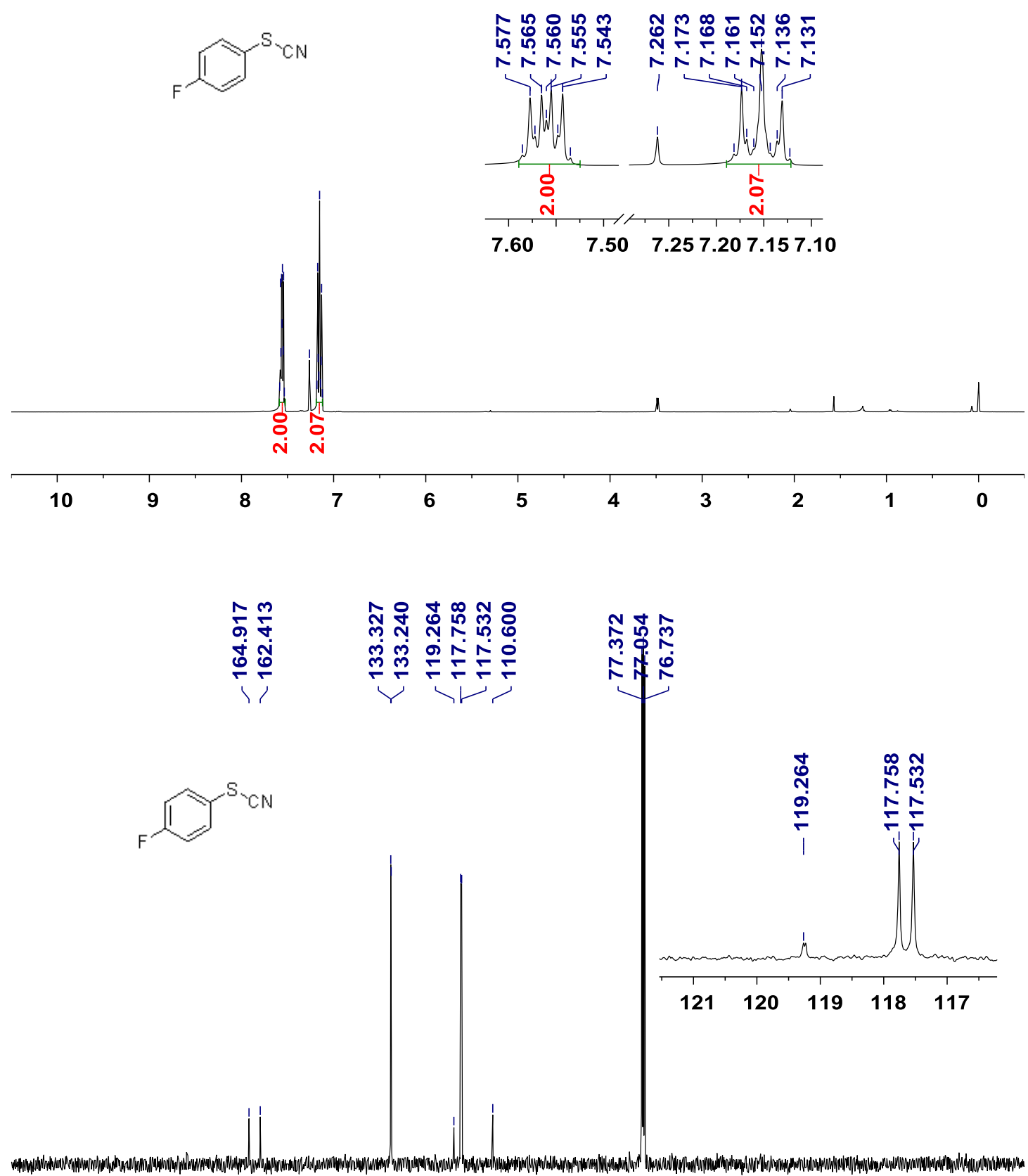

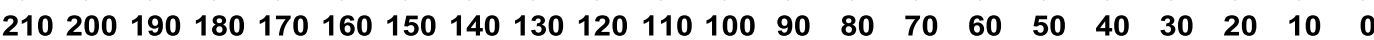


MS (EI) Spectrum of 1-fluoro-4-thiocyanatobenzene (2m).

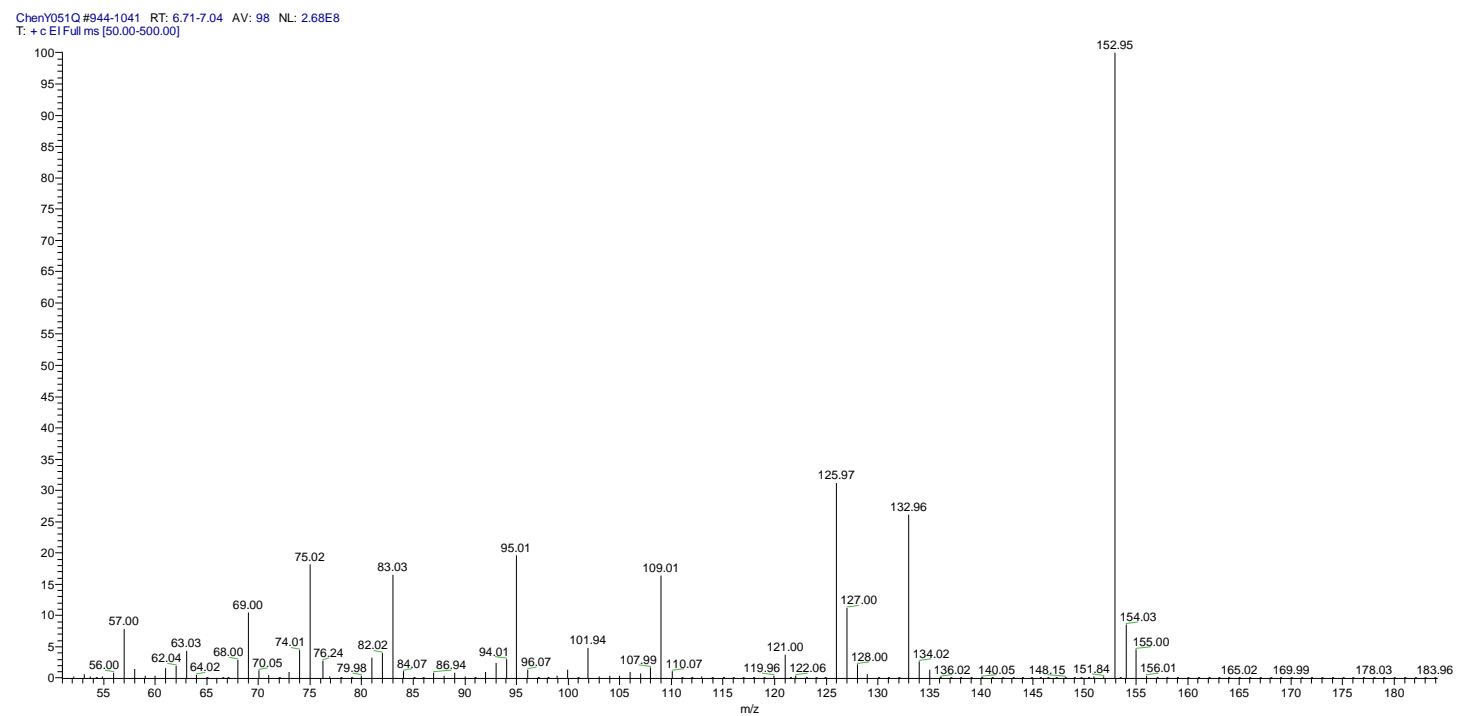


${ }^{1} \mathrm{H}$ and ${ }^{13} \mathrm{C}$ Spectra of 1-chloro-4-thiocyanatobenzene (2n) in $\mathrm{CDCl}_{3}(400 \mathrm{M})$
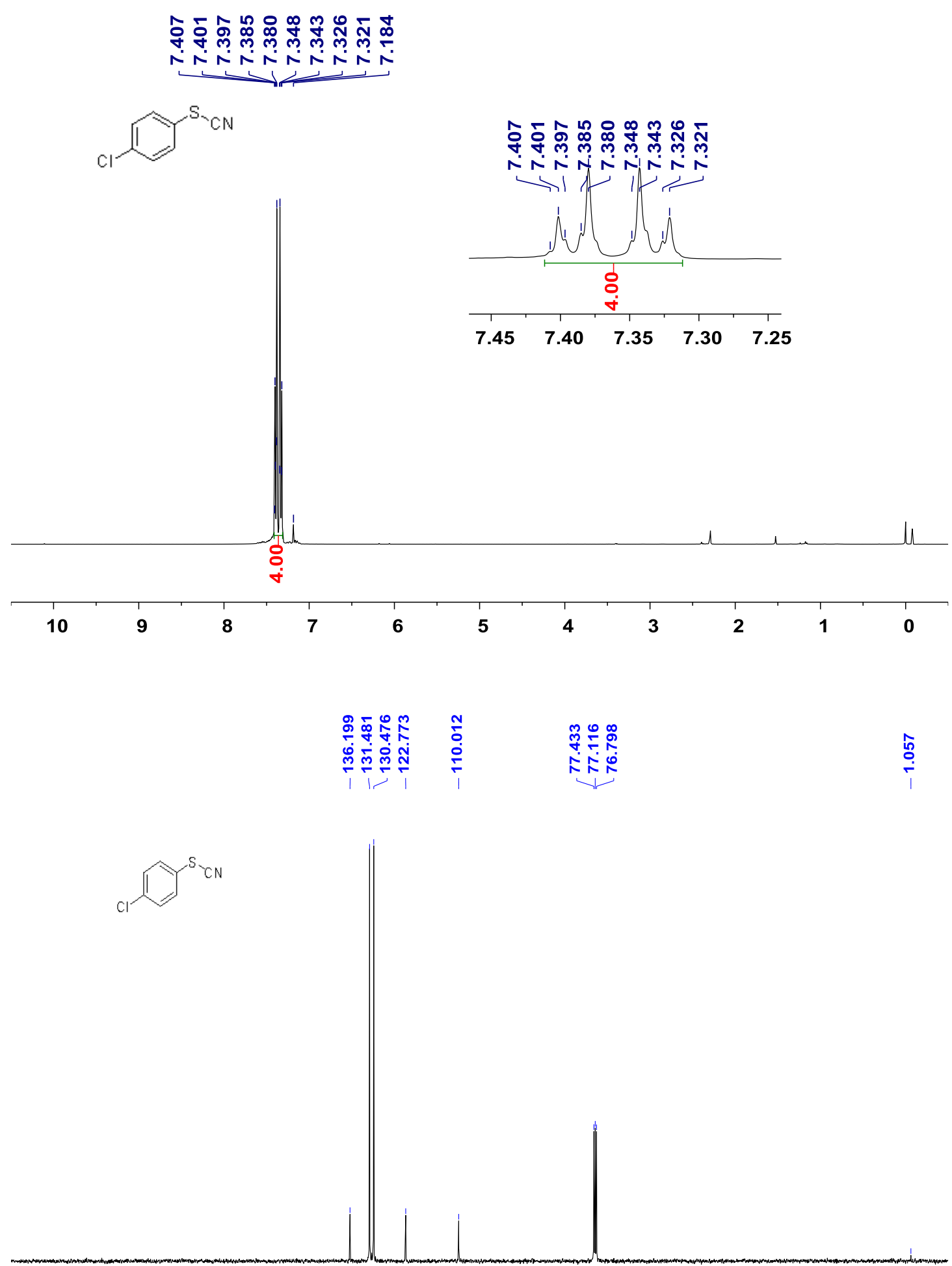

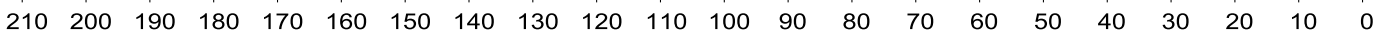


MS (EI) Spectrum of 1-chloro-4-thiocyanatobenzene (2n)

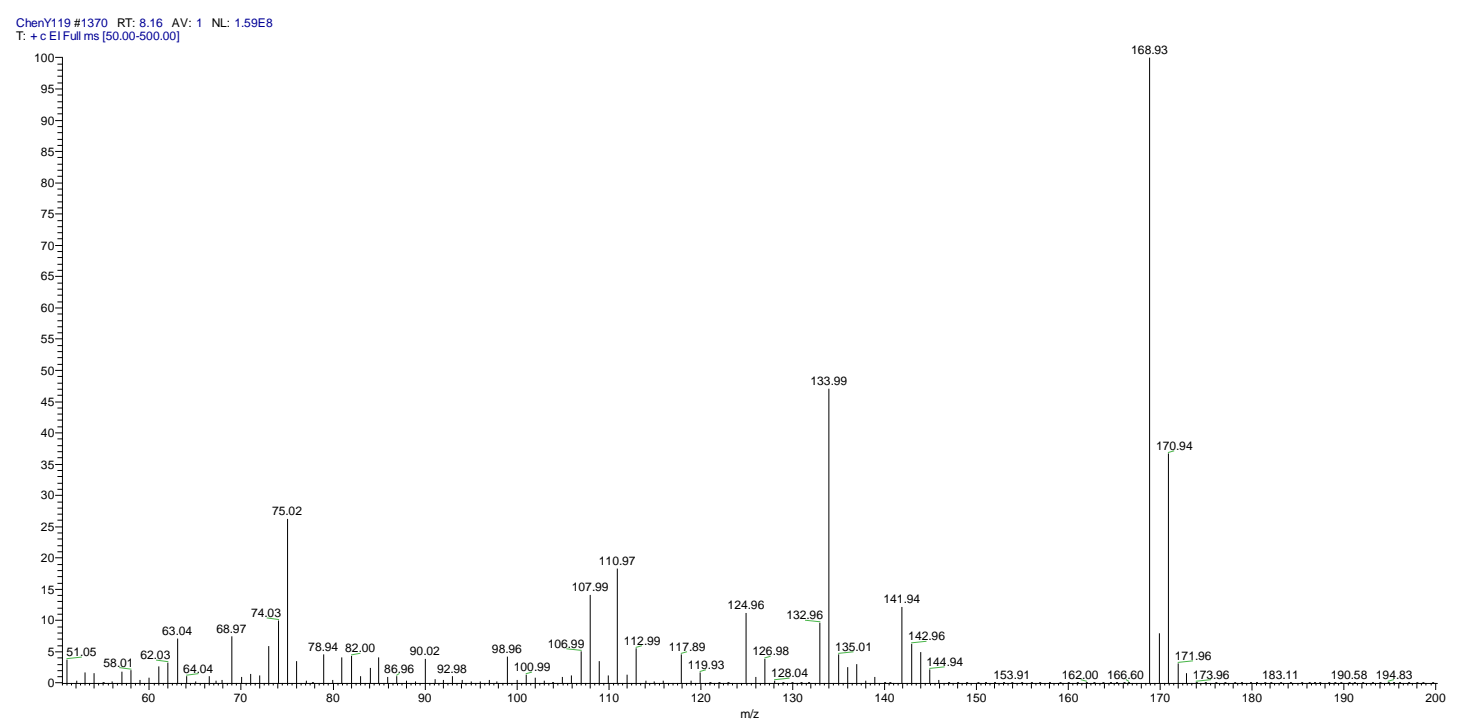


${ }^{1} \mathrm{H}$ and ${ }^{13} \mathrm{C}$ Spectra of 1-bromo-4-thiocyanatobenzene (2o) in $\mathrm{CDCl}_{3}(400 \mathrm{M})$

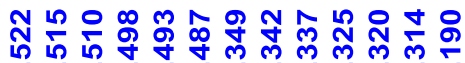

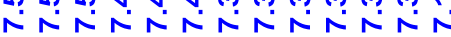
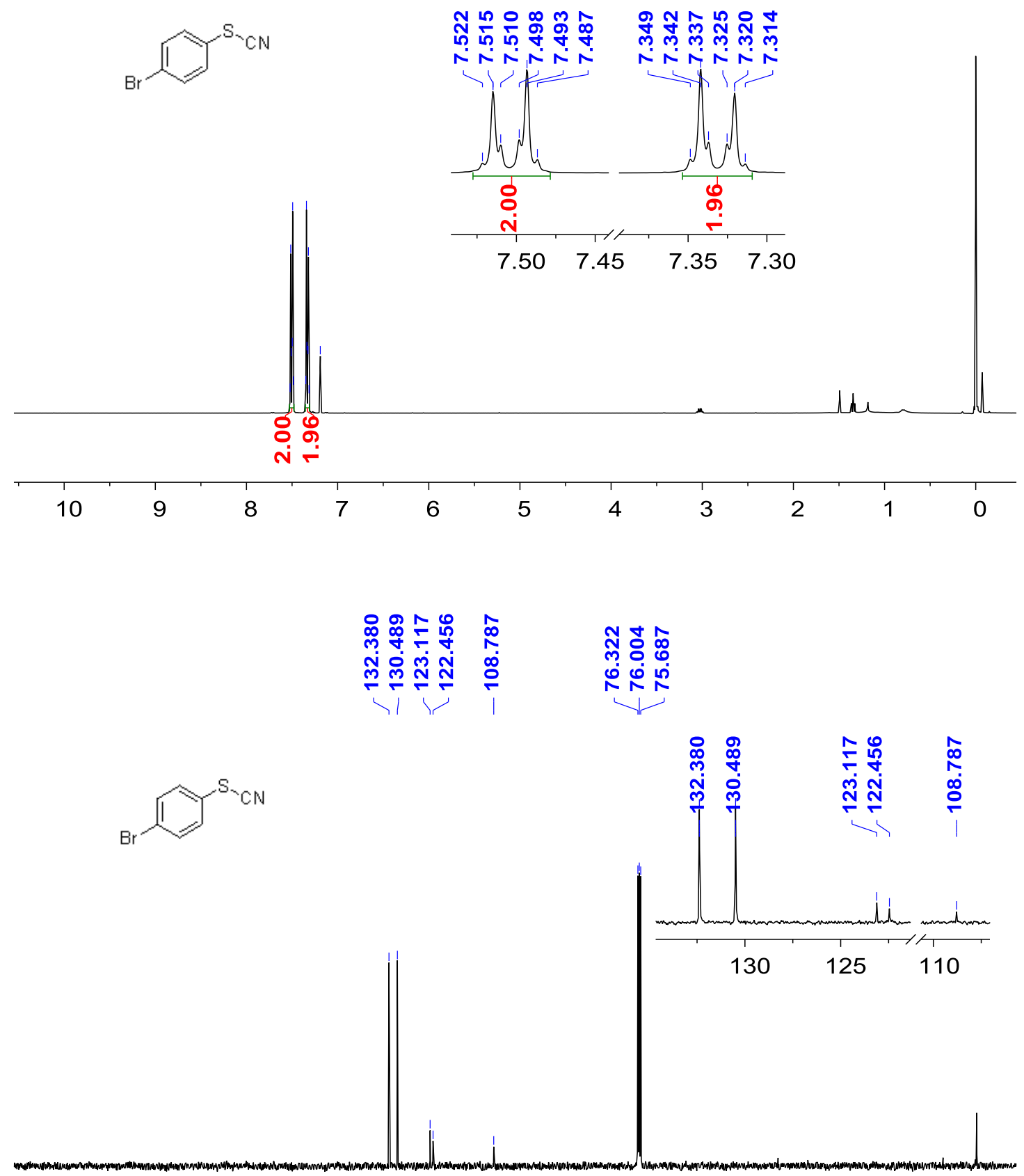

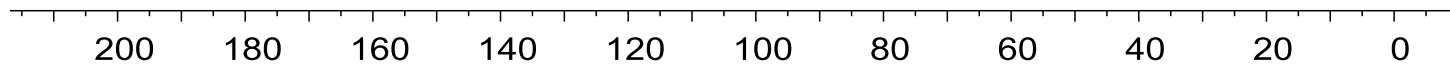


MS (EI) Spectrum of 1-bromo-4-thiocyanatobenzene (20)

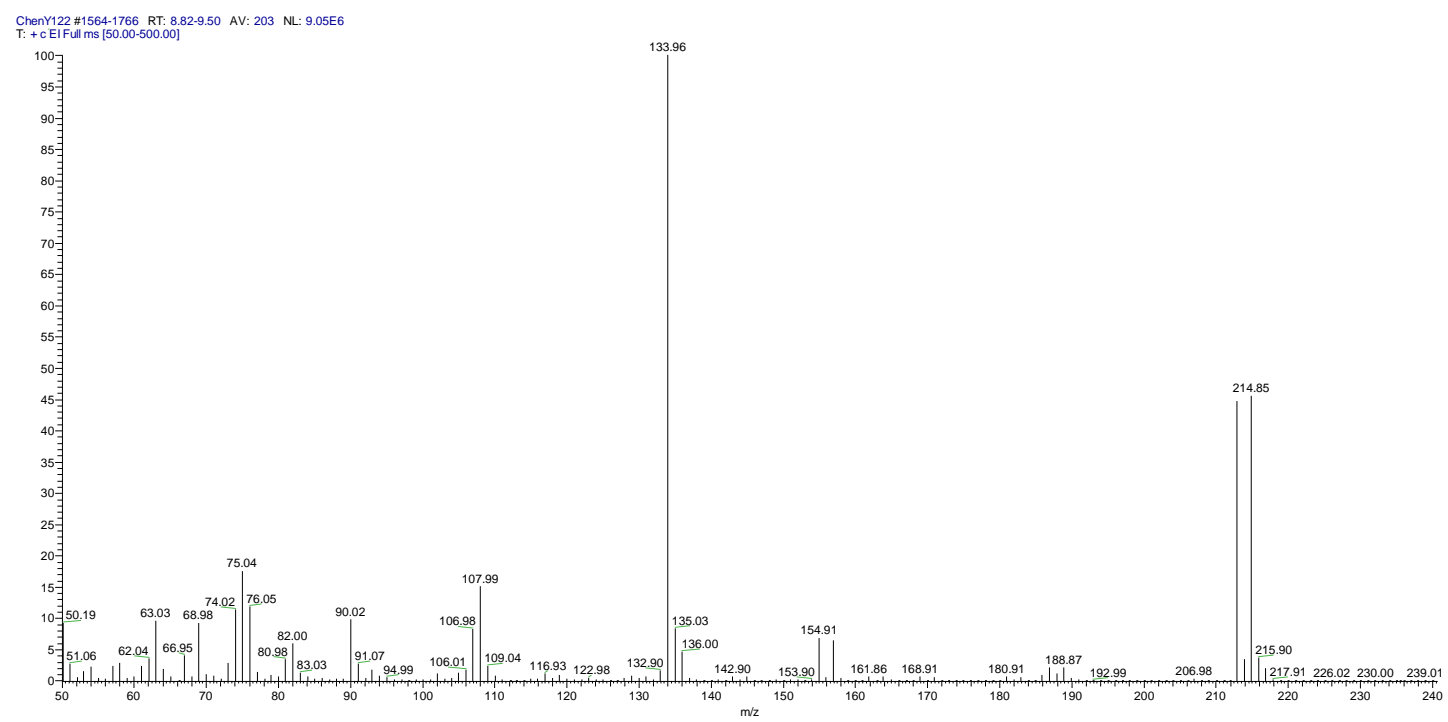


${ }^{1} \mathrm{H}$ and ${ }^{13} \mathrm{C}$ Spectra of methyl 4-thiocyanatobenzoate (2p) in $\mathrm{CDCl}_{3}(400 \mathrm{M})$

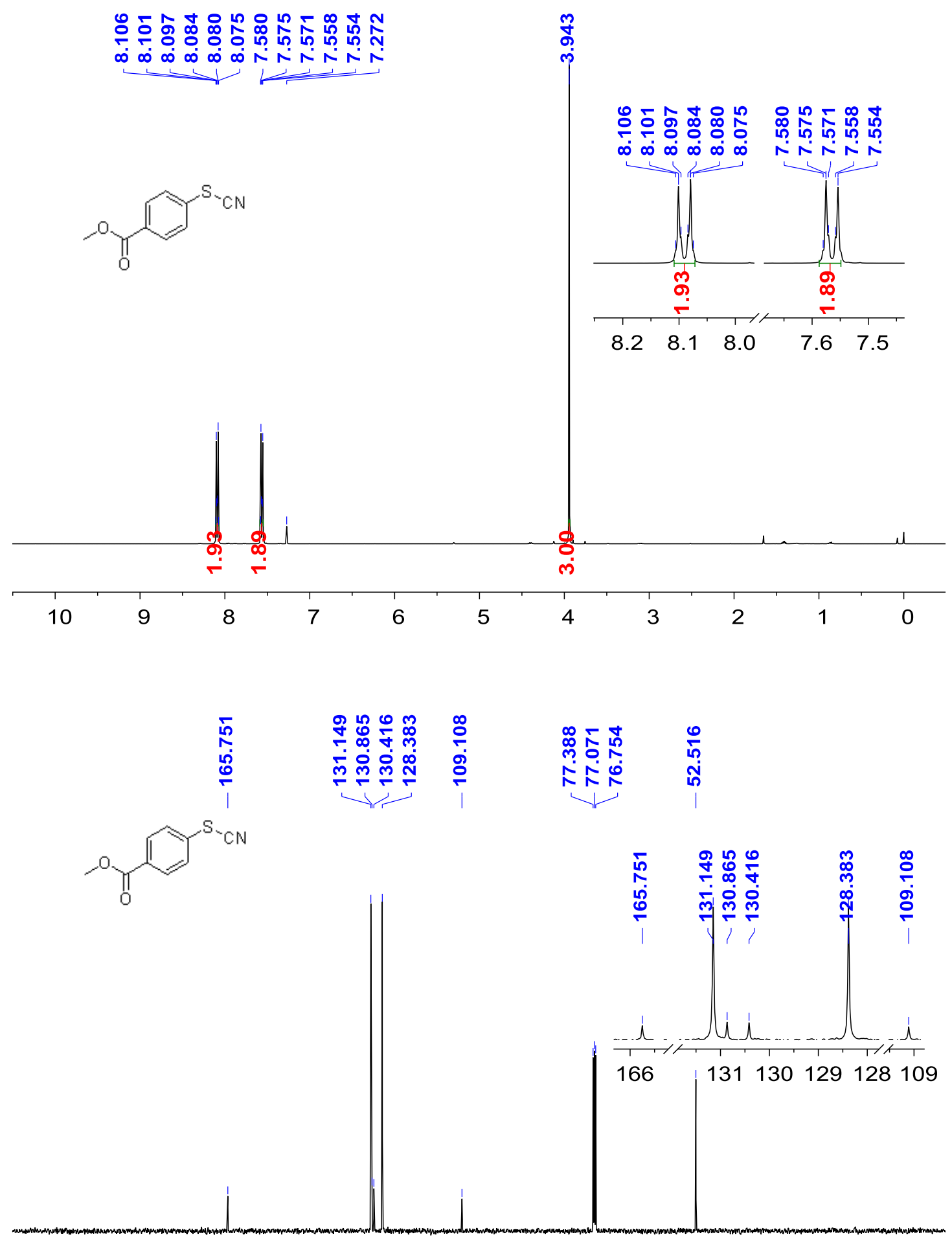

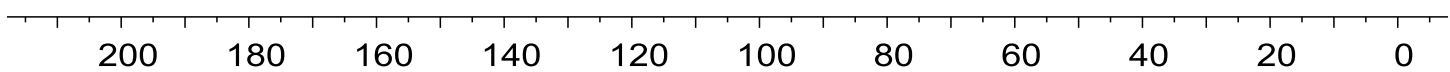


MS (EI) Spectrum of methyl 4-thiocyanatobenzoate (2p)

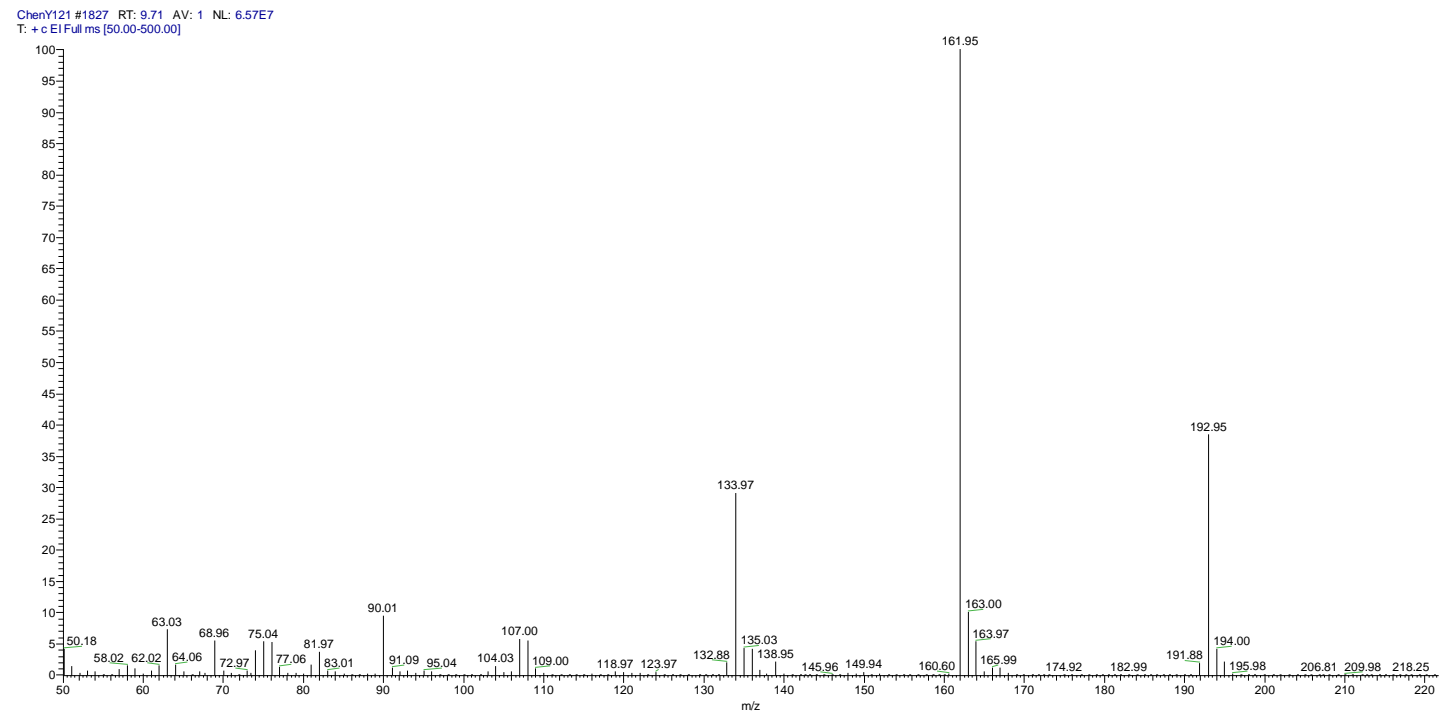


${ }^{1} \mathrm{H}$ and ${ }^{13} \mathrm{C}$ Spectra of 4-thiocyanatobenzaldehyde (2q) in $\mathrm{CDCl}_{3}(400 \mathrm{M})$
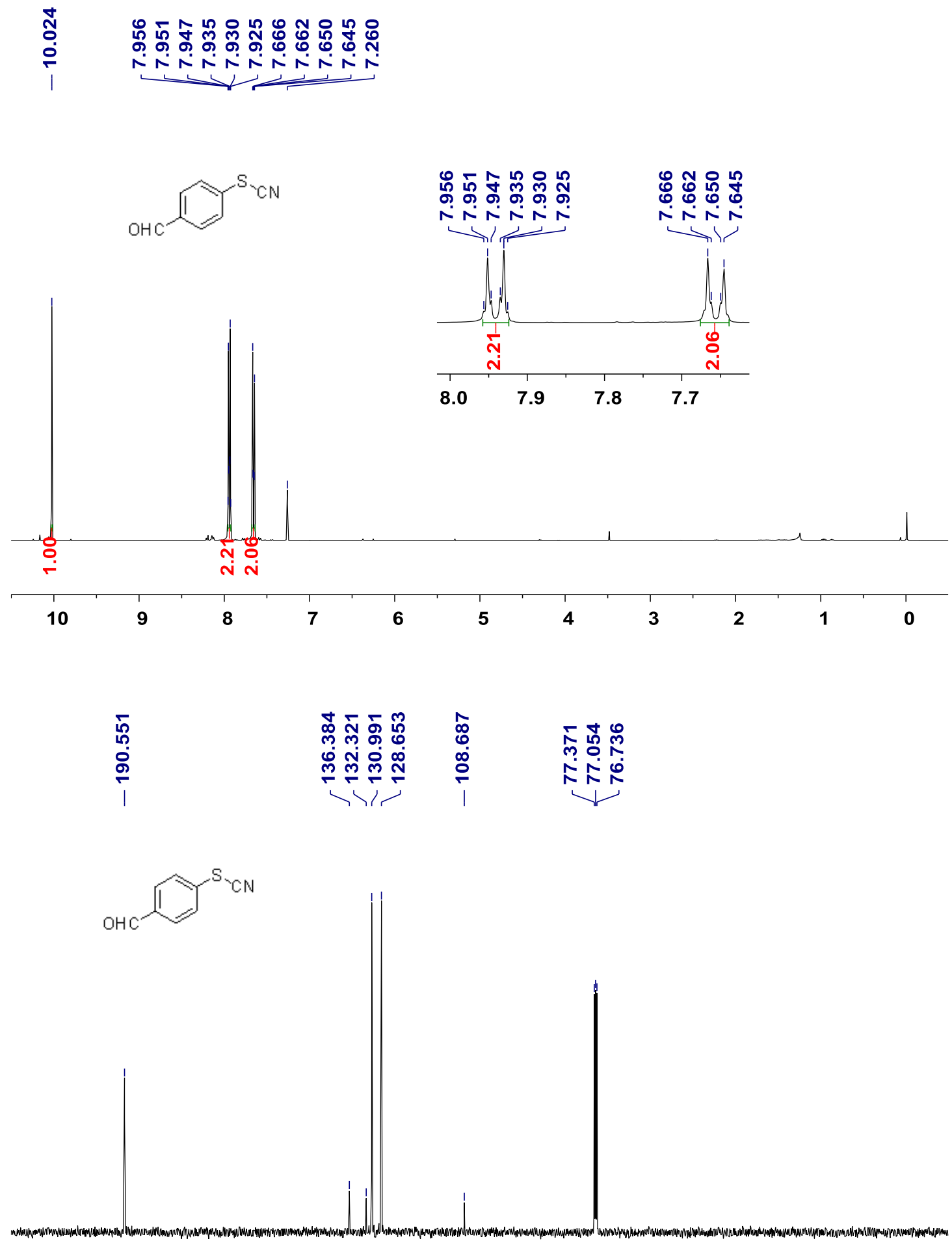

$210200190180170160150140130120110100 \quad 90 \quad 80 \quad 70 \quad 60 \quad 50 \quad 40 \quad 30 \quad 20 \quad 10 \quad 0$ 
MS (EI) Spectrum of 4-thiocyanatobenzaldehyde (2q)

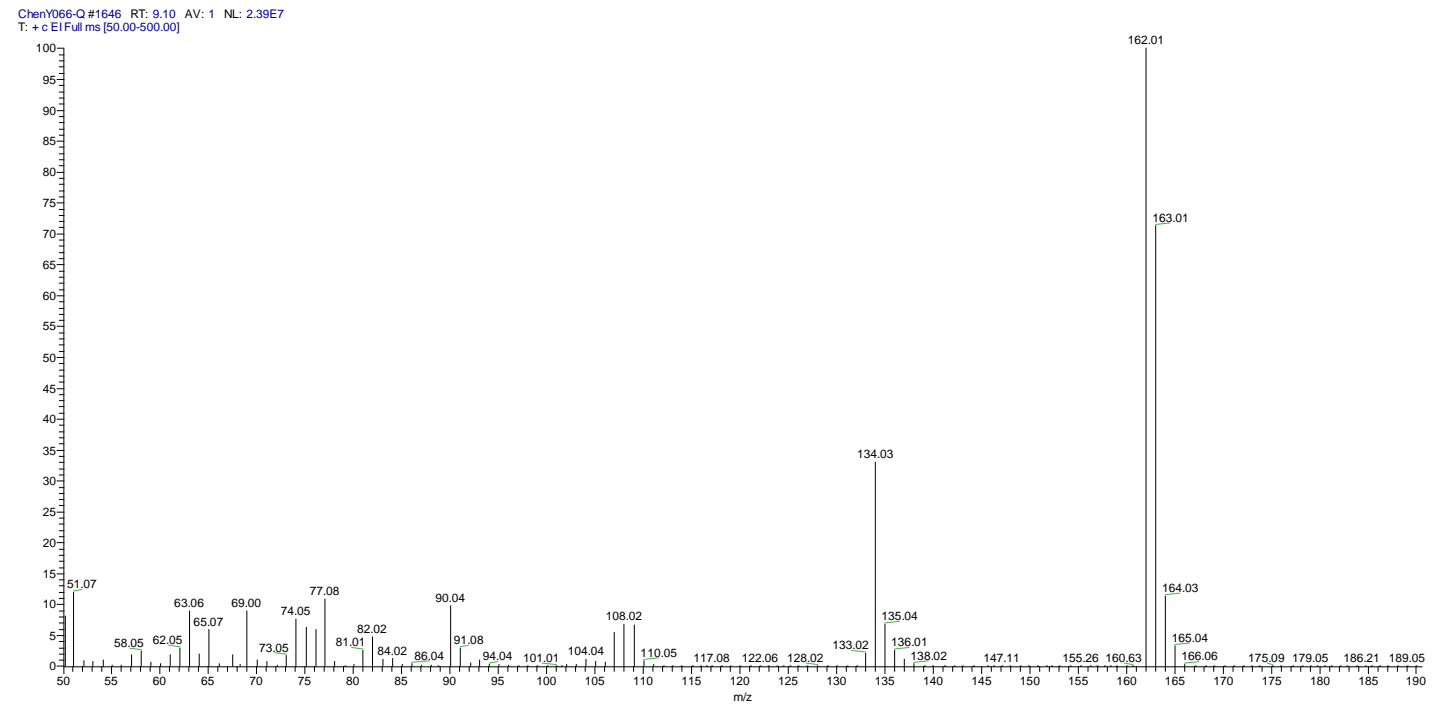


${ }^{1} \mathrm{H}$ and ${ }^{13} \mathrm{C}$ Spectra of 1-nitro-4-thiocyanatobenzene $(2 \mathrm{r})$ in $\mathrm{CDCl}_{3}(400 \mathrm{M})$

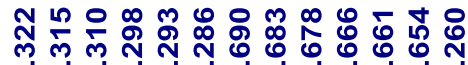

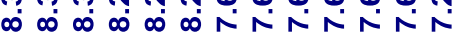

$\mathrm{O}_{2}^{\mathrm{S}} \mathrm{CN}$

సูল

$\infty \infty \infty \infty \infty \infty+N \hat{N} \infty$
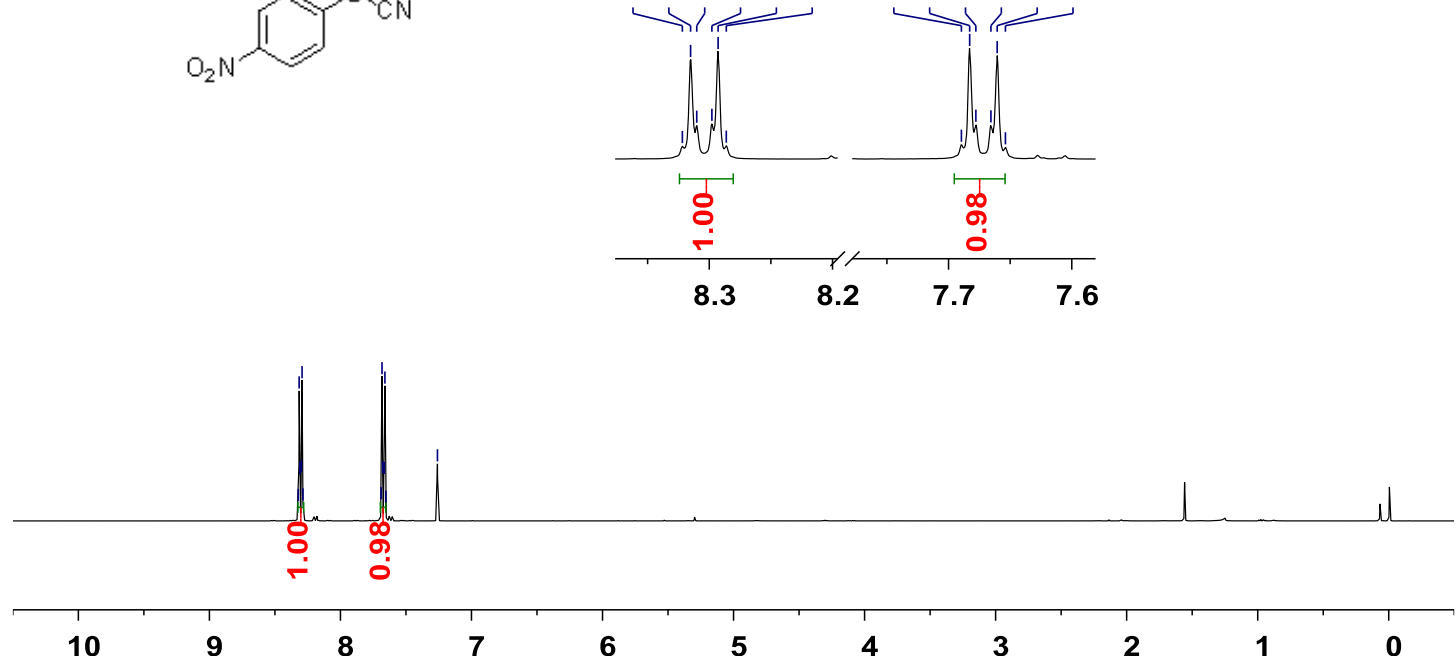

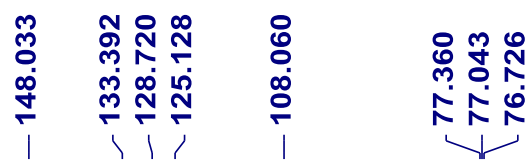
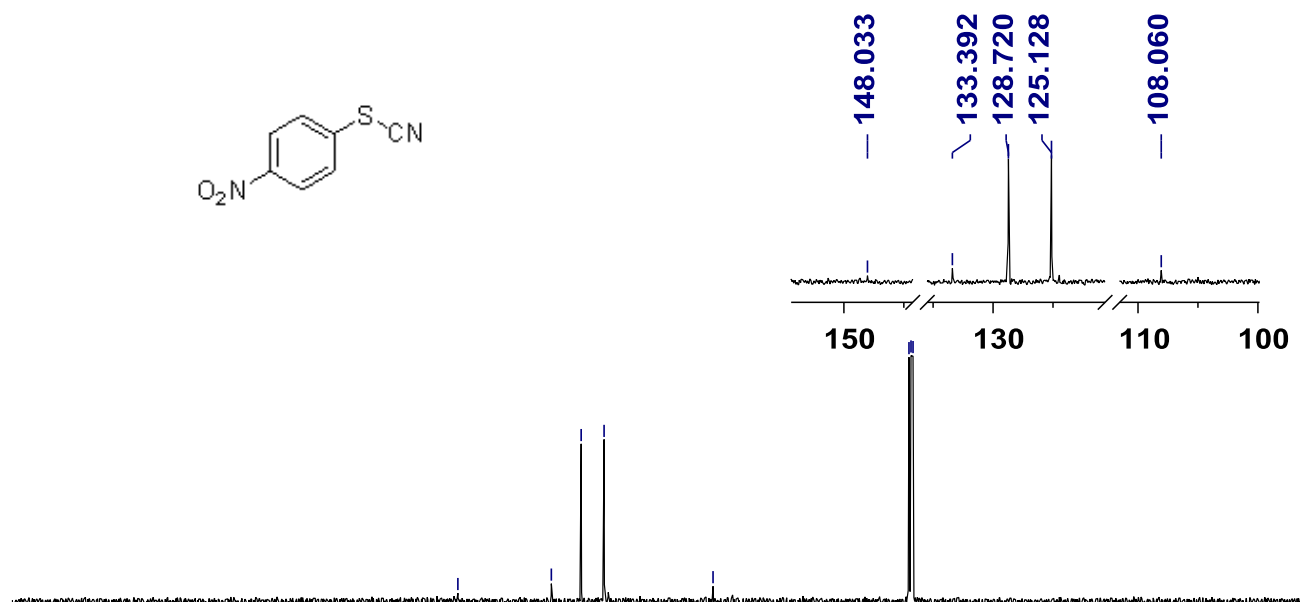

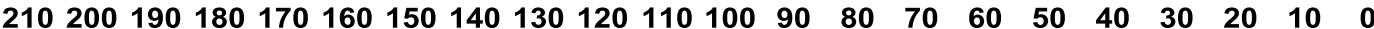


MS (EI) Spectrum of 1-nitro-4-thiocyanatobenzene (2r)

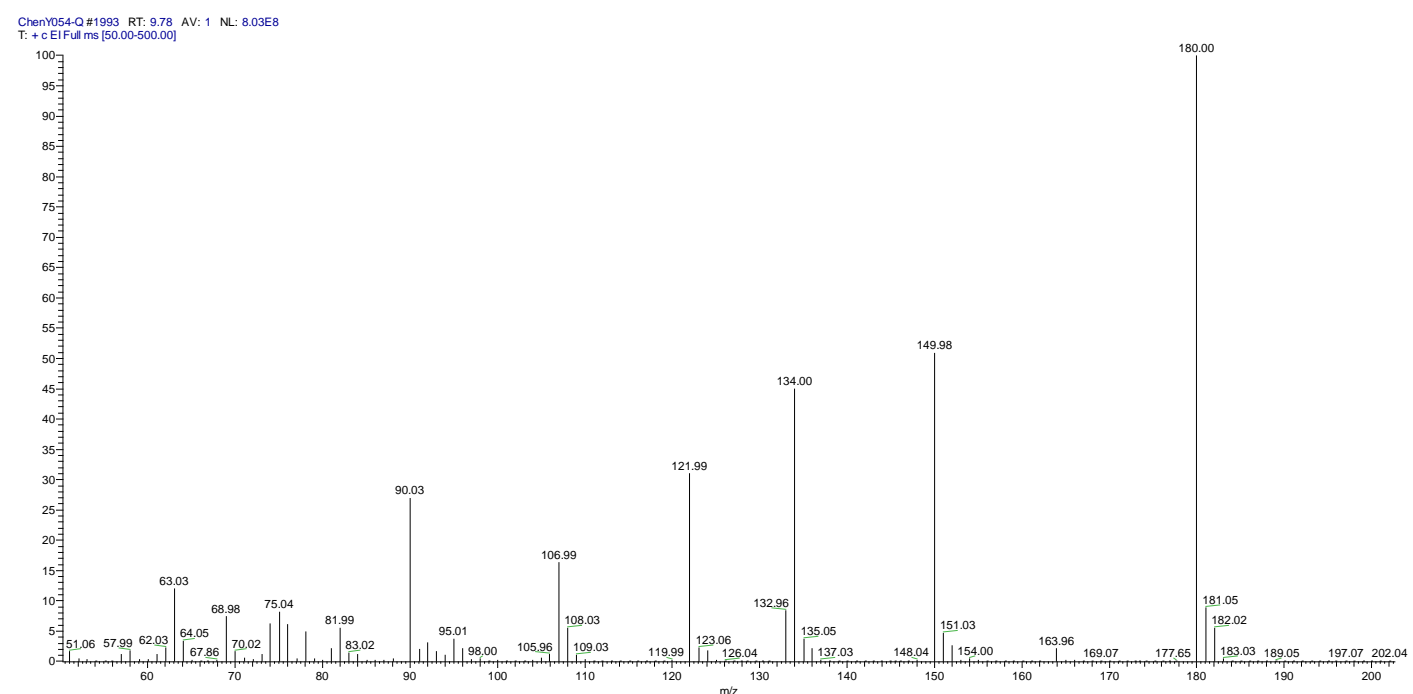


${ }^{1} \mathrm{H}$ and ${ }^{13} \mathrm{C}$ Spectra of 2-(4-thiocyanatophenyl)isoindoline-1,3-dione (2s) in $\mathrm{CDCl}_{3}(400 \mathrm{M})$

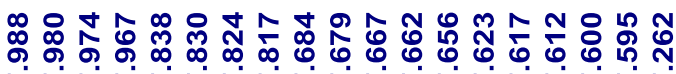

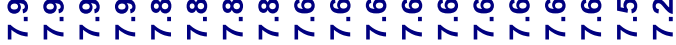
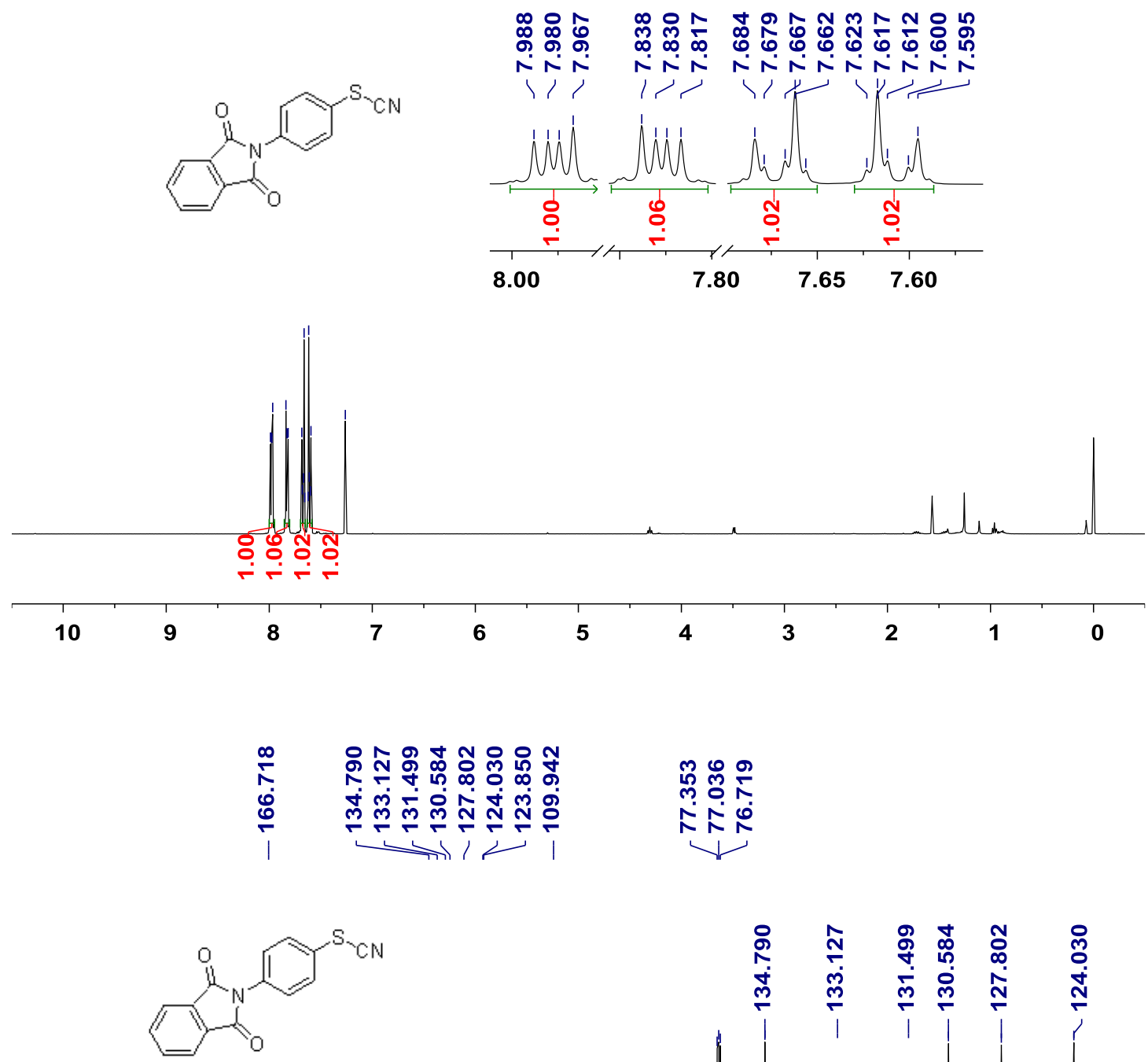

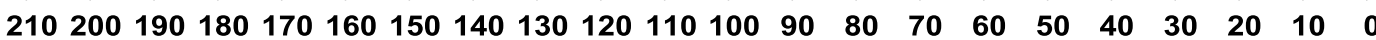


HRMS (ESI) Spectrum of 2-(4-thiocyanatophenyl)isoindoline-1,3-dione (2s) .

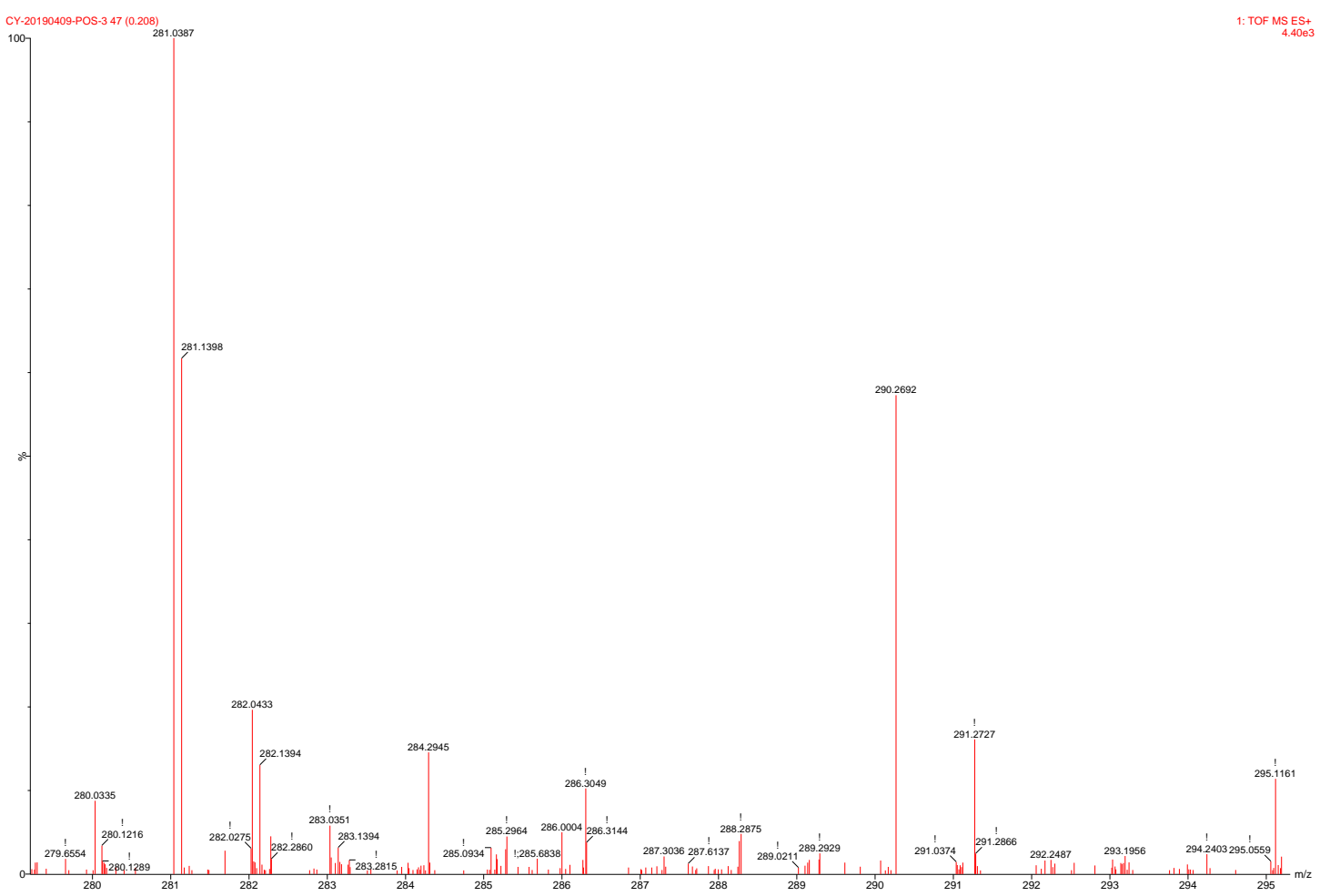


${ }^{1} \mathrm{H}$ and ${ }^{13} \mathrm{C}$ Spectra of 2-thiocyanatonaphthalene (2t) in $\mathrm{CDCl}_{3}$ (400M)

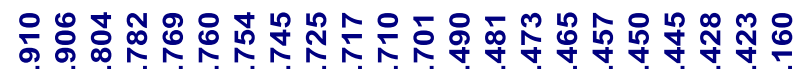

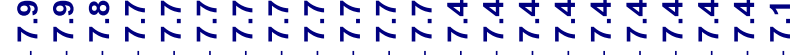

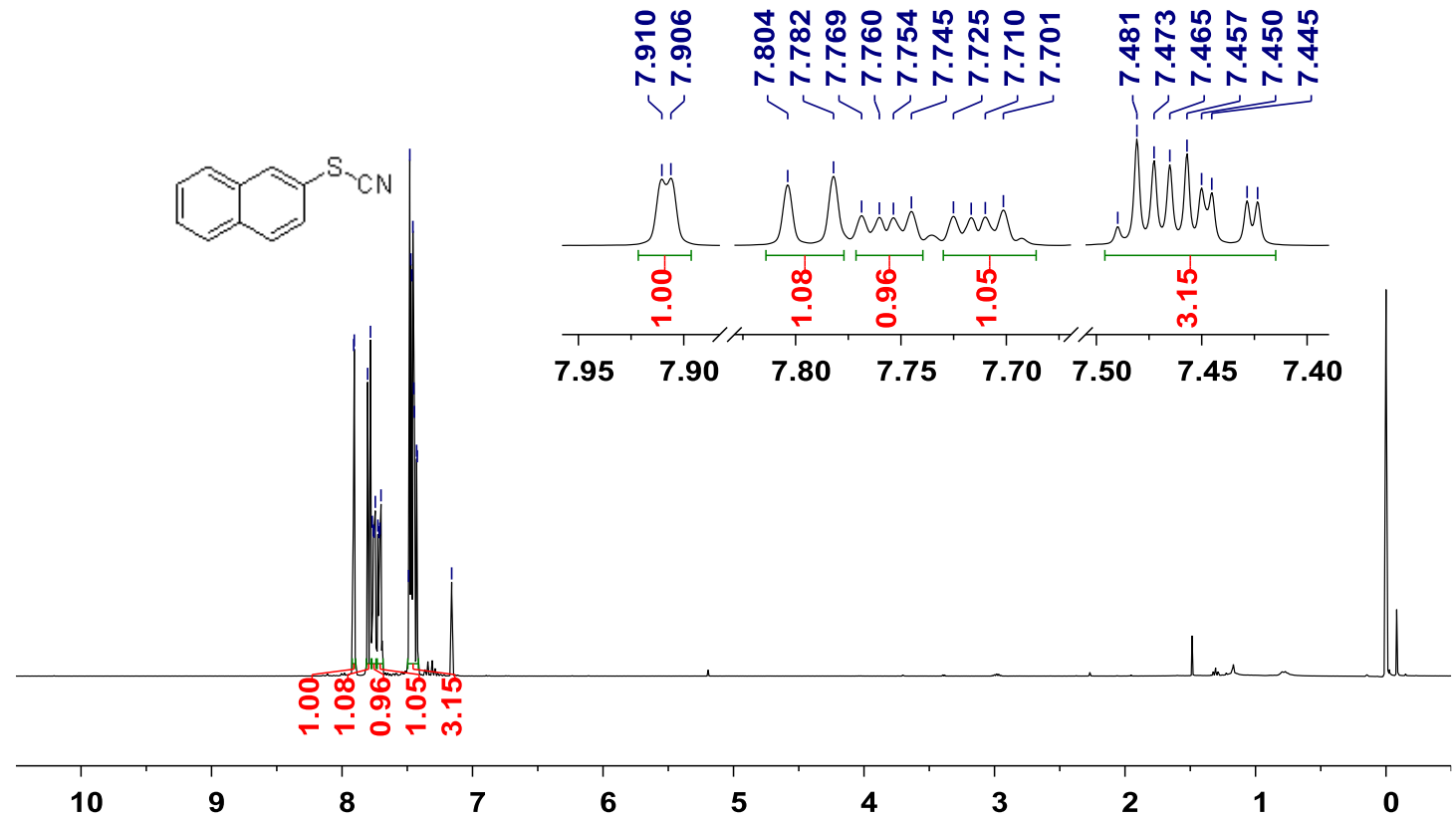

นึ⿱艹⿱日大,

Ni⿻日乚

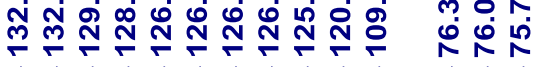

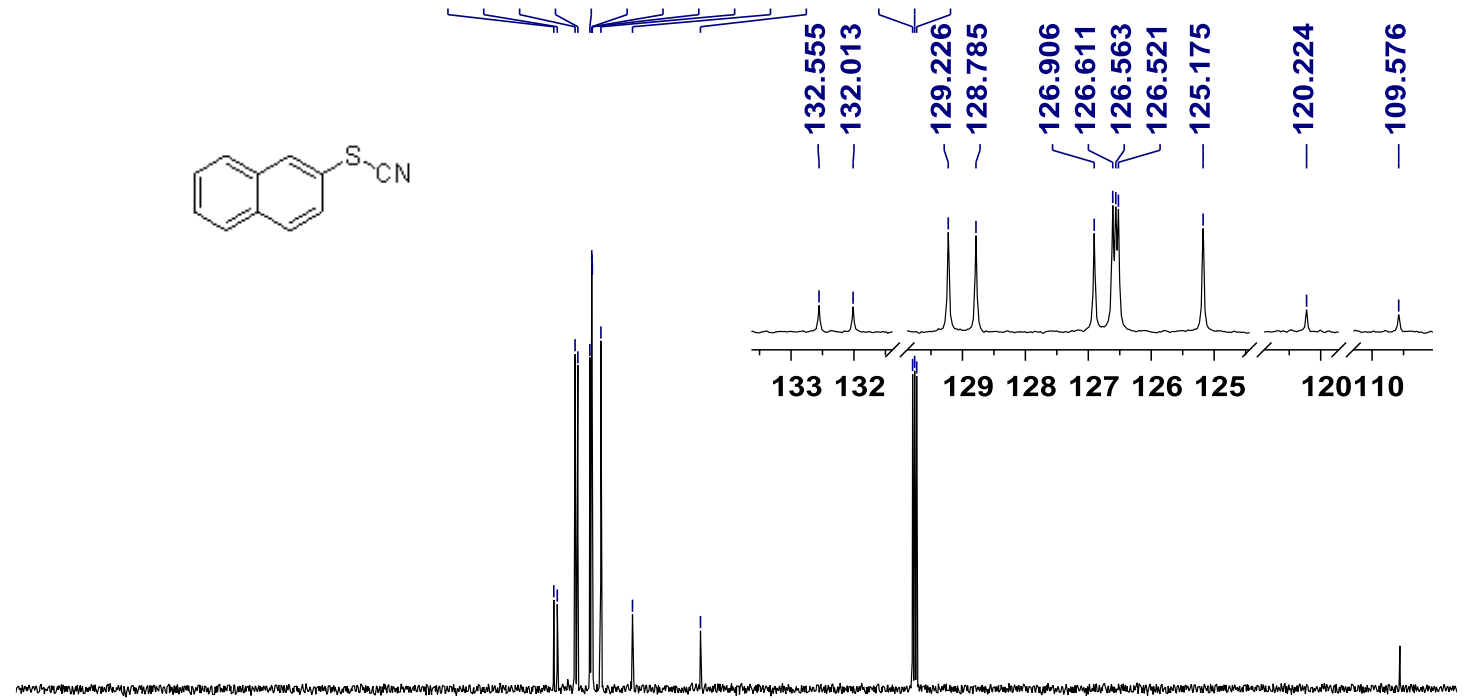

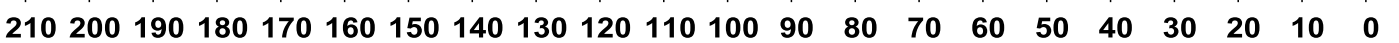


MS (EI) Spectrum of 2-thiocyanatonaphthalene (2t)

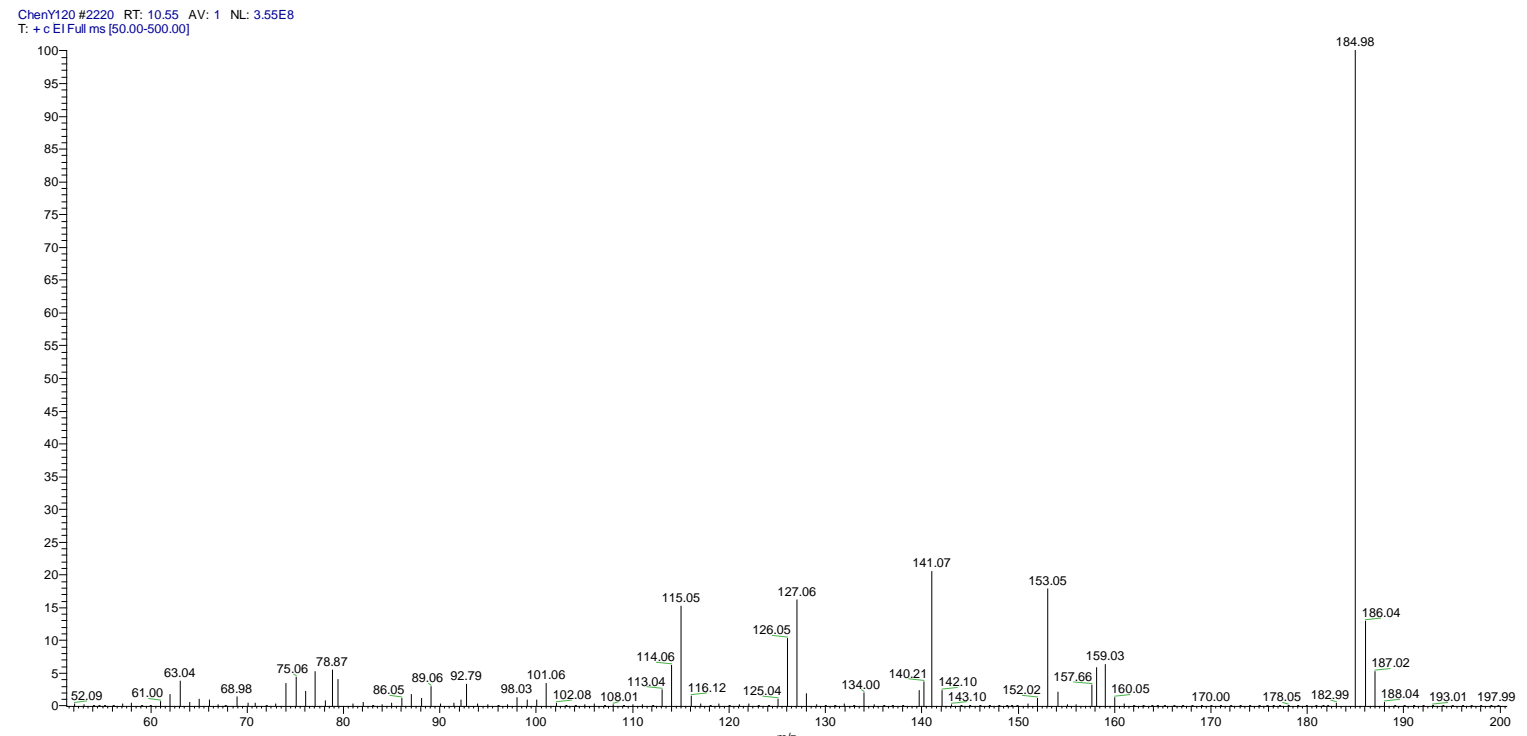


${ }^{1} \mathrm{H}$ and ${ }^{13} \mathrm{C}$ Spectra of 2-thiocyanatopyridine (2u) in $\mathrm{CDCl}_{3}(400 \mathrm{M})$

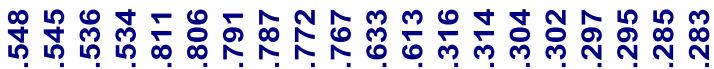

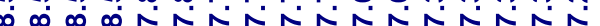

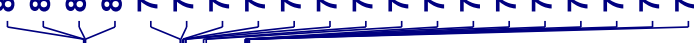

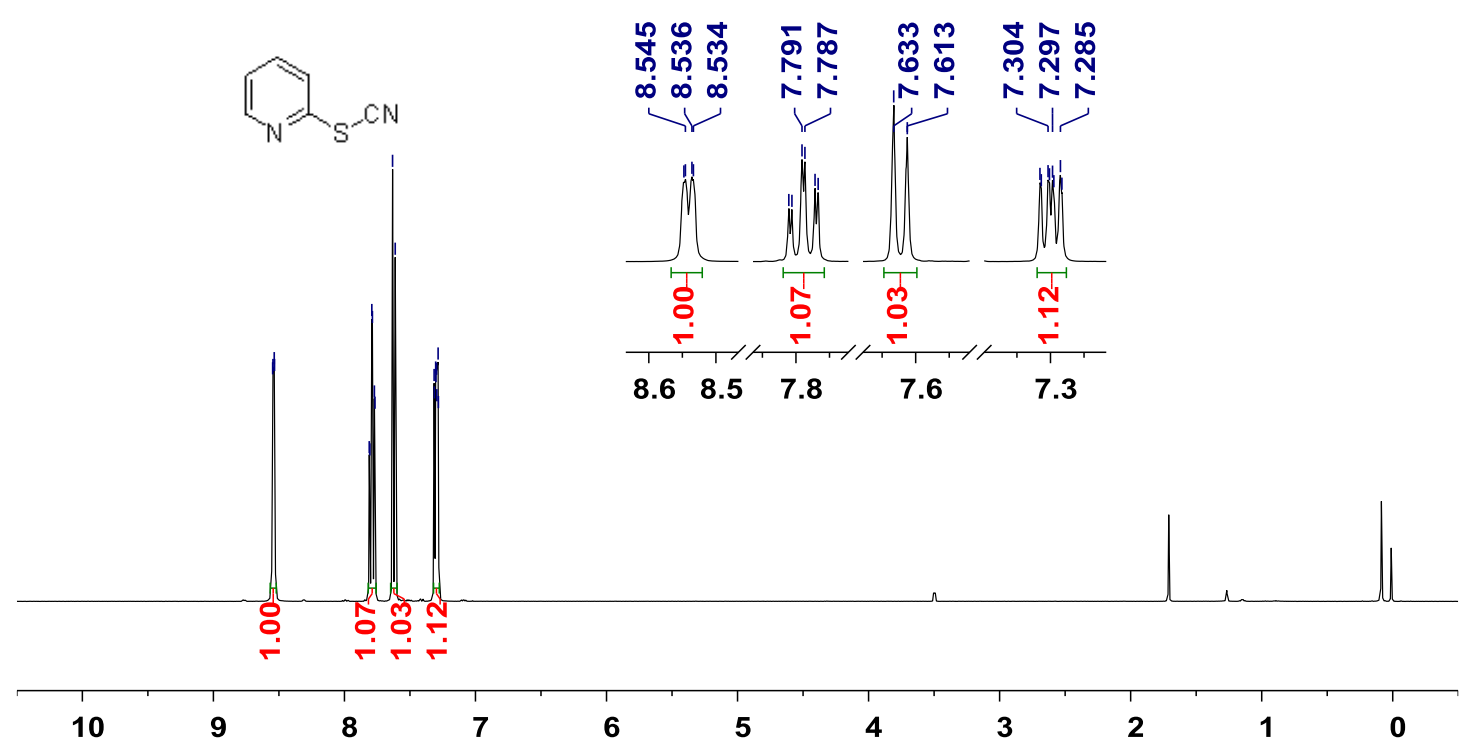

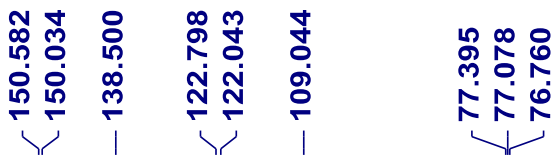

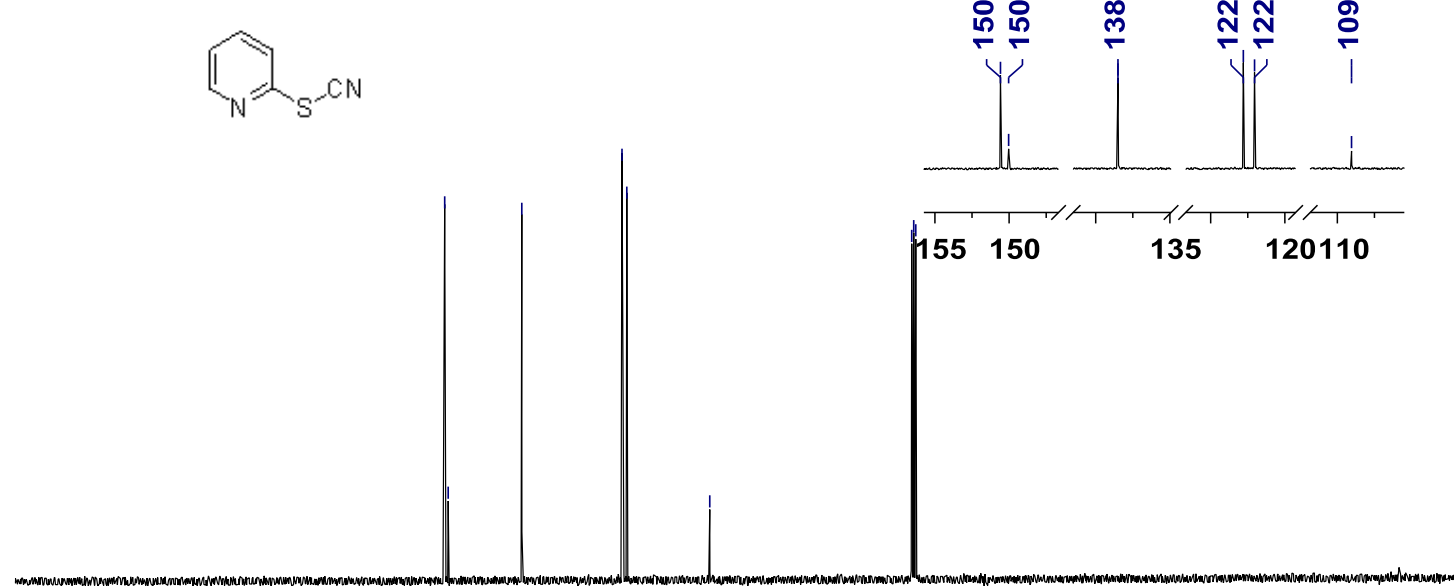

กับ

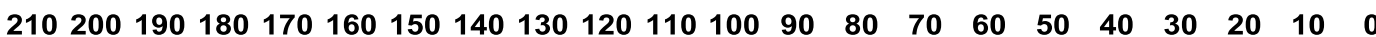


MS (EI) Spectrum of 2-thiocyanatopyridine (2u)

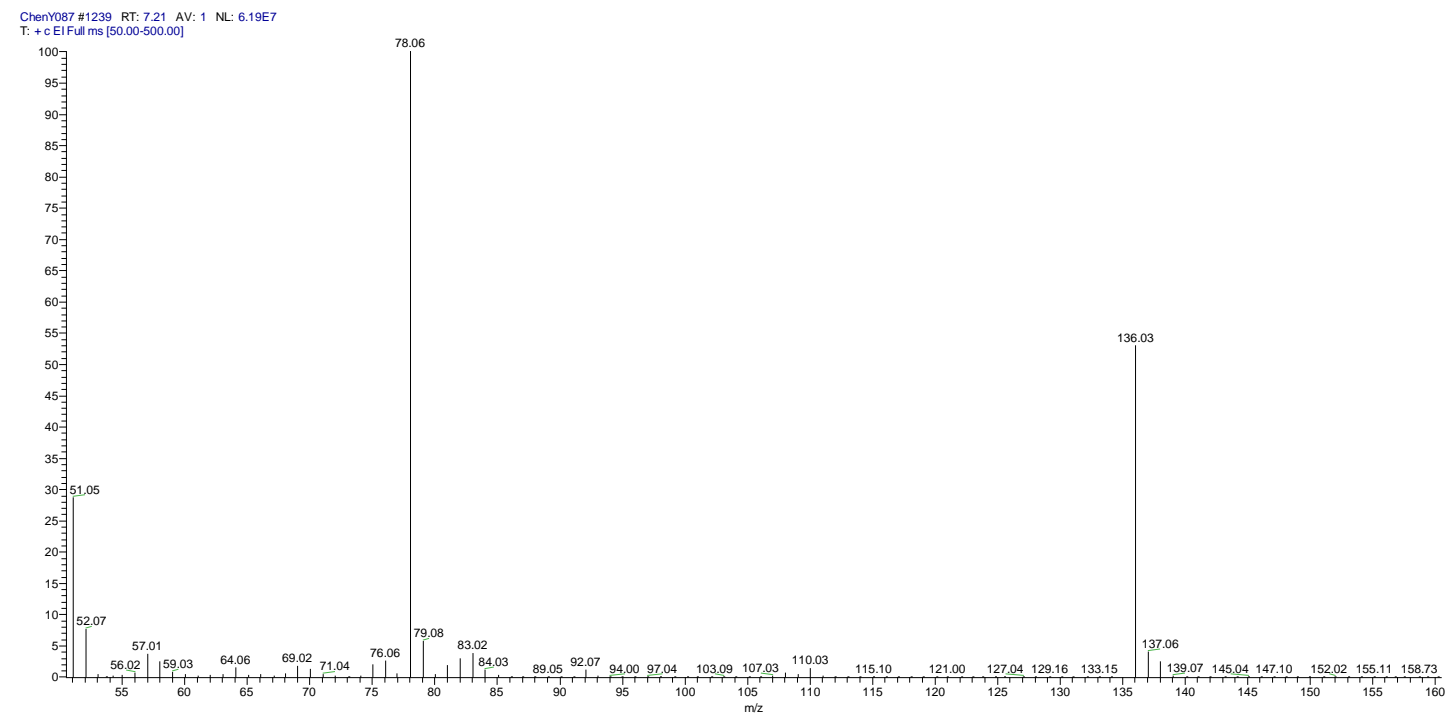


${ }^{1} \mathrm{H}$ and ${ }^{13} \mathrm{C}$ Spectra of 2-thiocyanatobenzo[d]thiazole (2v) in $\mathrm{CDCl}_{3}(400 \mathrm{M})$

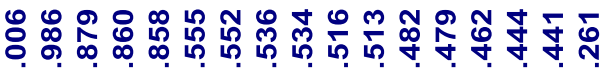

苗

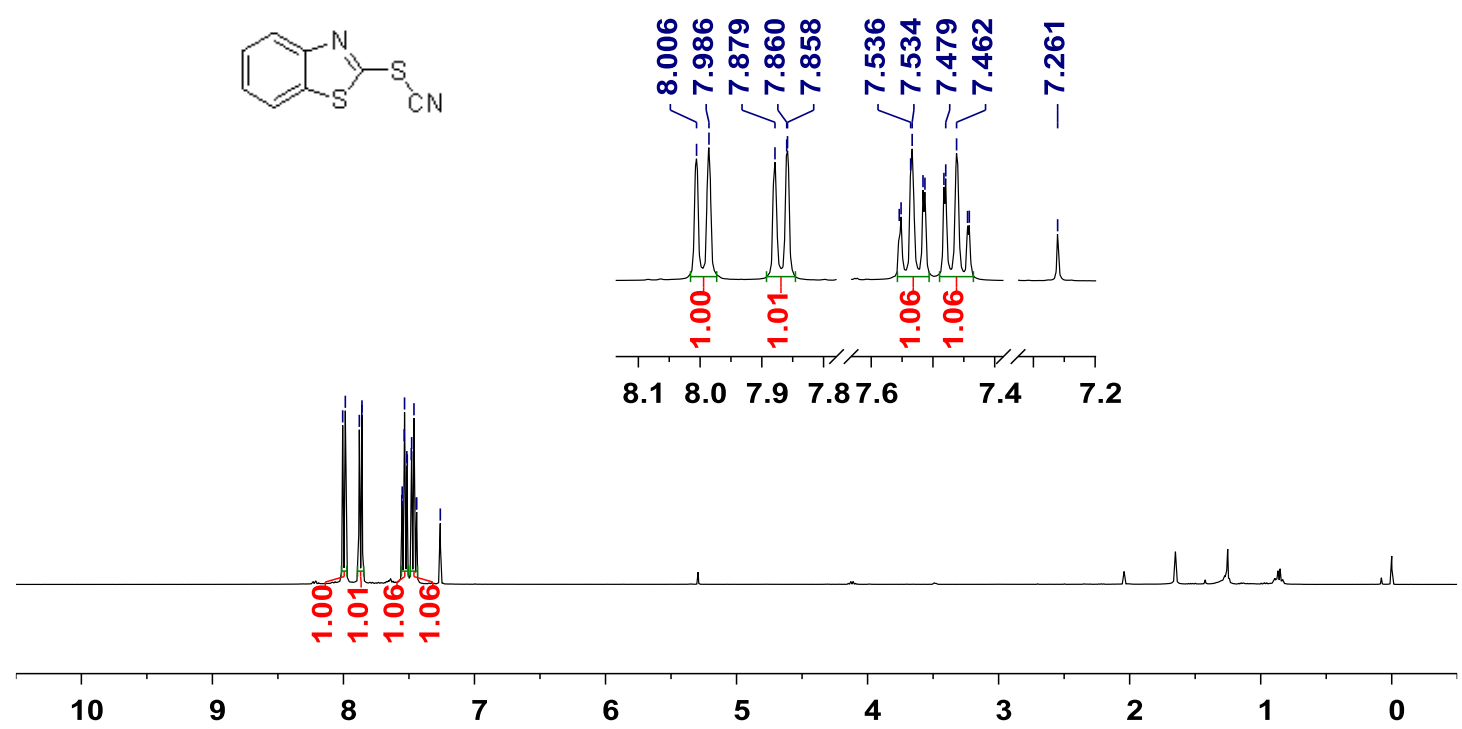

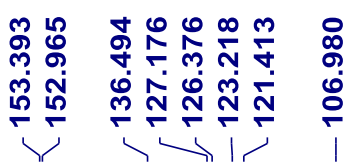

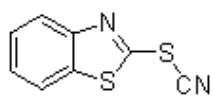

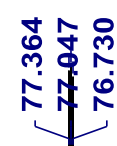

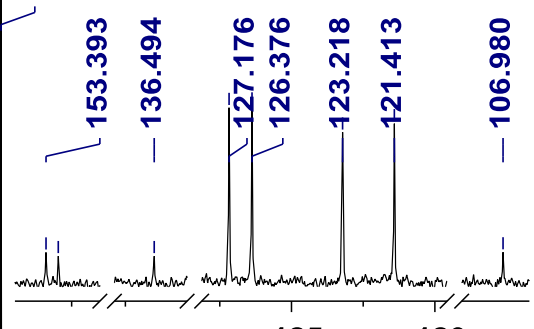

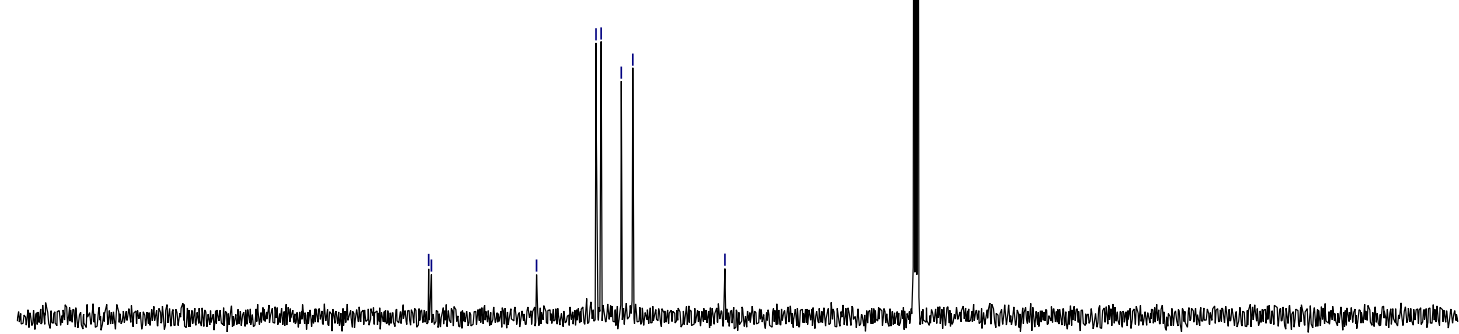

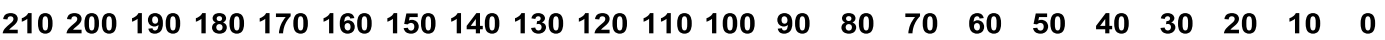


MS (EI) Spectrum of 2-thiocyanatobenzo[d]thiazole (2v).

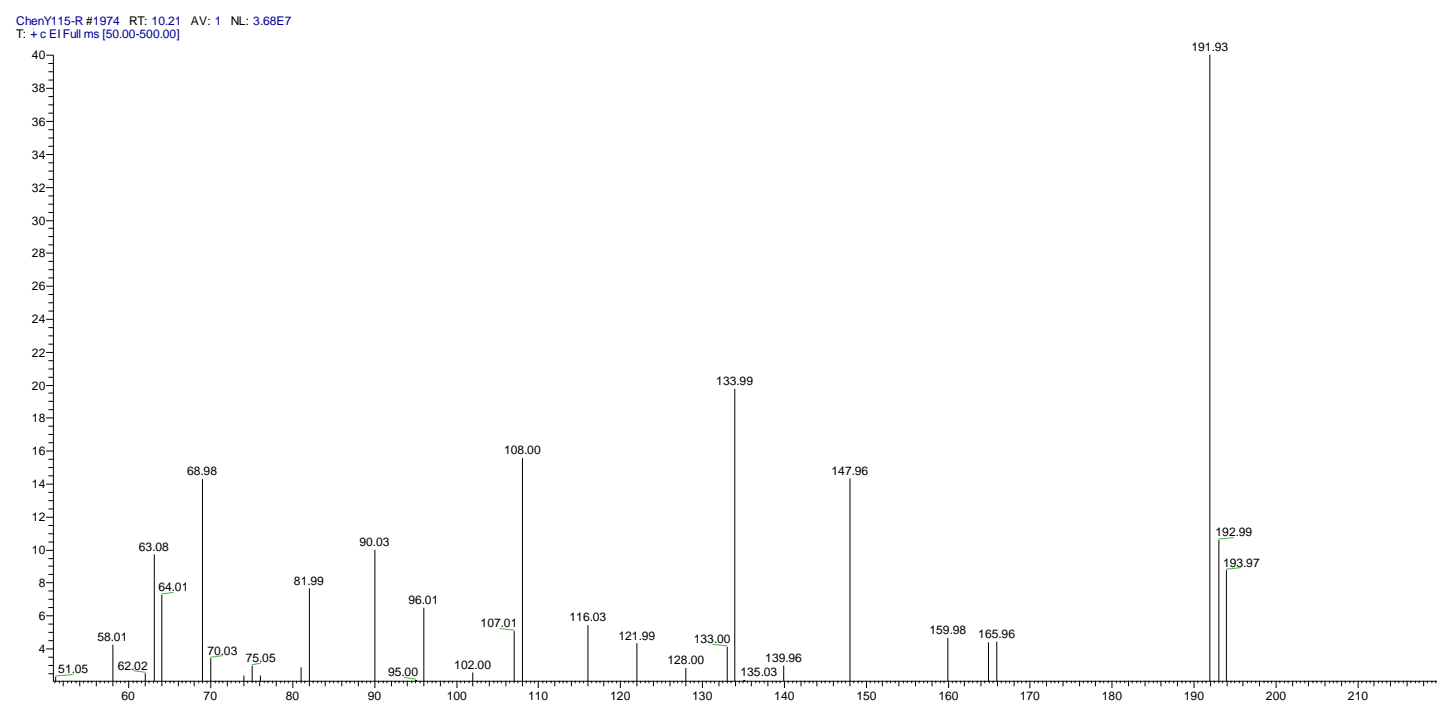


${ }^{1} \mathrm{H}$ and ${ }^{13} \mathrm{C}$ Spectra of (thiocyanatomethyl)benzene (2w) in $\mathrm{CDCl}_{3}(400 \mathrm{M})$

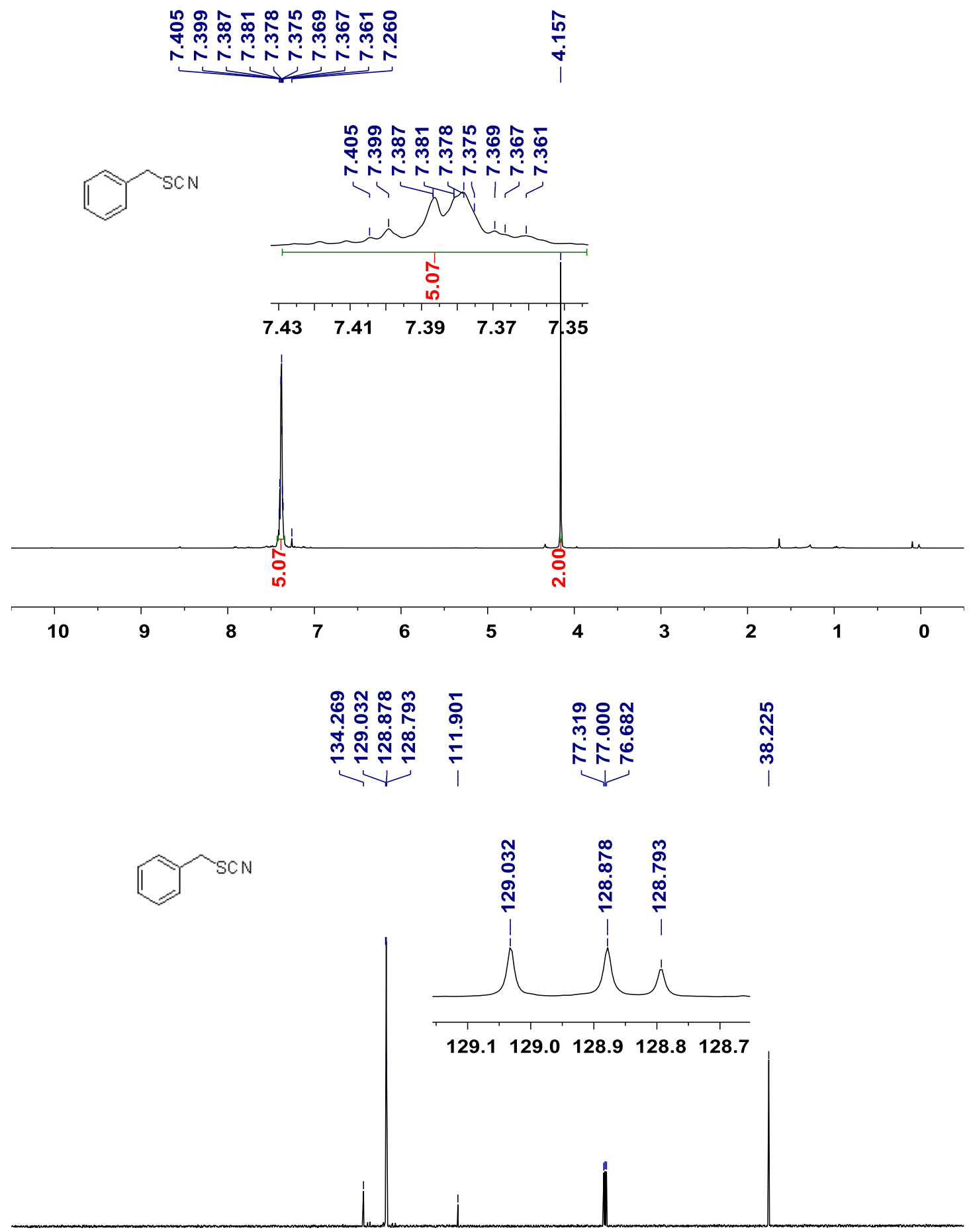

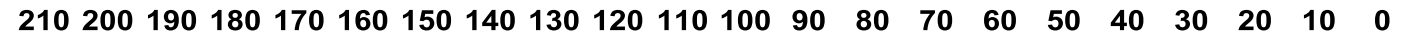


MS (EI) Spectrum of (thiocyanatomethyl)benzene (2w).

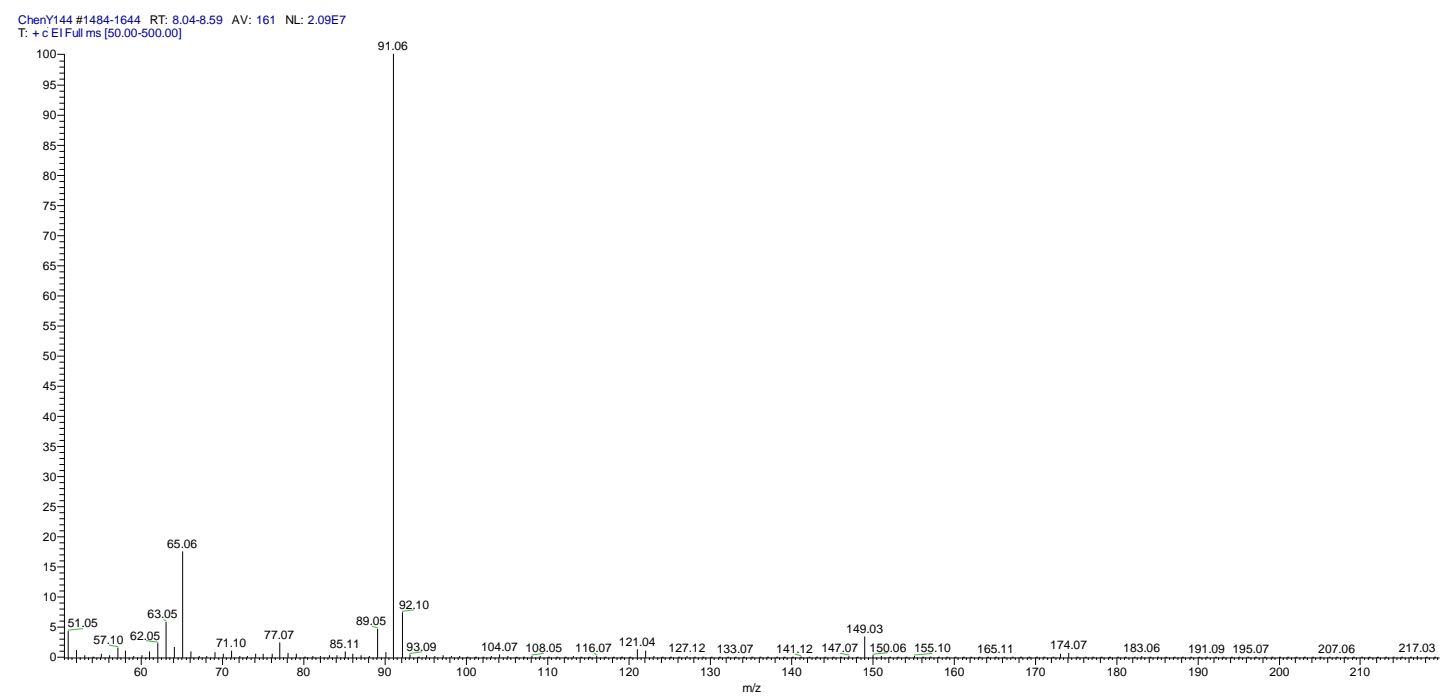


${ }^{1} \mathrm{H}$ and ${ }^{13} \mathrm{C}$ Spectra of (2-thiocyanatoethyl)benzene (2x) in $\mathrm{CDCl}_{3}(400 \mathrm{M})$

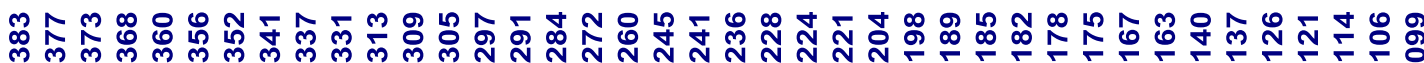
กิ m
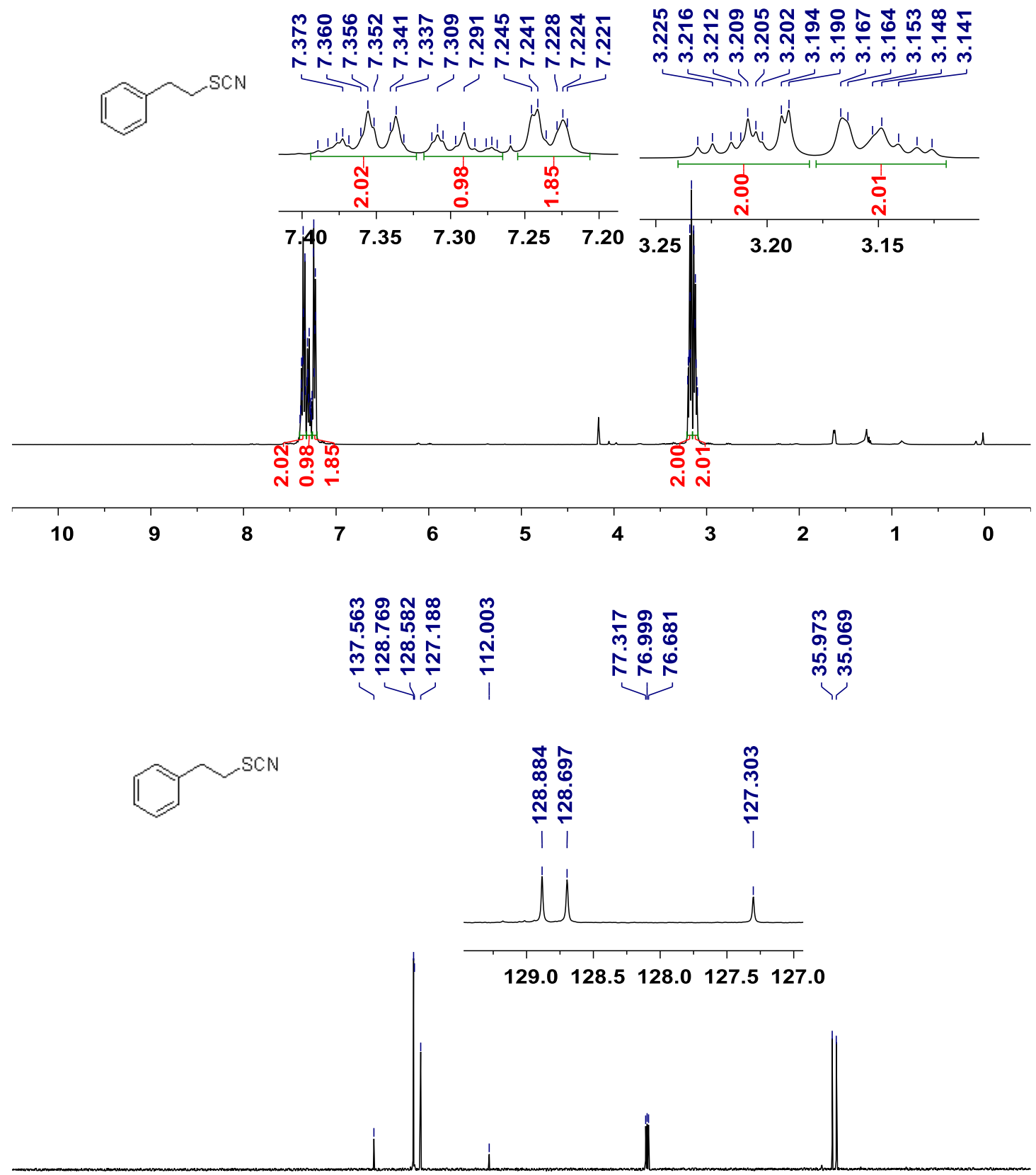

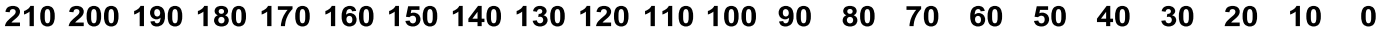


MS (EI) Spectrum of (2-thiocyanatoethyl)benzene (2x).

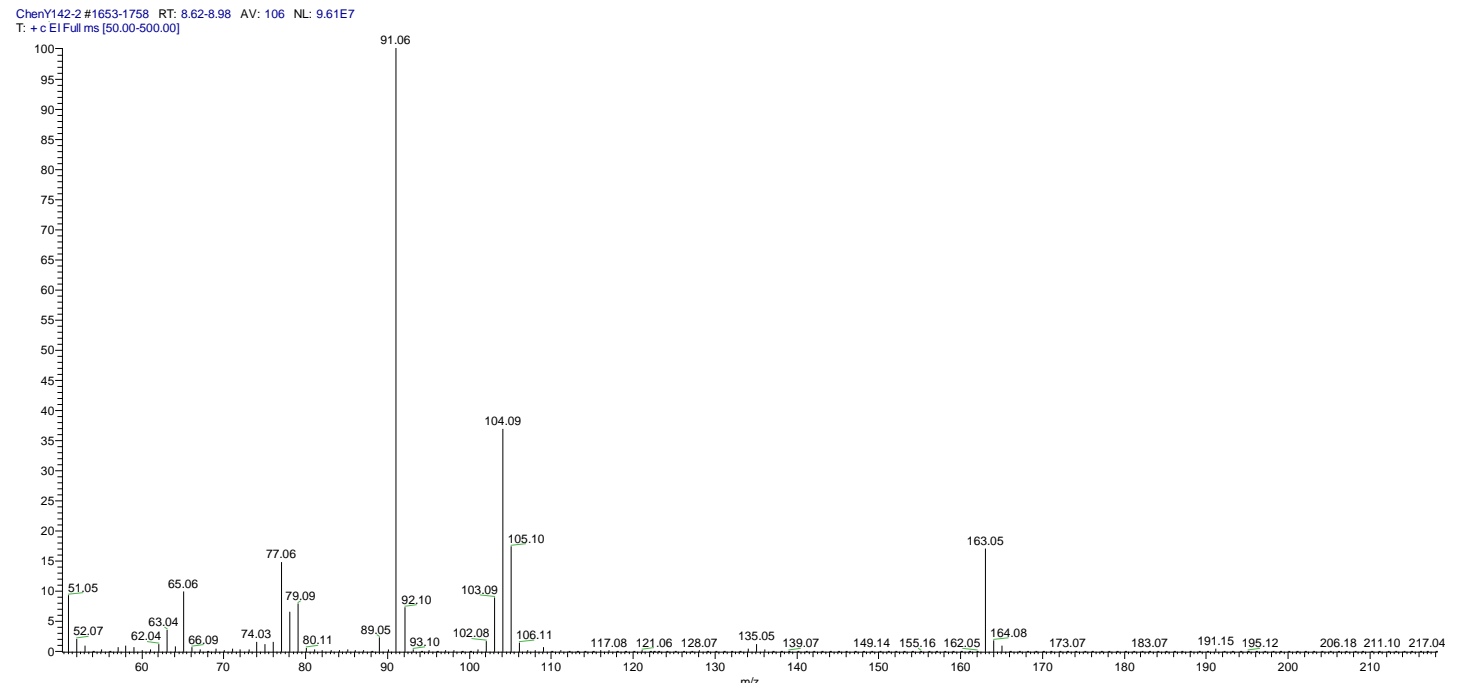


${ }^{1} \mathrm{H}$ and ${ }^{13} \mathrm{C}$ Spectra of 1-(bromomethyl)-4-thiocyanatobenzene (2y) in $\mathrm{CDCl}_{3}(400 \mathrm{M})$
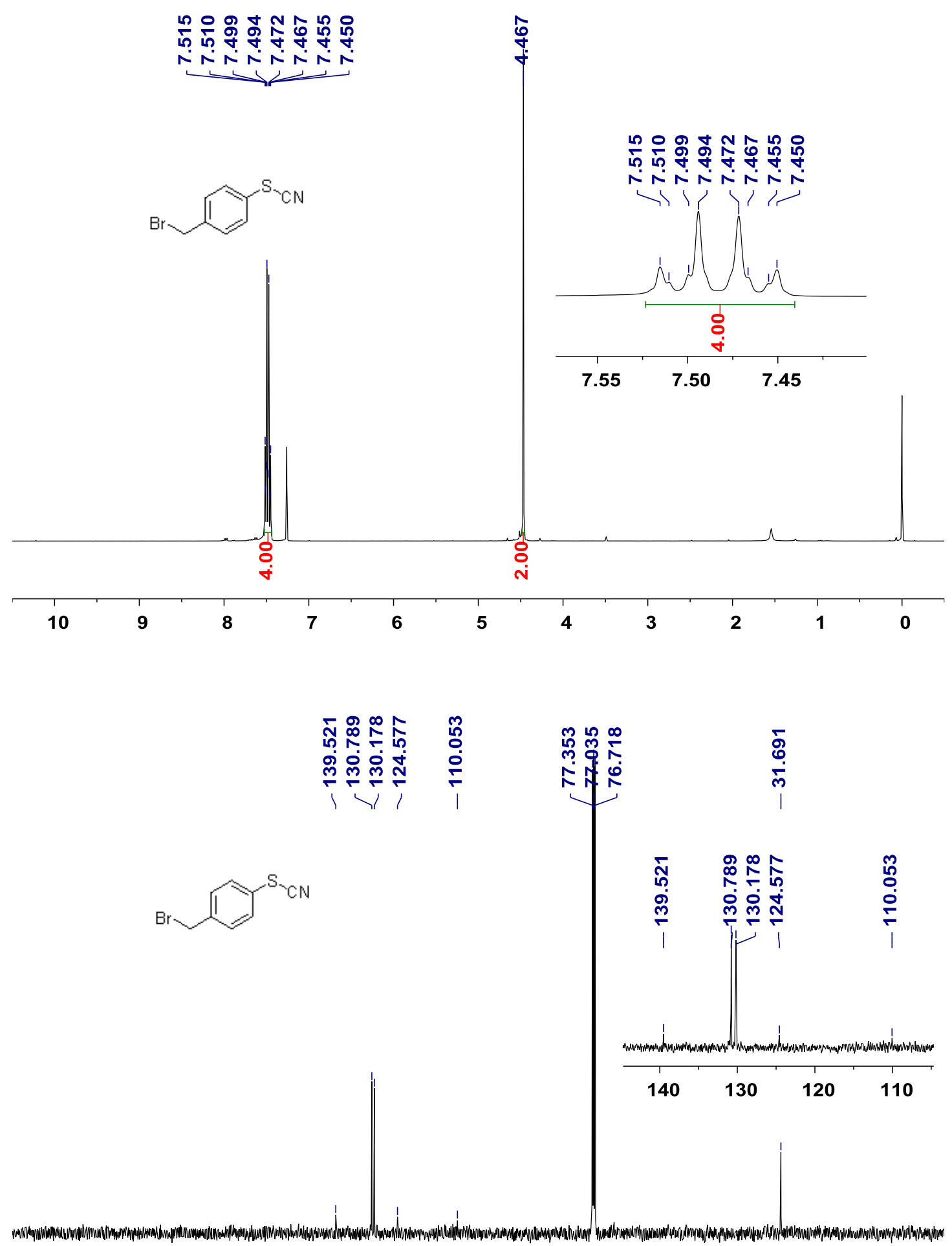

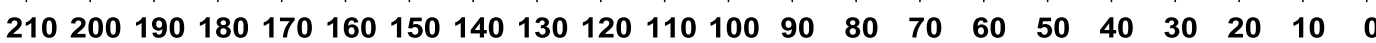


MS (EI) Spectrum of 1-(bromomethyl)-4-thiocyanatobenzene (2y).

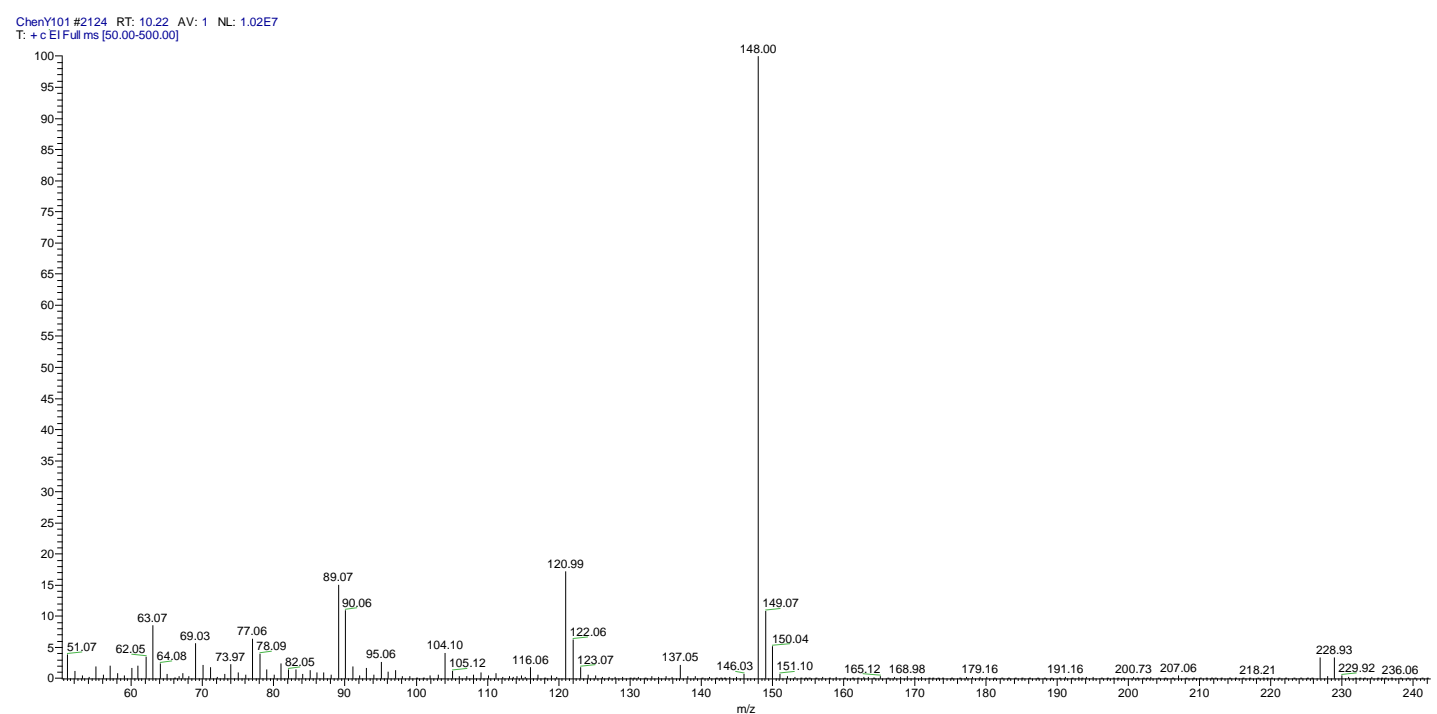


(8R,9S,13S,14S)-13-methyl-3-((4-thiocyanatobenzyl)oxy)-6,7,8,9,11,12,13,14,15,16-decahydro-1 $7 \mathrm{H}$-cyclopenta[a]phenanthren-17-one (14) in $\mathrm{CDCl}_{3}$ (400M)

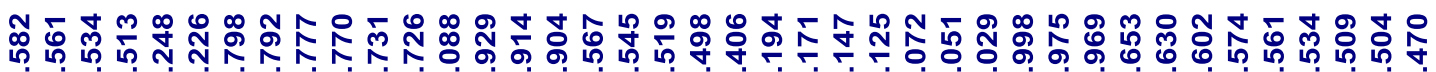
.
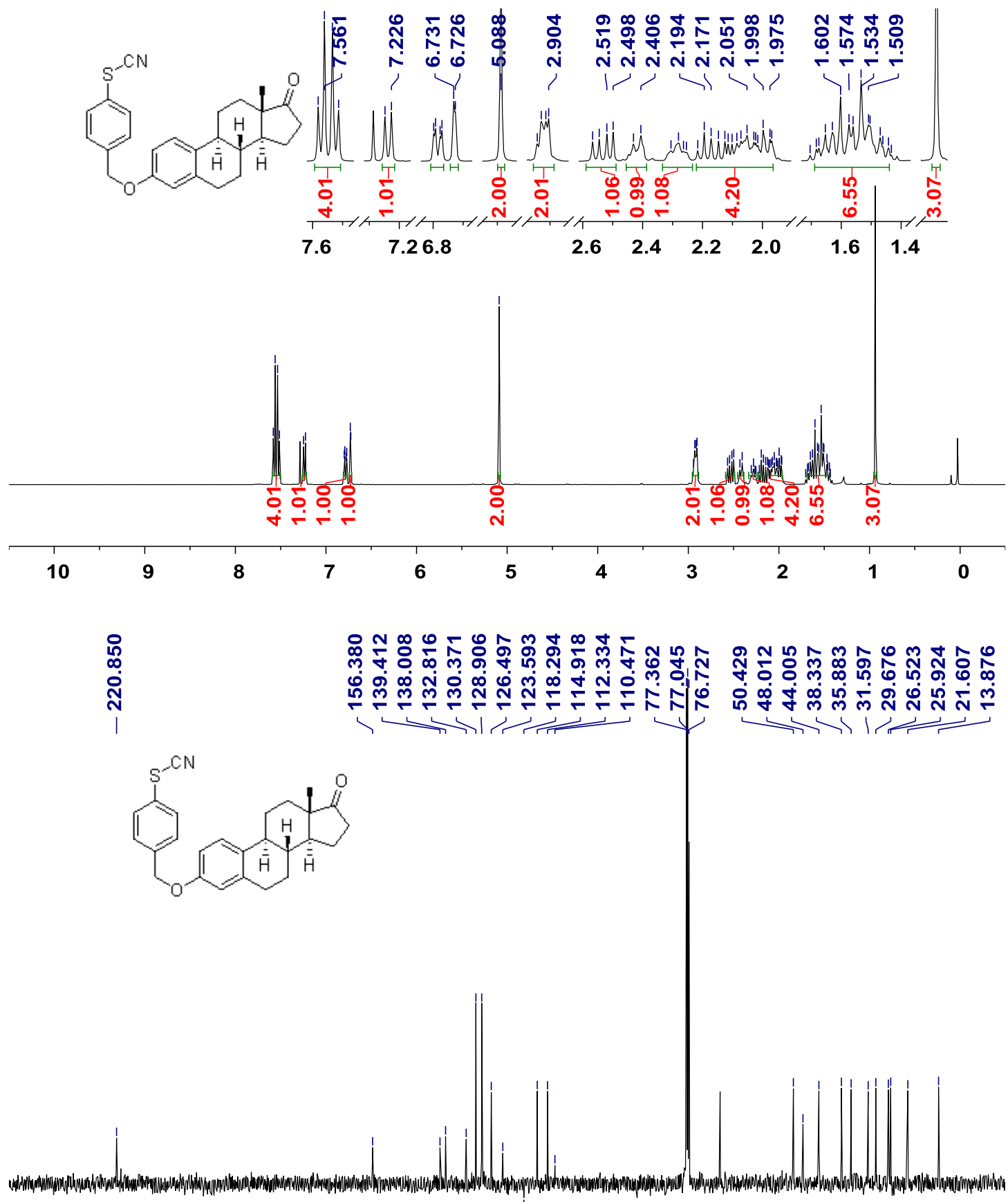

\begin{tabular}{lllllllllllll}
\hline 240 & 220 & 200 & 180 & 160 & 140 & 120 & 100 & 80 & 60 & 40 & 20 & 0
\end{tabular}




\section{4. ${ }^{1} \mathrm{H}$ NMR Spectra of Crude Reaction Mixtures in Table 3}

\section{$3 a$}

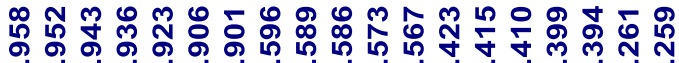

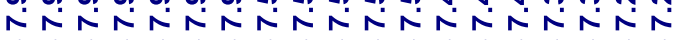

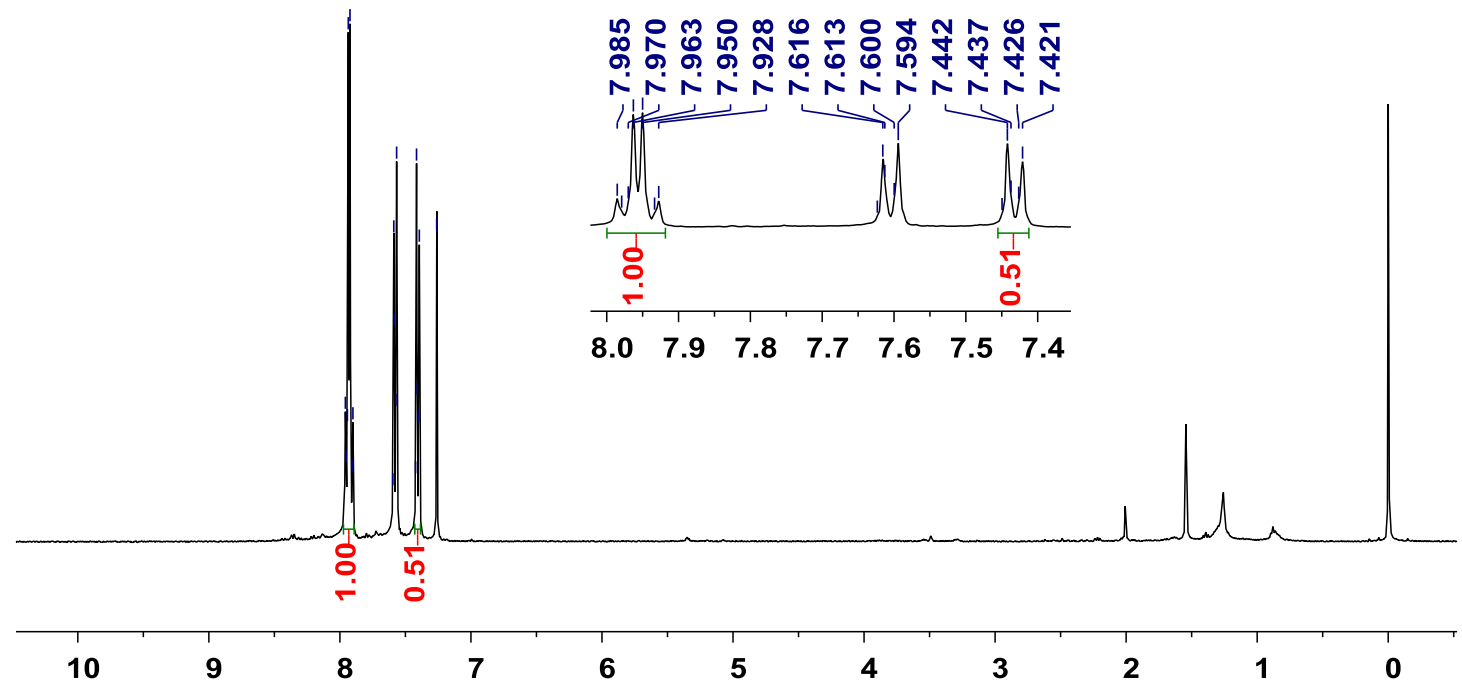

$3 b$

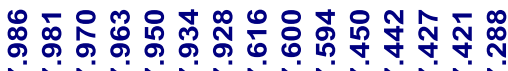

N N N N N N N N N N

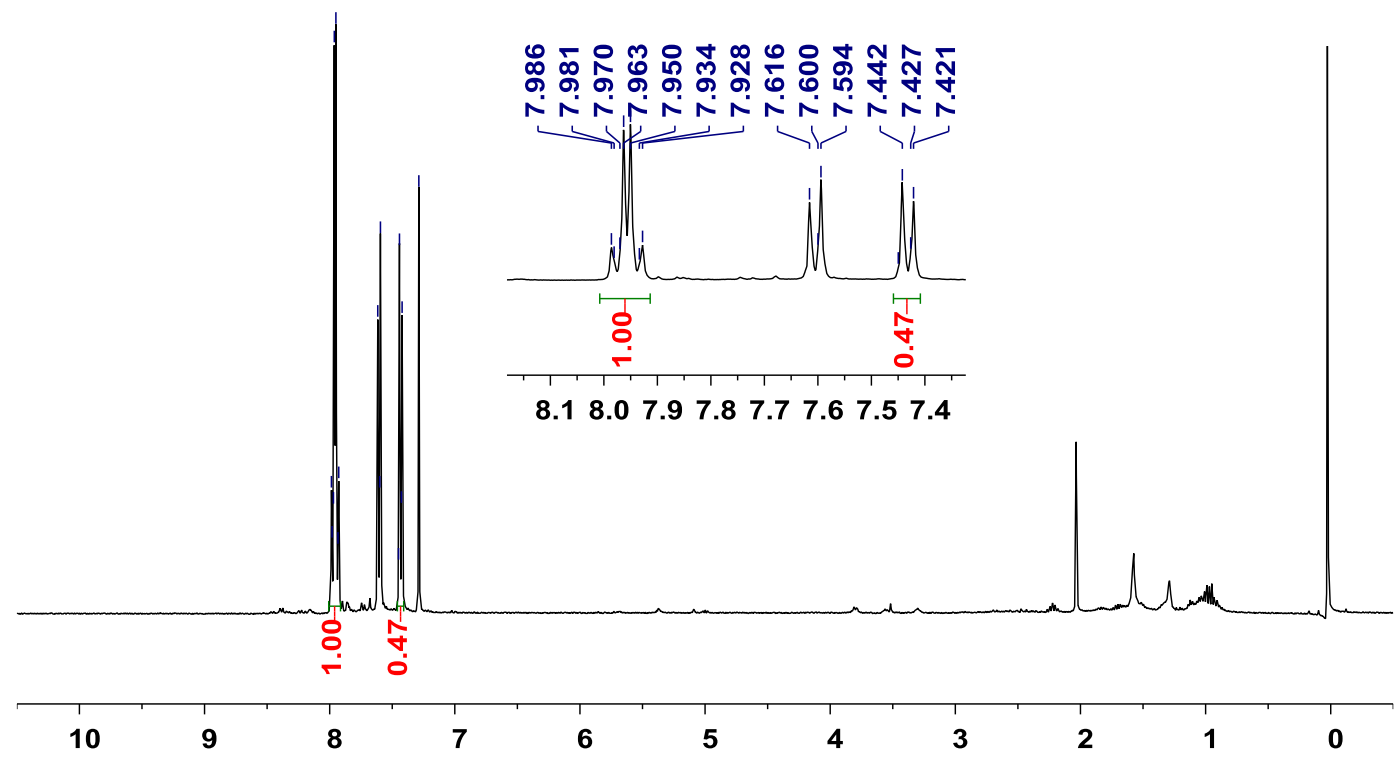


3c

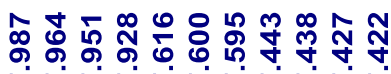

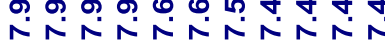

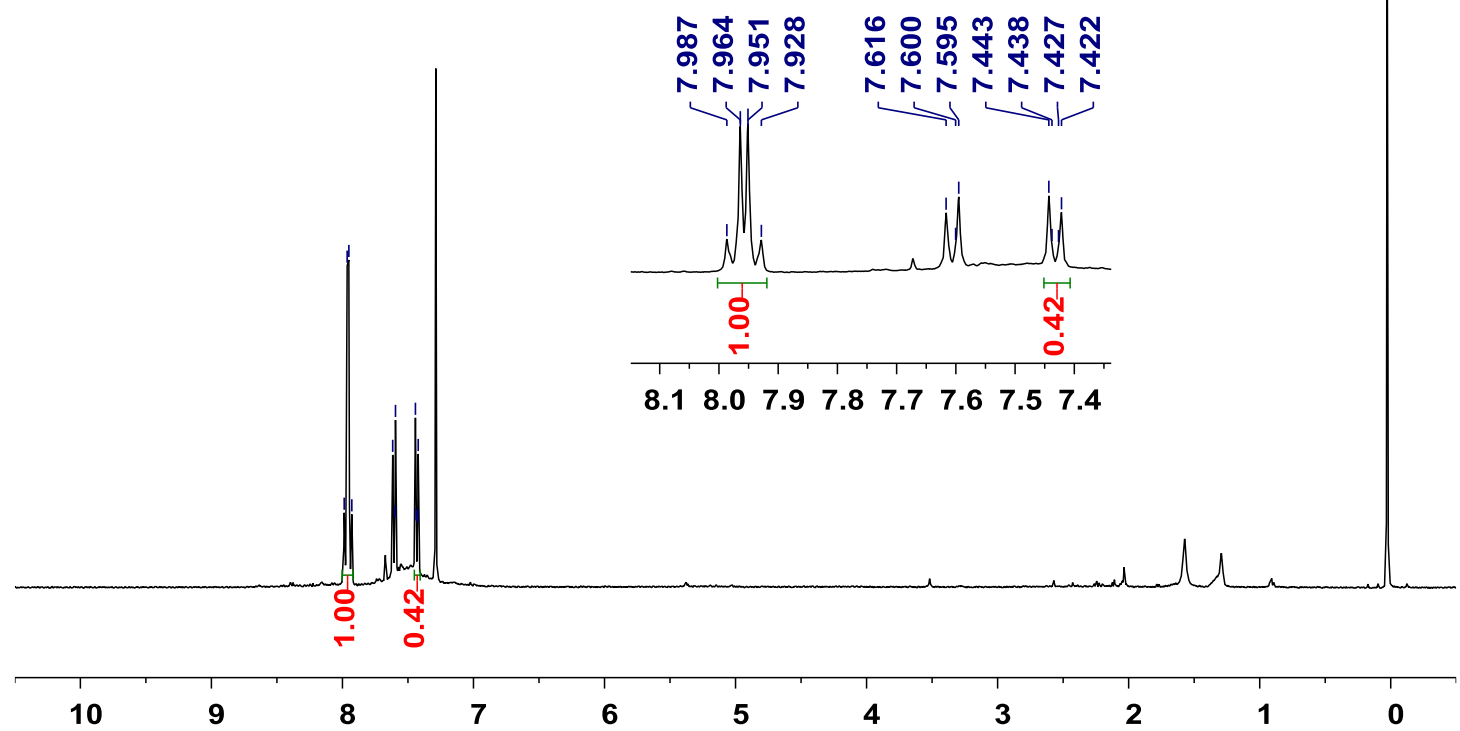

3d

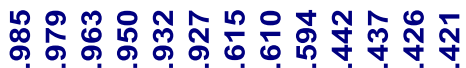

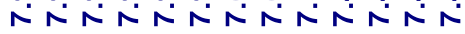

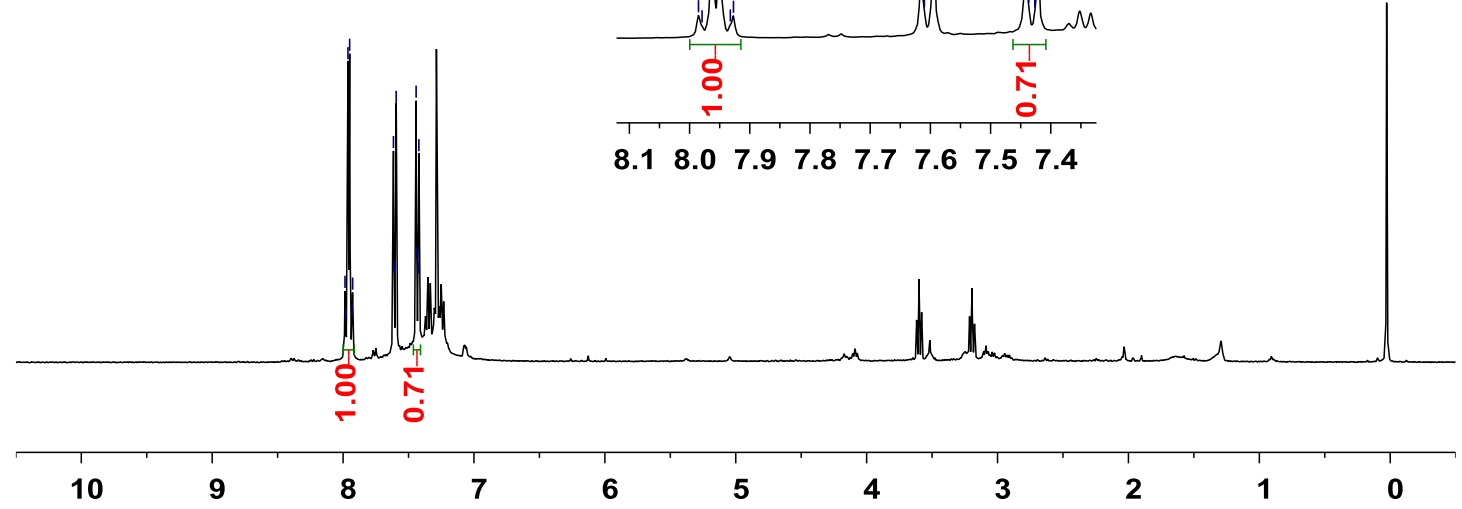

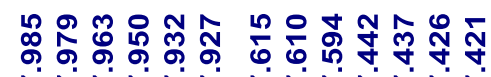
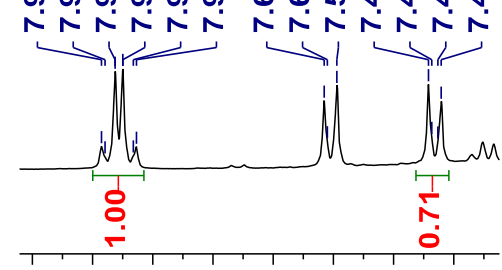

$\begin{array}{lllllllll}8.1 & 8.0 & 7.9 & 7.8 & 7.7 & 7.6 & 7.5 & 7.4\end{array}$

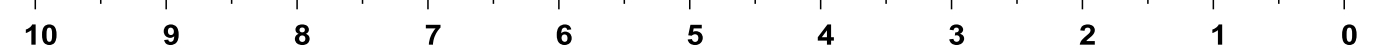


$3 e$

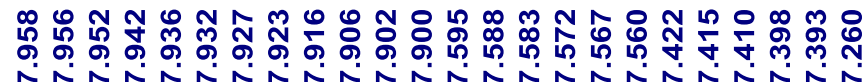

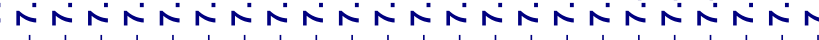

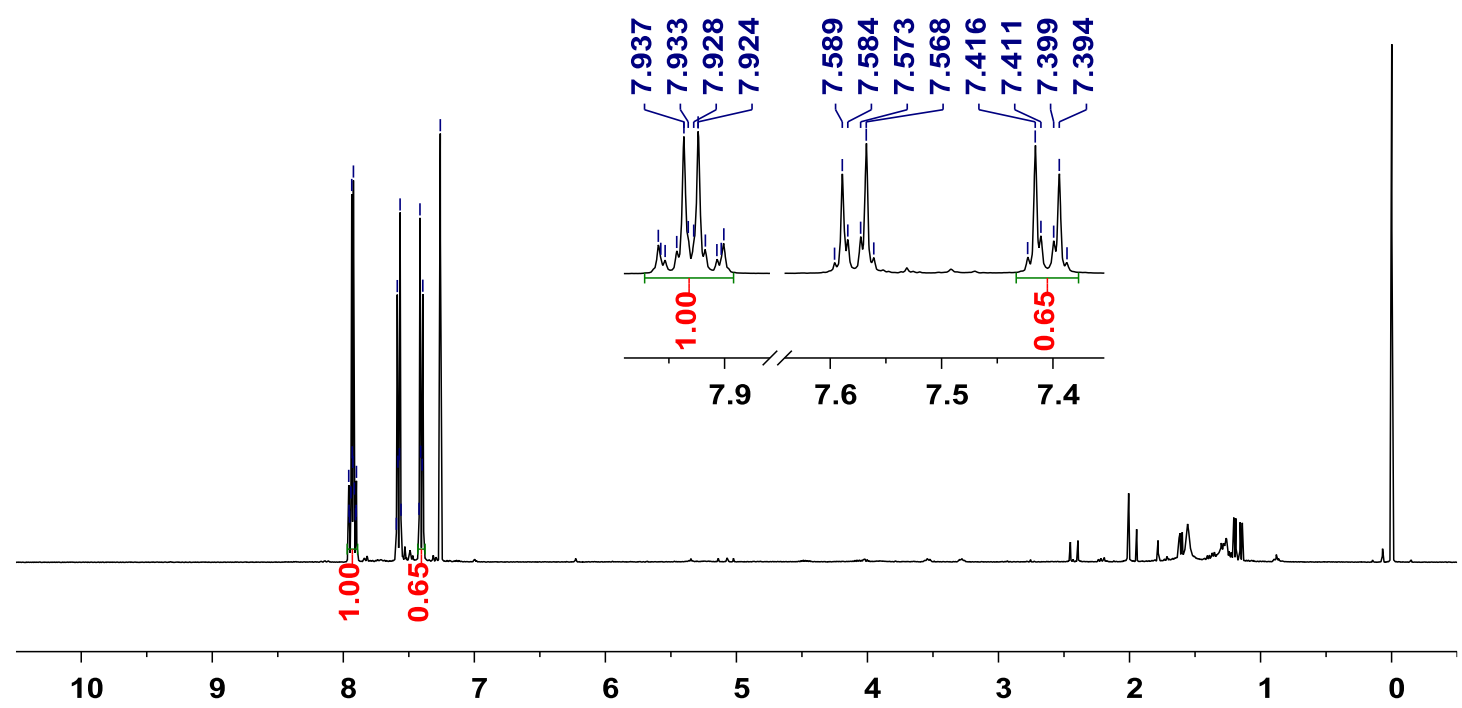

$3 f$

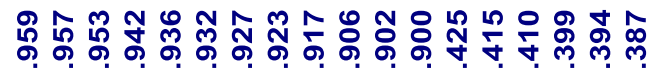

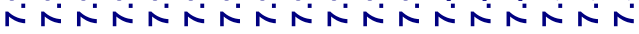

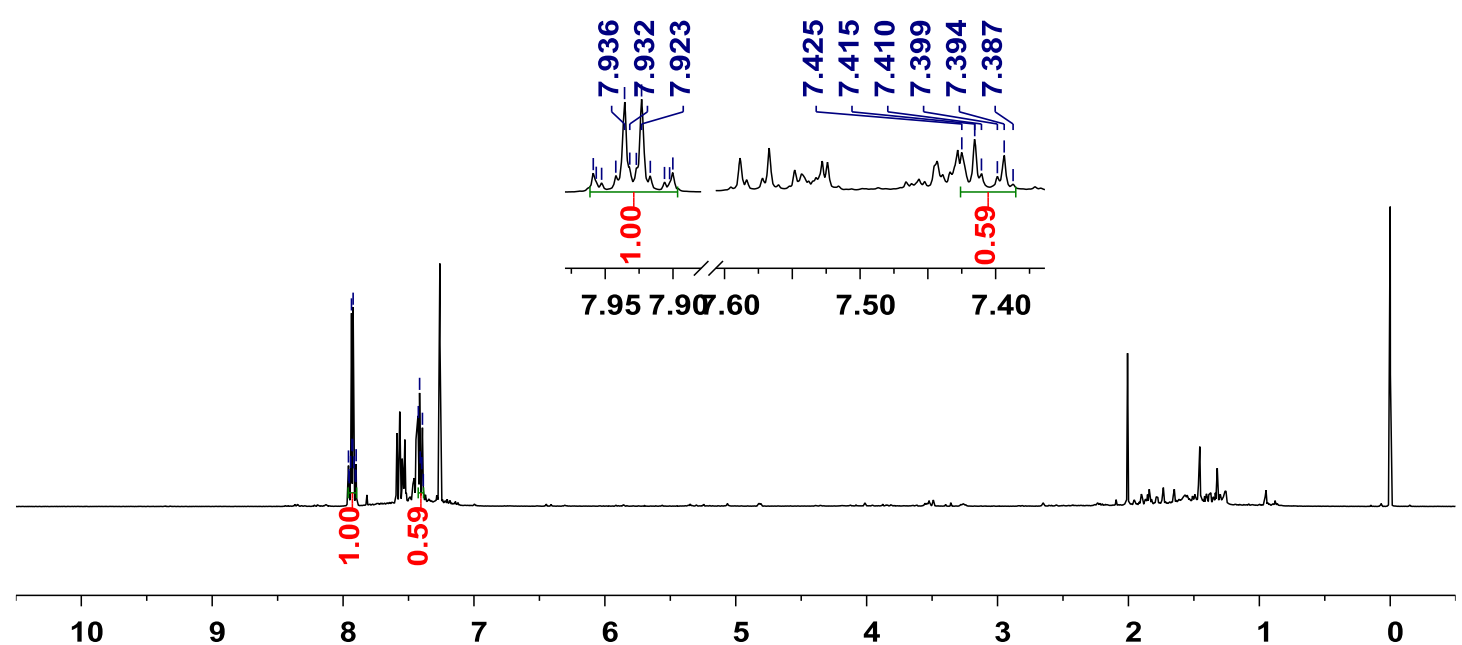


$3 g$

ま

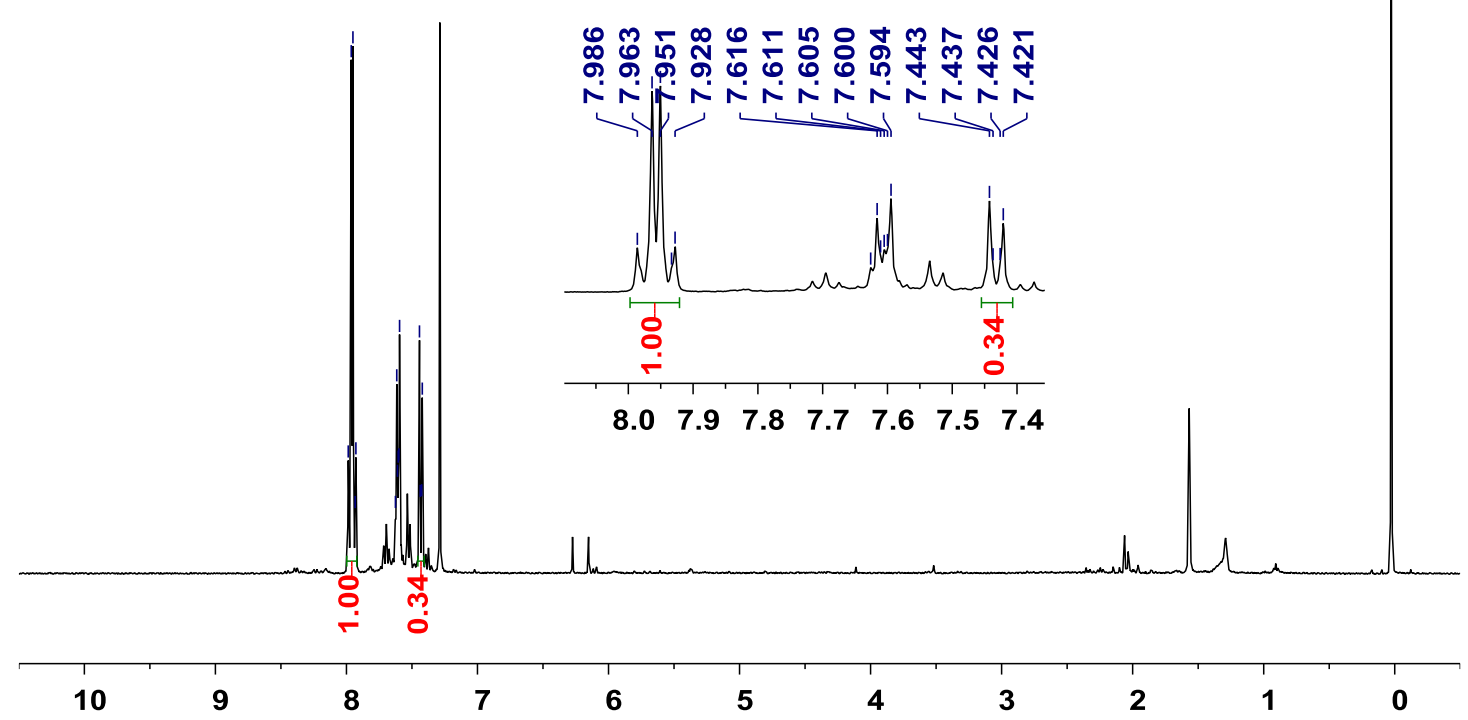

3h

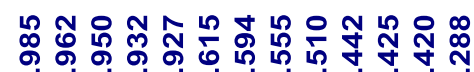

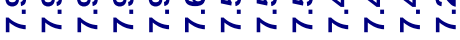

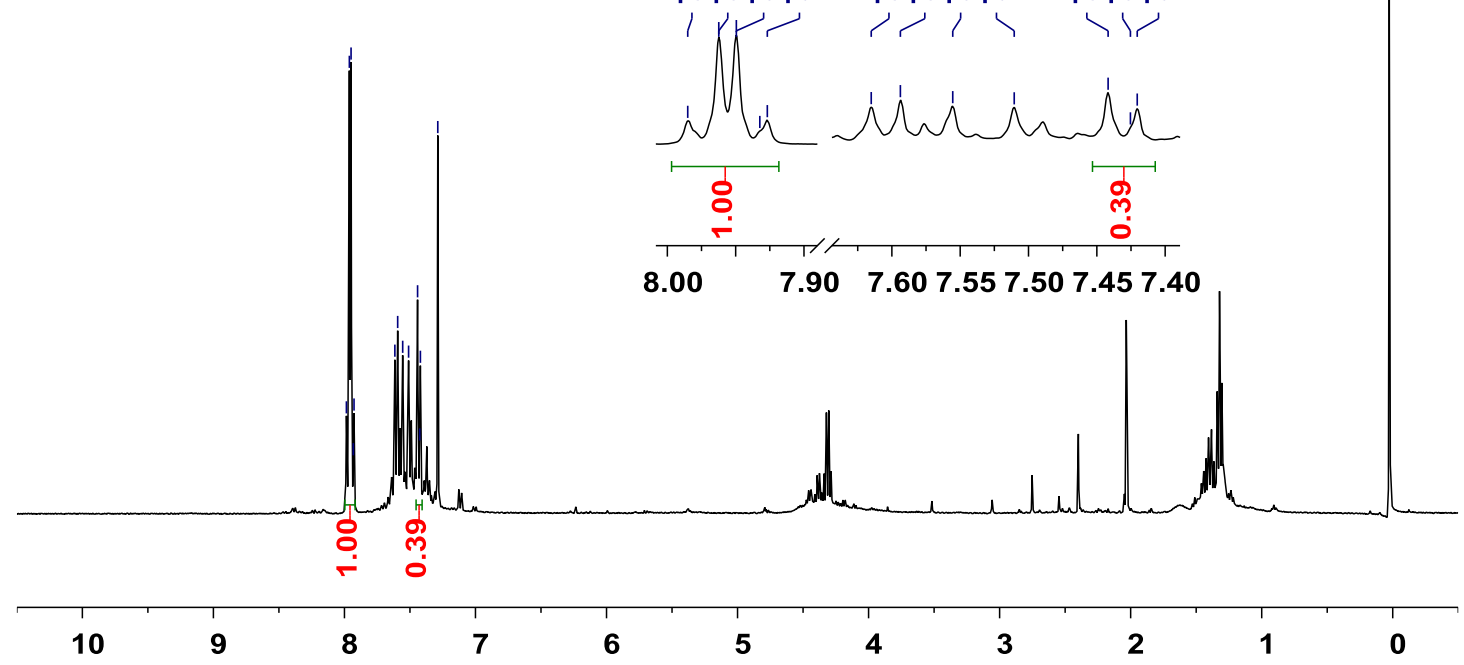




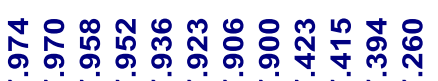

๙ง

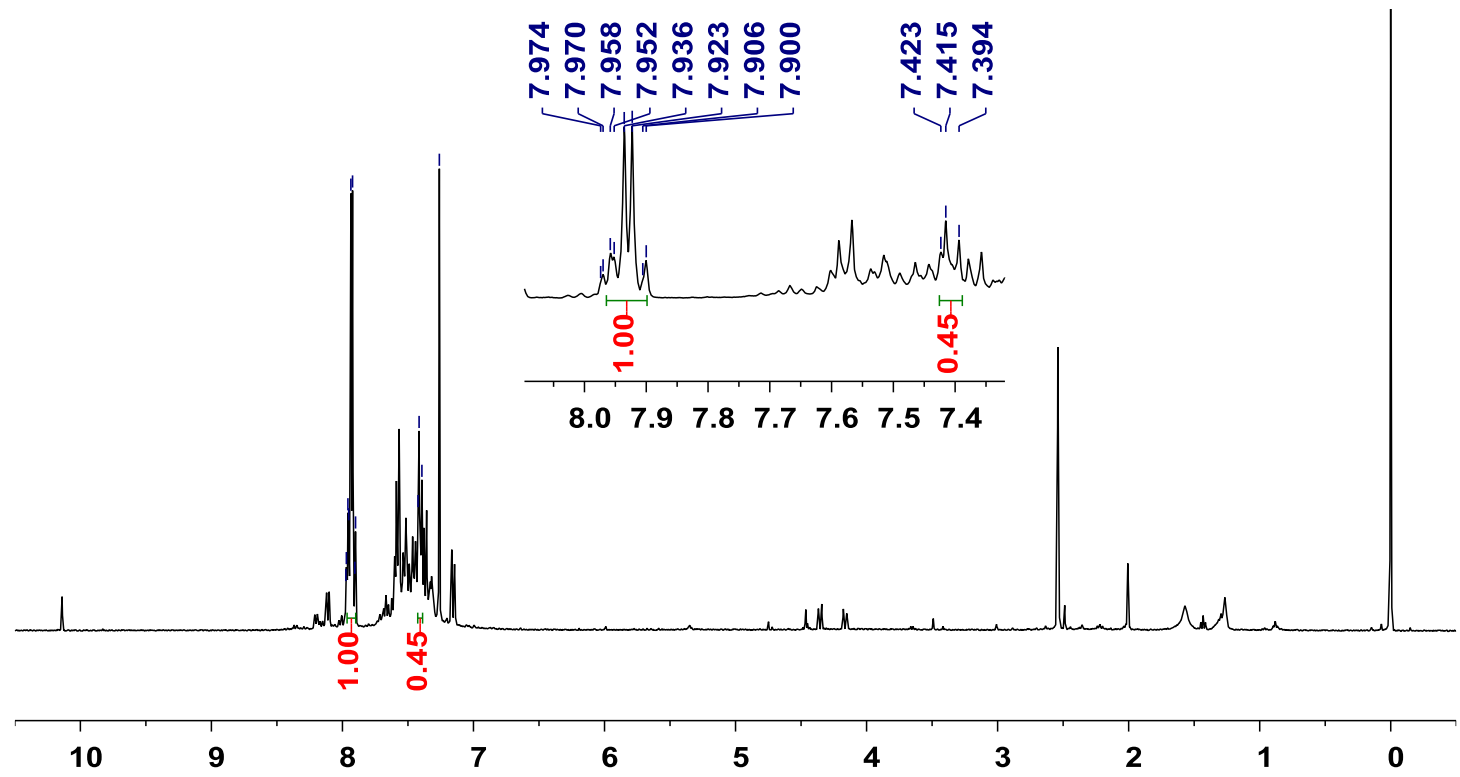

